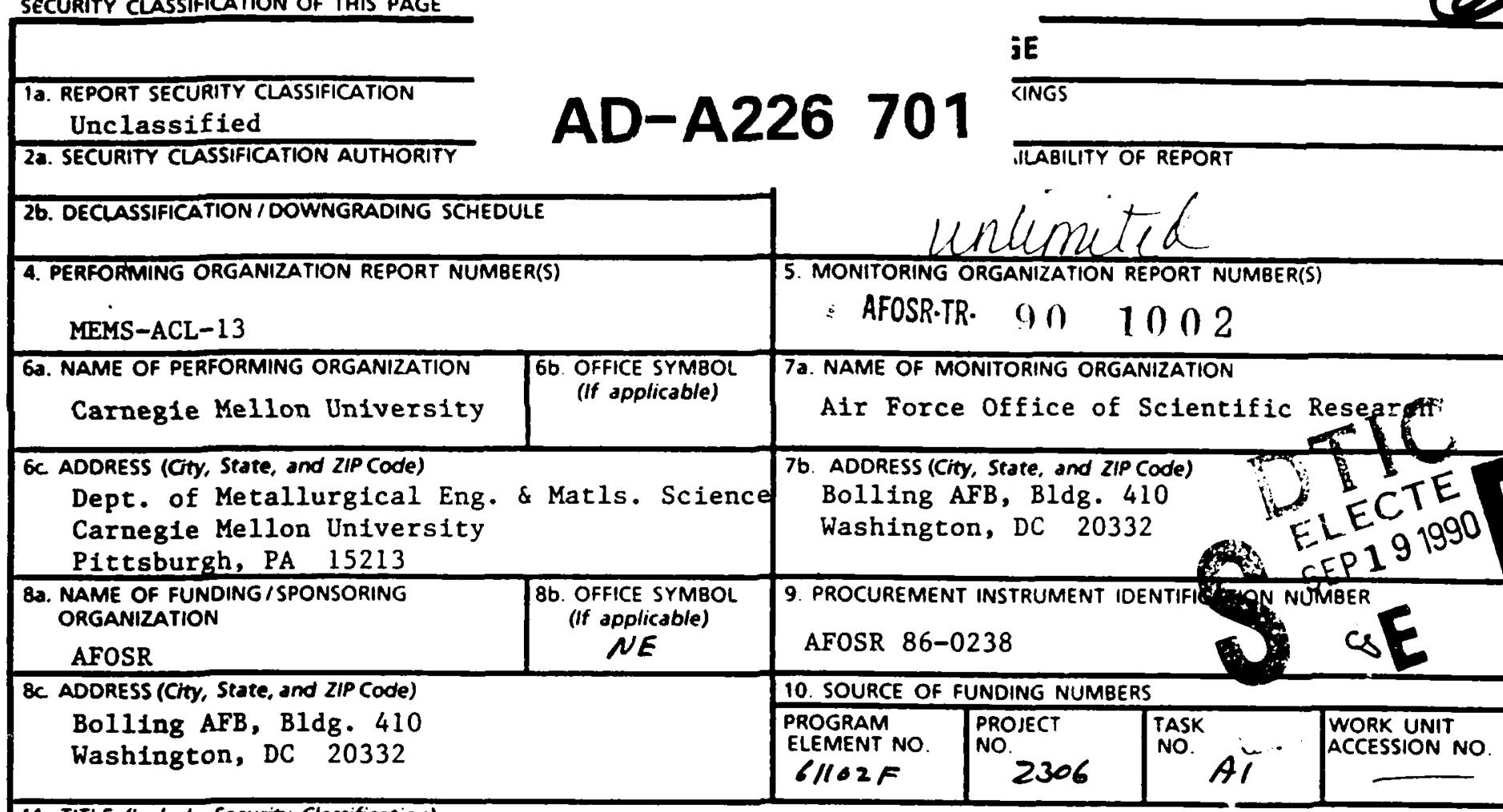

11. TITLE (Include Security Classification)

Fundamentals of Interfacial Strength in Composite Materials

12. PERSONAL AUTHOR(S)

A.W. Thompson and I.M. Bernstein

\begin{tabular}{l|l|c|c|}
\hline 13a. TYPE OF REPORT & 13b. TIME COVERED \\
Final & FROM $7-1-86$ & TO $9-30-89$ & $\begin{array}{c}\text { DATE OF REPORT (Year, Month, Day) } \\
1 \text { May } 1990\end{array}$ \\
\hline
\end{tabular}

16. SUPPLEMENTARY NOTATION

\begin{tabular}{|c|c|c|c|}
\hline \multicolumn{3}{|c|}{ COSATI CODES } & \multirow{3}{*}{ 18. SUBJECT TERMS (Continue on reverse if necessary and identify by block number) } \\
\hline FIELD & GROUP & SUB-GROUP & \\
\hline & & & \\
\hline $\begin{array}{l}\text { comp } \\
\text { unde } \\
\text { matr } \\
\text { and } \\
\text { chos } \\
\text { the }\end{array}$ & $\begin{array}{l}\text { search } \\
\text { tes w1 } \\
\text { anding } \\
\text { s with } \\
\text { corros } \\
\text { are pr } \\
\text { erved }\end{array}$ & $\begin{array}{l}\text { se if necess } \\
\text { he third } \\
61 \text { and } 7 \\
\text { elations } \\
\text { iculate } \\
\text { nvironme } \\
\text { ed, alon } \\
\text { ness lev } \\
\text { asized, }\end{array}$ & $\begin{array}{l}\text { Identify by block number) } \\
\text { gram year has examined fatigue and toughness behavior of } \\
\text { or } 7191 \text { alloy matrix material, with the goal being better } \\
\text { between microstructure and mechanical properties of these } \\
\text { reinforcement. Tensile and fatigue testing results, in air } \\
\text { of the various microstructures (i.e. aging conditions) } \\
\text { th toughness results and finite-element studies to interprot } \\
\text { The strong microstructural dependence of mechanical } \\
\text { with possible avenues for improvement of these properties. }\end{array}$ \\
\hline
\end{tabular}

20. CISLRTBUTION / AVAILABILITY OF ABSTRACT QUUNCLASSIFIEDAULIMITED $\square$ SAME AS RPT $\square$ DTIC USERS 21. ABSTRACT SFCURITY RLASSIFICATIQN . 22a. NAME OF RESPONSHALE INDIVIL'JAL $7606 \times 20 \%$

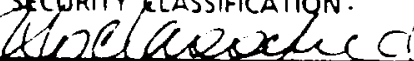
(1) 


\title{
FUNDAMENTALS OF INTERFACIAL STRENGTH IN COMPOSITE MATERIALS
}

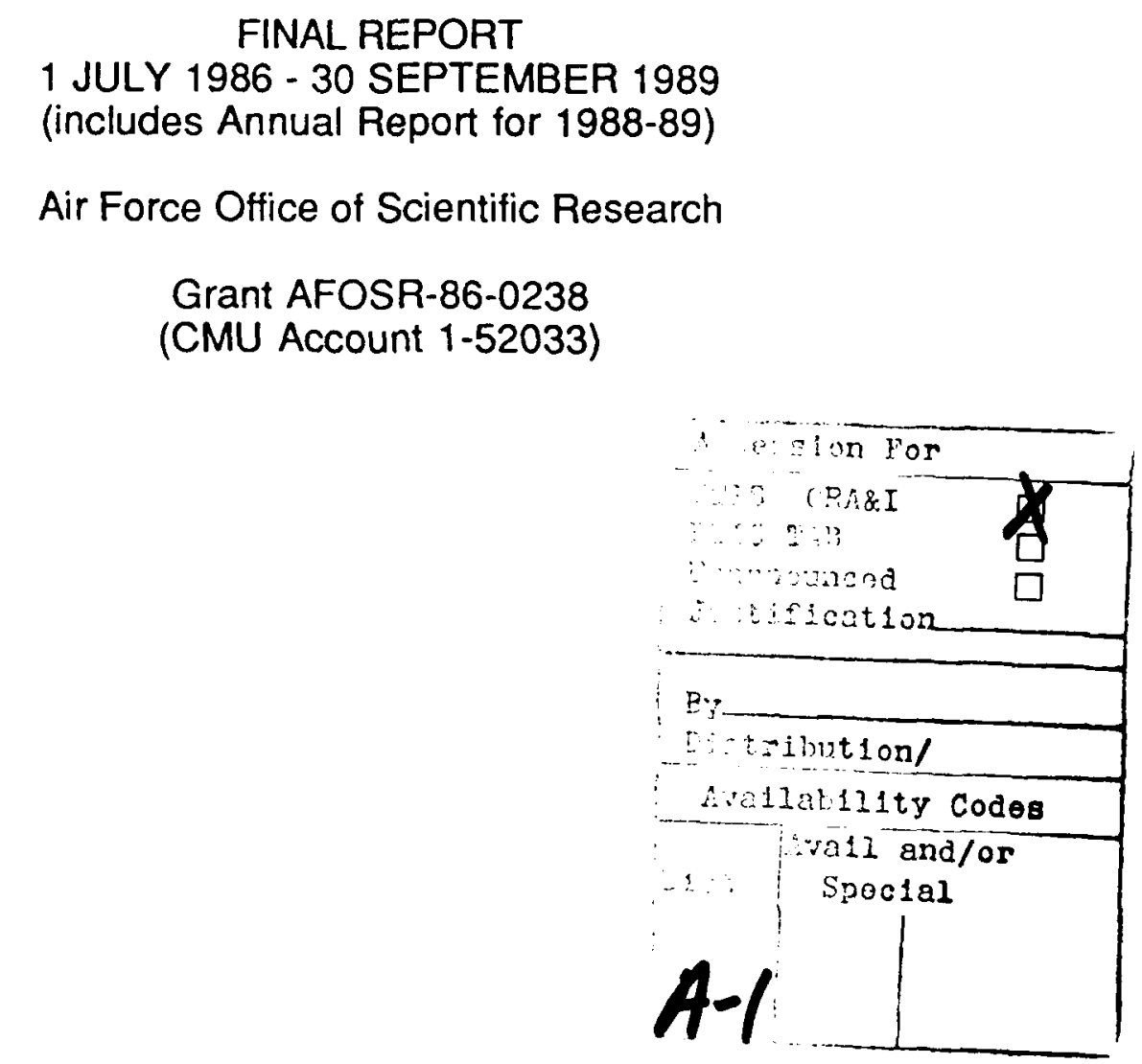

A.W. Thompson and I.M. Bernstein

Principal Investigators

\begin{abstract}
Dept. of Metallurgical Engineering and Materials Science
Carnegie Mellon University
\end{abstract}

Report No. MEMS-ALC-13

1 May 1990 


\section{TABLE OF CONTENTS}

Abstract

Background and Summary

Technical Progress Reports

Part 1: Carnegie Mellon University report, R.F. Buck and A.W. Thompson

Part 2: Illinois Institute of Technology report, I.M. Bernstein, et al. 


\title{
Fundamentals of Interfacial Strength in Composite Materials \\ FINAL REPORT including THIRD ANNUAL REPORT
}

\begin{abstract}
Research in the third program year has examined fatigue and toughness behavior of composites with 6061 and 7090 or 7191 alloy matrix material, with the goal being better understanding of relationships between microstructure and mechanical properties of these matrices with particulate $\mathrm{SiC}$ reinforcement. Tensile and fatigue testing results, in air and in corrosive enviroments, of the various microstructures (i.e. aging conditions) chosen are presented, along with toughness results and finite-element studies to interpret the observed toughness levels. The strong microstructural dependence of mechanical properties is emphasized, along with possibie avenues for improvement of these properties.
\end{abstract}




\section{Background and Summary}

This is the final report, incorporating the third annual report, on the subject program. During this third year, the program has been conducted with a sub-contract to the Illinois Institute of Technology (IIT) in Chicago, where I.M. Bernstein is now Provost and Academic Vice President. The experimental materials for this research are composites with an aluminum-alloy matrix and particulate $\mathrm{SiC}$ reinforcements. The goal of the work is to advance fundamental understanding of the performance of these and related composites, since the $\mathrm{Al}-\mathrm{SiC}$ system can serve as a model system for composite behavior. There is already ample evidence that properties and performance of these composites depend on both processing variables and on metallurgical variables such as microstructure. We have been particularly interested in the behavior of the interfaces in the composites, because of indications that the properties are sensitively dependent on interfacial strength. One means of addressing the behavior of interfaces is to introduce hydrogen into the composite, in order to alter interfacial behavior without greatly affecting other mechanical characteristics of the composite. As was reported in the first annual report (MEMS-ALC-11), considerable experimental work has demonstrated the profound effects of hydrogen on ductile fracture behavior. That report highlighted research at Carnegie Mellon University, particularly the M.S. research of Ann Voelkel.

The second annual report (MEMS-ACL-12) emphasized work on mechanical behavior conducted at IIT, under the direction of Professors S. Mostovoy and M. Dollar of the Dept. of Metallurgical and Materials Engineering, together with I.M. Bernstein. That work concentrated on crack arrest toughness in 7091 aluminum matrix composites with $20 \% \mathrm{SiC}$ reinforcement. Fracture initiation sites were identified, as were the roles of microcracking and crack deflection in the observed magnitudes of fracture toughness, $\mathrm{K}_{\mathrm{Ic}}$. These toughness values were higher than would be expected from the relative values of tensile ductility.

For the third year, Robert F. Buck has completed his M.E. research project on fatigue in both 6061 and 7090 alloy matrix composites with $\mathrm{SiC}$ particle reinforcement, and those results are presented below in some detail. In addition, the extensions of last year's work at IIT are presented, particularly finite-element studies to understand móre fully the toughness and sharpcrack testing results obtained earlier. 


\section{PART 1}

ENVIRONMENTAL AND FREQUENCY EFFECTS ON FATIGUE CRACK GROWTH RATES IN ALUMINUM-SILICON CARRBIDE COMPOSITES

R.F. Buck and A.W. Thompson

Carnegie Mellon University 


\title{
ENVIRONMENTAL AND FREQUENCY EFFECTS ON FATIGUE CRACK GROWTH RATES IN ALUMINUM-SILICON CARBIDE COMPOSITES
}

\author{
R.F. Buck, Jr. and A.W. Thompson \\ Metallurgical Engineering \& Materials Science Department \\ Carnegie Mellon University \\ Pittsburgh, Pennsylvania 15213
}

\section{ABSTRACT}

Fatigue crack growth rate (FCGR) of two aluminum-based $(6061,7090)$ silicon carbide reinforced ( $20 \mathrm{vol} . \%)$ composites tested in dry argon, distilled water and $3.5 \% \mathrm{NaCl}$ environments have been investigated. Compact tension (CT) specimens were subjected to two loading frequencies: $10 \mathrm{~Hz}$ and $1 \mathrm{~Hz}$. Load ratio was 0.15 . Both composites exhibited Paris law dependence at mid-to-high $\Delta \mathrm{K}$ ranges. At low $\Delta \mathrm{K}$ values, however, some 6061 specimens initially exhibited decreasing FCGR with increasing $\Delta K$, possibly due to hydrogen diffusing ahead of the fatigue precrack tip and becoming trapped at $\mathrm{SiC}$ particles. This behavior only occurred for specimens stored in laboratory air prior to testing. The 7090 composite system was insensitive to the hydrogen ingress phenomenon. For both composites when tested in the transverse orientation at low $\Delta K$ levels, microscopic effects such as hydrogen diffusion and dislocation transport, and hydrogen crack tip evolution determined FCGR behavior. At low $\triangle \mathrm{K}$ both systems exhibited progressively higher growth rates in the order: argon, distilled water, salt water. The 7090 composite, though, was more sensitive to salt water than was the 6061 composite. As crack speed increased crack growth rates became progressively less sensitive to environment and loading frequency, suggesting that at high $\Delta K$ values, above a critical growth rate, macroscopic mechanical (inertial) effects dominate the aforementioned microscopic effects. In most environments for both composites, increasing the loading frequency increased FCGR behavior, implying that strain rate (impulse) effects generally dominate environmental (corrosion) effects. FCGR was corrolated to a microscopic fracture surface parameter, the 'characteristic length', L, defined as the total striation length in a given fatigue fracture surface area, and is a function of pinnacle area fraction and morphology, and the number of striations per pinnacle. Qualitatively, it was observed that da/dN scales as $\mathrm{L}$. 


\section{INTRODUCTION}

Aluminum-based silicon carbide reinforced composites are currently being considered as candidate materials for aerospace applications due primarily to their high stiffness-to-weight ratio. Through advanced processing techniques $<1>$, several composite systems such as aluminum + silicon carbide show engineering promise due to improvements in yield and ultimate tensile strengths over their respective unreinforced base alloys. $<2,3\rangle$ Unfortunately composite designers have not been able to systematically advance the state-of-the-art since it is not clear exactly how $\mathrm{SiC}$ particles strengthen aluminum. $<4>$ Nor are the mechnisms governing fatigue resistance well understood $<5-9>$, especially the environment's degradating role on mechanical properties.<10-19> The particle reinforcement/metal matrix interaction during various loading conditions is very complex $<20>$, and as yet there are still unanswered questions regarding the possible detrimental environmental effects on such salient material properties as static and cyclic fatigue life and fatigue crack growth rate. In addition, the influence of testing parameters such as load ratio, $R$, load frequency and crack orientation (relative to rolling direction) have not been fully quantified for the $6 x x x$ and $7 \times x x$ family of aluminum composites. Regarding environmental corrosion fatigue, many researchers have suggested possible mechanisms including hydrogen embrittlement . $\langle 21,22>$ Since corrosion fatigue in aqueous solutions involves simultaneous anodic and cathodic processes, it is impossible to separate each from the other. However, it is possible to increase the hydrogen concentration and/or promote hydrogen charging at the tip of a growing crack by changing the environmental testing condition.

Our goal was to investigate, on a macroscopic scale, the effect of three different environments, each supporting different hydrogen conditions at the crack tip, and concommitant mechanical Mode I cyclic loading frequency variations on FCGR; and to corrolate the observed behavior to (a) microscopic fracture surface parameter(s). 


\section{BACKGROUND}

We investigated the fatigue crack growth rates of two aluminum based composites: 6061 and 7090. See Table 1 for base compositions.

\section{Table 1}

\section{Base Aluminum Chemistry}

$\begin{array}{lllllllll}\text { Alloy } & \mathrm{Mg} & \underline{\mathrm{Zn}} & \mathrm{Si} & \mathrm{Cu} & \mathrm{Co} & \mathrm{Cr} & \mathrm{Al} & \\ 6061 & 1.0 & -- & 0.6 & 0.3 & -- & 0.2 & \mathrm{Bal} . & \text { (all weight percents) } \\ 7090 & 2.5 & 8.0 & -- & 1.0 & 1.5 & -- & \mathrm{Bal} . & \end{array}$

Each base metal, through powder metallurgical techniques $\langle 20>$ was combined with silicon carbide particles such that the final composite contained 20 volume percent silicon carbide. The average diameter of the particles in the 6061 system was $5 \mu$ (average aspect ratio: 1.5, max aspect ratio: 4 ) while in the 7090 composite the average particle diameter was $2 \mu$ (ave. A.R.: 1.1, max. A.R.: 4). Typical polished and etched microstructures appear in Figs. 1\&2, 6061 and 3\&4, 7090. The 7090 composite microstructure contained numerous surface "holes" ranging in size frem 0.5 to $3 \mu$. This feature is probably due to inadvertant $\mathrm{SiC}$ particle pullout during polishing. Similar bi-modal void distributions have been observed elsewhere. $<2>$ Particle clustering in the 6061 composite is evident from Fig. 5 (500x). In regions of clustering, $\mathrm{SiC}$ particles pin aluminum grains, whereas in particle-depleted zones, grains are larger. A higher magnification SEM image of aluminum grains in the 6061 composite is shown in Fig.6.

Both the 6061 and 7090 composites were produced by DWA Composite Specialties (Chatsworth, CA.) Each was shipped in the 'as-extruded' condition; 6061: 0.5"x5.0", 7090: 0.5"x3.0". Westmoreland Mechanical Testing (Youngstown, PA) machined the compact tension specimens to final dimensions of: $B=0.157 ", W=1.0^{\prime \prime}$, nominal. 


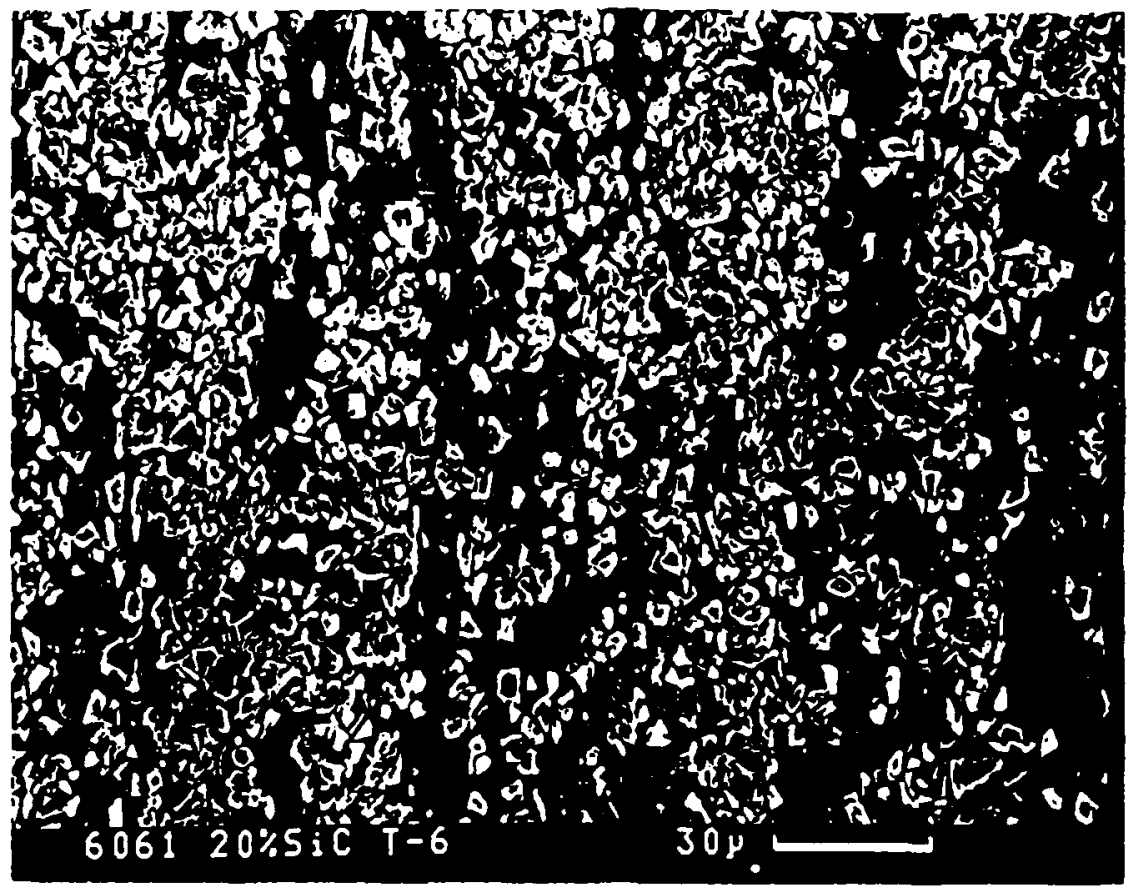

Figure 1: Typical polished and etched 6061 composite microstructure (low magnification.)

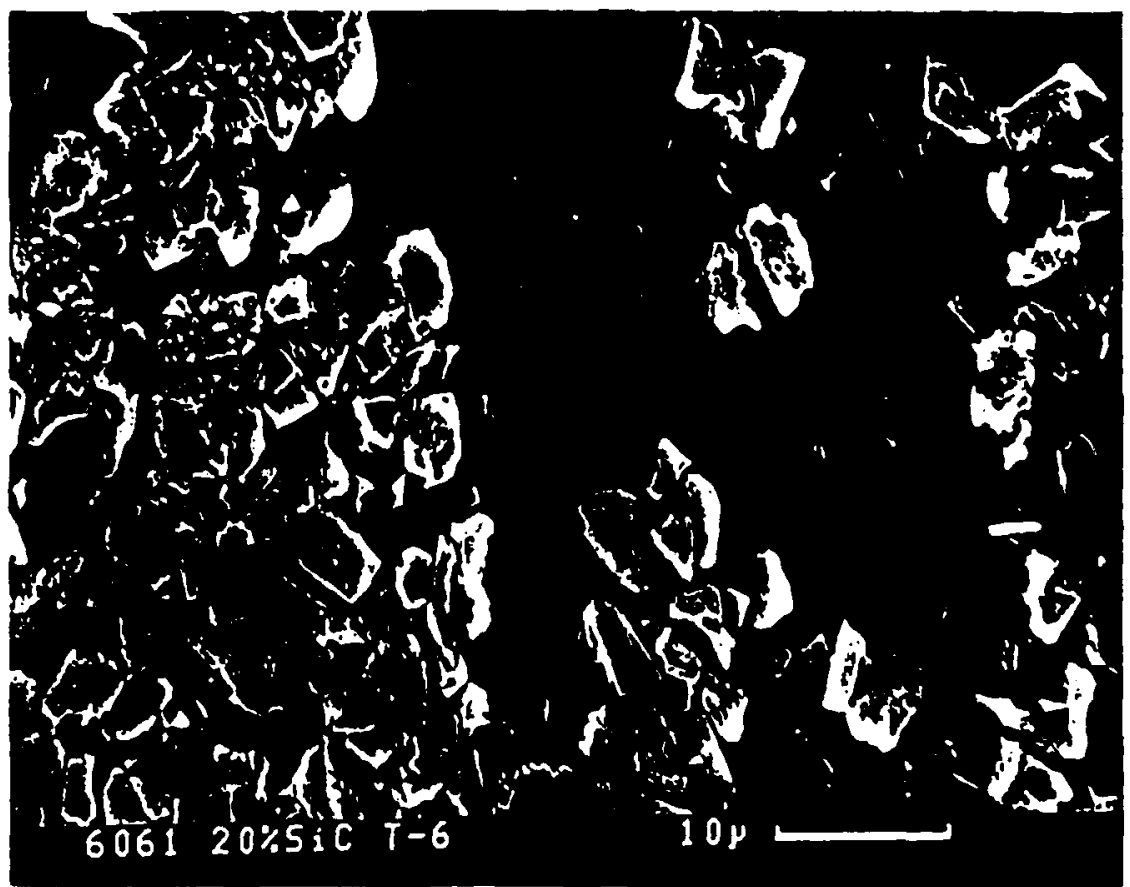

Figure 2: Typical polished and etched 6061 composite microstructurc (high magnification.) 


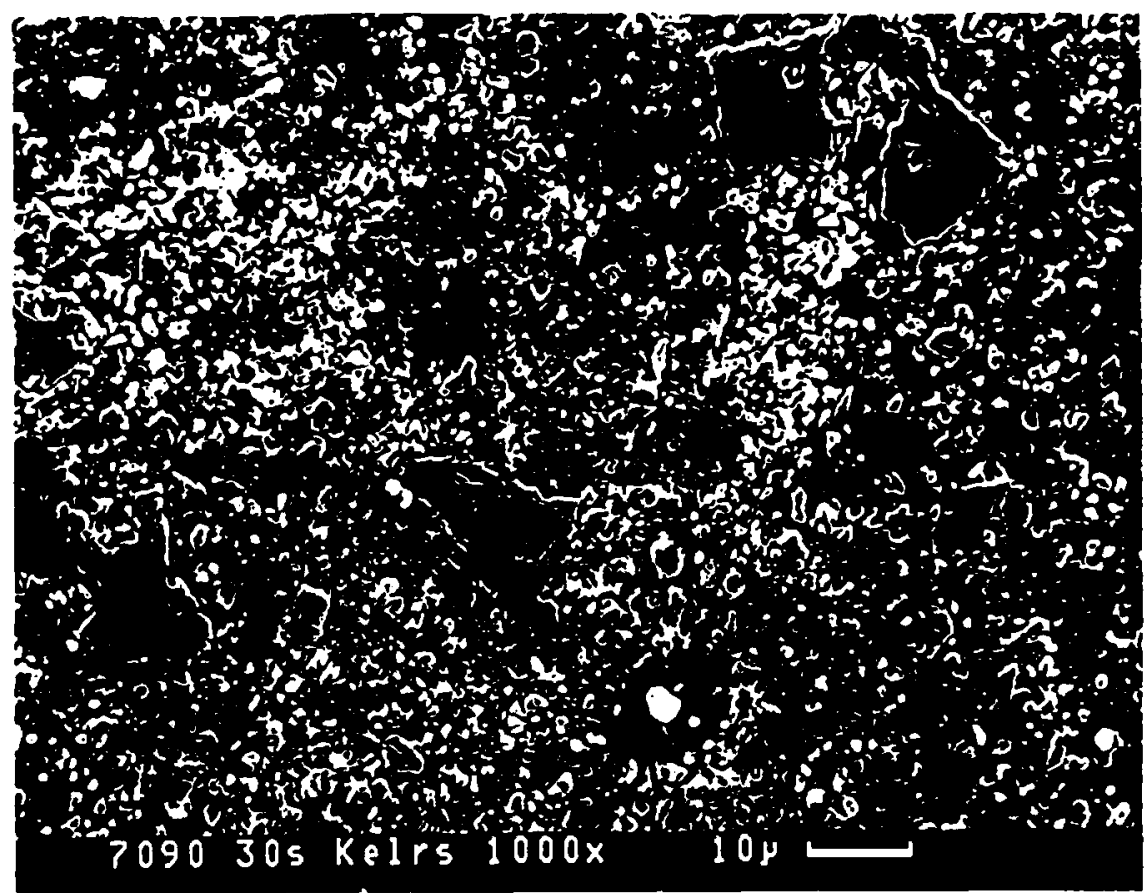

Figure 3: Typical polished and etched 7090 composite mictostructure (low magnification.)

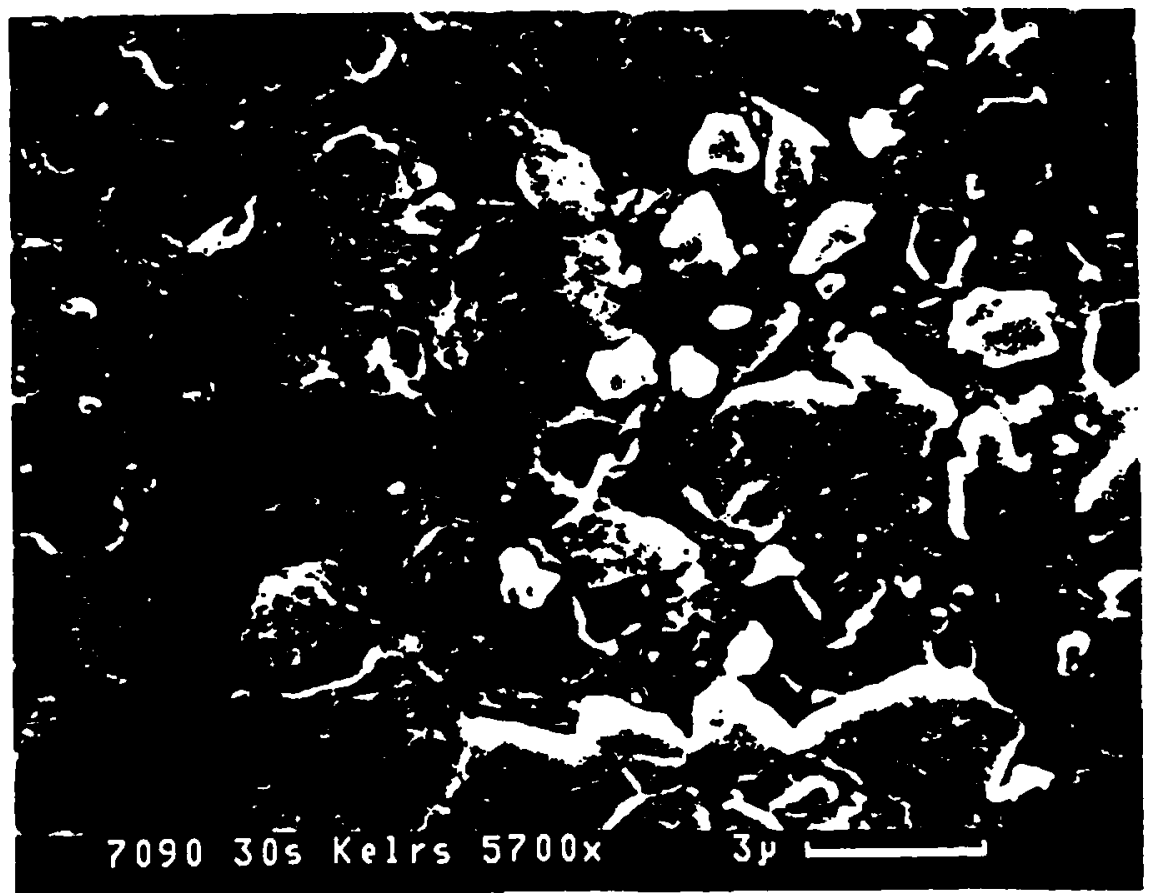

Figure 4: Typical polished and etched 7090 composite microstructure (high magnification.) 


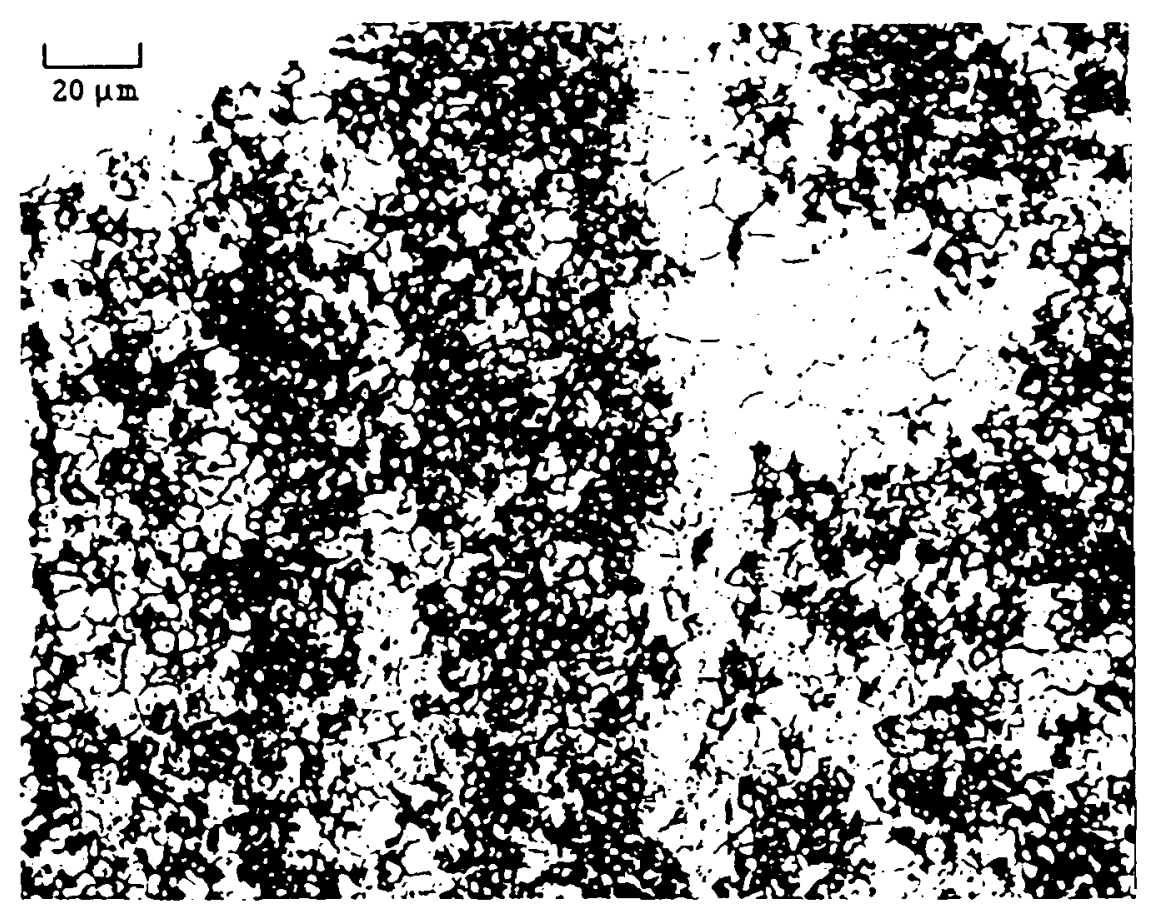

Figure 5: $\mathrm{SiC}$ particle clustering in 6061 composite.

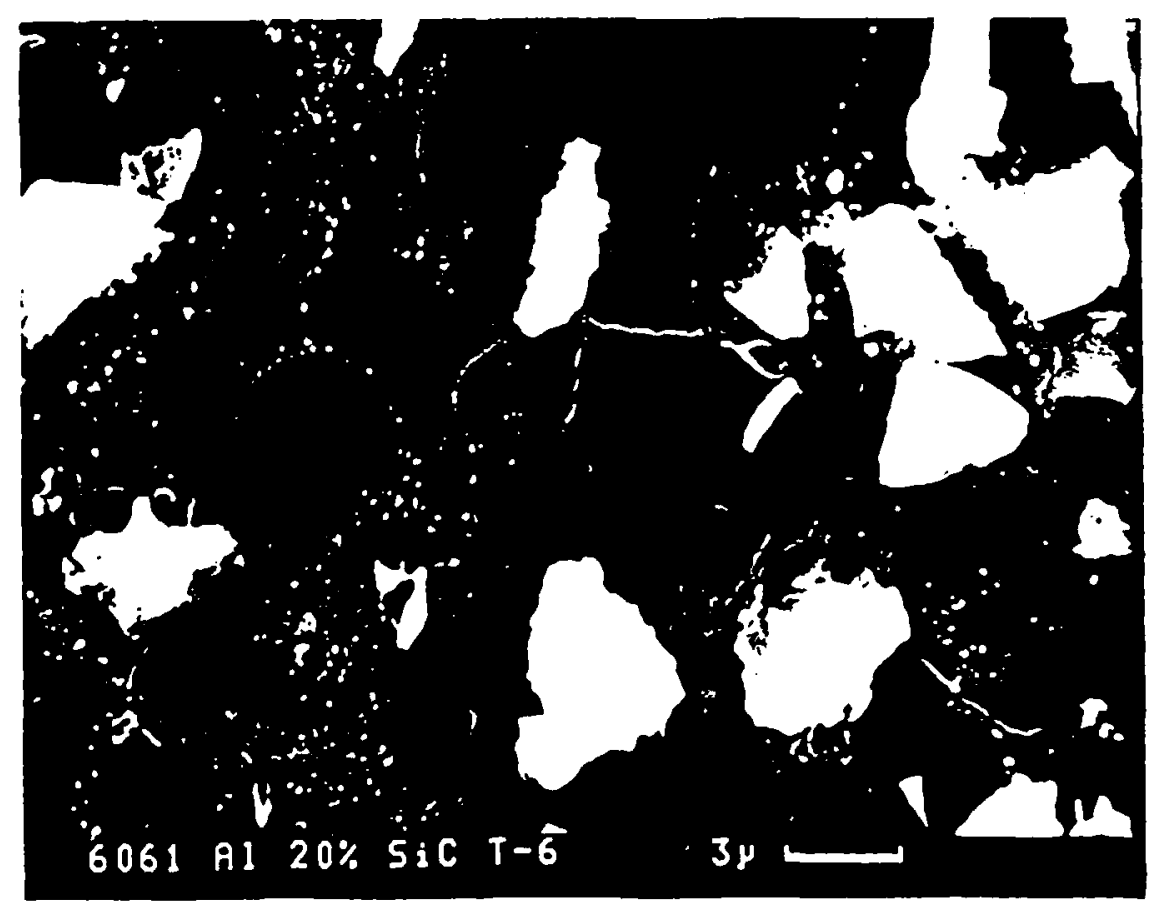

Figure 6: High magnification SEM image of aluminum grains in 6061 composite. 
The as-received specimens were heat treated, then polished using $240,320,400 \& 60)$ $\mathrm{SiC}$ grit and $6 \& 1 \mu$ diamond paste. Each composite was tested in three different environments: dry argon, distilled water and 3.5\% salt water at a fatigue frequency of either 1 or 10 hertz.

See Table 2 for specimen designation.

Table 2

Material Test Matrix (Environment Orientation - Frequency)

\begin{tabular}{|c|c|c|c|}
\hline \multicolumn{2}{|c|}{$\underline{6061}\left(T-6^{*}\right)$} & \multicolumn{2}{|c|}{$\underline{7090}(* *)$} \\
\hline $\mathrm{AL}-10 \mathrm{~Hz}$ & $\mathrm{AT}-10 \mathrm{~Hz}$ & $\mathrm{AL}-10 \mathrm{~Hz}$ & AT $-10 \mathrm{~Hz}$ \\
\hline WL-10 & WT-10 & & WT-10 \\
\hline & WT-1 & & WT-1 \\
\hline & ST-10 & & ST-10 \\
\hline & $S T-1$ & & ST-1 \\
\hline
\end{tabular}

A, argon; W, distilled water, S, salt water, L, longitudinal; T, transverse

A problem arose when we attempted to grow fatigue precracks in the 7090 T- 6 composite. Specimens broke catastrophically even when low loads and frequencies were used. After realizing the impracticality of testing the $7090 \mathrm{~T}-6$ composite, several non-standard heat treatments were devised and tried. (This procedure is not unusual; peak aged heat treatments for many matrix alloys are not always the ideal heat treatment for the corresponding composite.) $<25>$ See Table 3 for candidate heat treatments.

* $1 \mathrm{hr} .\left(530^{\circ} \mathrm{C}\right)$; water quench; $6.5 \mathrm{hr} .\left(175^{\circ} \mathrm{C}\right)$; water quench.

** T-6 heat treatment (peak age) resulted in an extremely hard and brittle material (RH-B =98) which precluded practical fatigue crack growth testing and crack measurement.. An alternate heat treatment is described below. 
Table 3

Candidate Heat Treatments for 7090 Composite

\begin{tabular}{|c|c|c|c|}
\hline Number & $\begin{array}{l}\text { Solutionizing } \\
\text { temp. }\left({ }^{\circ} \mathrm{C}\right) / \text { time }\end{array}$ & $\begin{array}{l}\text { Aging } \\
\text { temp. }\left({ }^{\circ} \mathrm{C}\right) / \text { time }\end{array}$ & $\begin{array}{l}\text { Annealing } \\
\text { temp. }\left({ }^{\circ} \mathrm{C}\right) / \text { time }\end{array}$ \\
\hline 1 & $495 / 2$ hours & R.T./ ongoing & N/A \\
\hline 2 & $495 / 2$ hours & $120 / 2$ hours & N/A \\
\hline 3 & $495 / 2$ hours & N/A & $410 / 3$ hr.; decr.@2\%/min. 10270 \\
\hline 4 & $495 / 2$ hours & $120 / 24$ hours & $410 / 3 \mathrm{hr}$; decr.@2\% $/ \mathrm{min}$. to 270 \\
\hline 5 & $495 / 2$ hours & $120 / 40$ hours & N/A \\
\hline 6 & $495 / 2$ hours & $120 / 4.5$ days & N/A \\
\hline
\end{tabular}

The most promising heat treatment was \#4 in which the 7090 composite was solitionized for 2 hrs. $\left(495^{\circ} \mathrm{C}\right)$, water quenched, aged 24 hrs. $\left(120^{\circ} \mathrm{C}\right)$, water quenched, annealed 3 hrs. $\left(410^{\circ} \mathrm{C}\right)$, slowly cooled to $260^{\circ} \mathrm{C}$, and water quenched. This alternate heat treatment resulted in a soitened microstructure, containing stable precipitates - as evidenced by its steady state room temperature hardness value of 60 RH-B (vs. 99 RH-B for $7090-\mathrm{T} 6$ and 82.5 for 6061 -T6). The hardness vs. aging time (at room temperature) behavior of this and other "candidate" heat treatments is shown in Figure 7. Roum temperature tensile properties for each extruded composite, found elsewhere $<20,34,35>$, are shown in Table 4 .

Table 4

Composite Tensile Properties (Extruded, Typical)

$\begin{array}{llllll}\underline{\text { Material }} & \text { orientation } & \underline{\mathrm{E}(\mathrm{GPa})} & \underline{\mathrm{YS}(\mathrm{MPa})} & \underline{\mathrm{TS}(\mathrm{MPa})} & \underline{\varepsilon f} \\ 6061+\mathrm{SiC} & \text { transverse } & 91 & 409-427 & 480-500 & 4.3 \\ 6061+\mathrm{SiC} & \text { longitudinal } & 108-122 & 414-447 & 545-588 & 2.0 \\ 6061 & \mathrm{~N} / \mathrm{A} & 74 & 276-357 & 311-386 & 12 \\ 7090+\mathrm{SiC} & \text { transverse } & -- & 643-723 & 675-784 & 1.3 \\ 7090 & \mathrm{~N} / \mathrm{A} & -. & 586 & 627 & 10\end{array}$




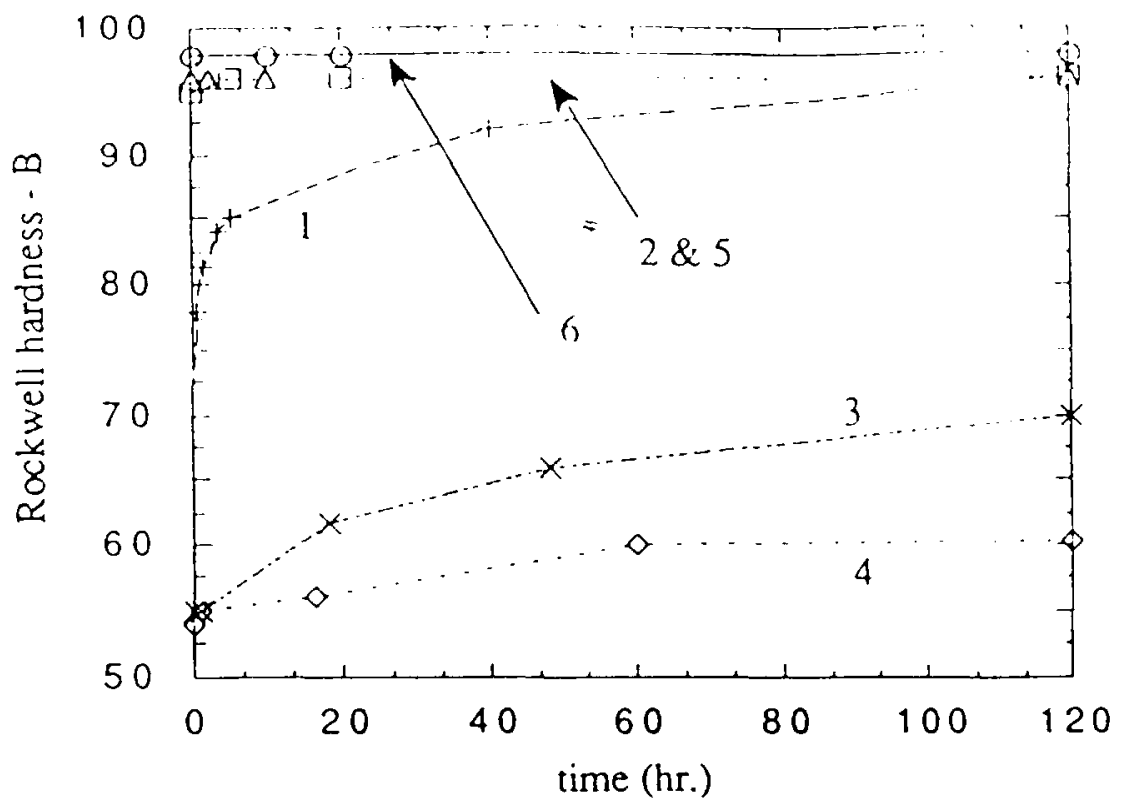

Figure 7: Hardness vs. room temperature aging time for various 7090 heat treatments.

The majority of the specimens were tested in the LT orientation, See Figure 8.

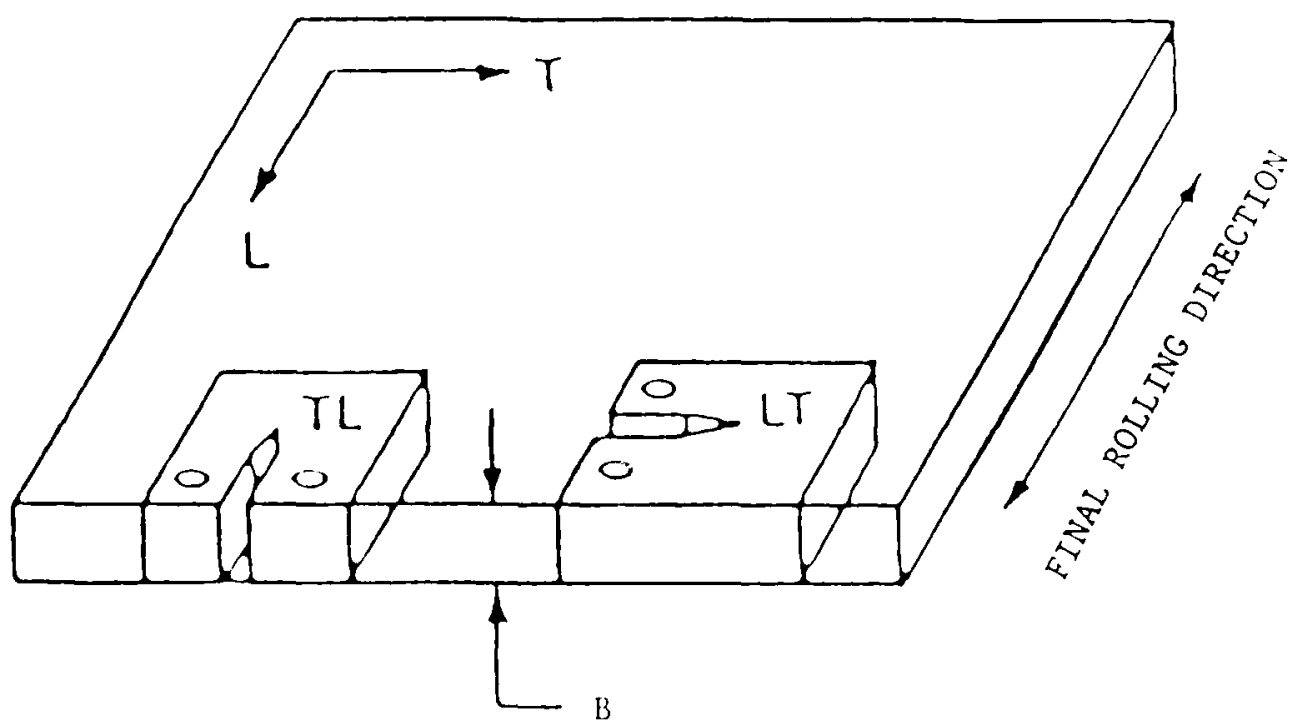

Figure 8: Specimen orientation 


\section{EXPERIMENTAL PROCEDURE}

Our experimental set-up is shown in Figure 9. All specimens were fatigue precracked in laboratory air at 3,5 or $10 \mathrm{~Hz}$. Cracks were grown to the appropriate precrack length, recommended by ASTM-E647-81,<24> and were measured using a 20x traveling microscope with precision to $0.013 \mathrm{~mm}(0.5 \mathrm{mils})$. Specimens were thin enough to permit visual crack monitoring from only one side, per ASTM guideline. In all cases except one (7090 salt water, 1 $\mathrm{Hz}$ ) a specimen's crack length was measured in situ. To accurately note the correct crack length the loading frequency of specimens being tested at $10 \mathrm{~Hz}$ was temporarily lowered to $0.5 \mathrm{~Hz}$ to facilitate precise crack measurement, afterwhich $10 \mathrm{~Hz}$ load cycling resumed. Cracks, growing under $1 \mathrm{~Hz}$ frequencies, were measured without interrupting the cyclic periodicity. [The 7090 salt water, $1 \mathrm{~Hz}$. specimen, being immersed in salt water for several days, developed surface corrosion which prevented visual crack length measurement in situ. To obtain each crack growth rate data point, the specimen was unloaded from the environmental chamber and testing machine, repolished to $1 \mu$, installed into the chamber again whereby the original maximum and minimum loads were applied, and the crack length finally measured. This process was repeated until the specimen broke.]

For both fatigue precracking and actual testing the load ratio $=\mathrm{P}_{\min } / \mathrm{P}_{\max }=0.15$. Load shedding decreased $\Delta K$ during the precracking such that when the crack was sufficiently long (per ASTM guideline), $\Delta \mathrm{K}_{\text {th }}$ was reached. The actual test was then begun using $\mathrm{P}_{\max }$ and $\mathrm{P}_{\min }$ of $\Delta \mathrm{K}_{\mathrm{th}}$. These loads were not changed for the duration of the test. In some cases, $C T$ specimens were stored in laboratory air for as long as 20 days prior to testing. The consequence of this action will be discussed in the 'Results and Discussion' section. 


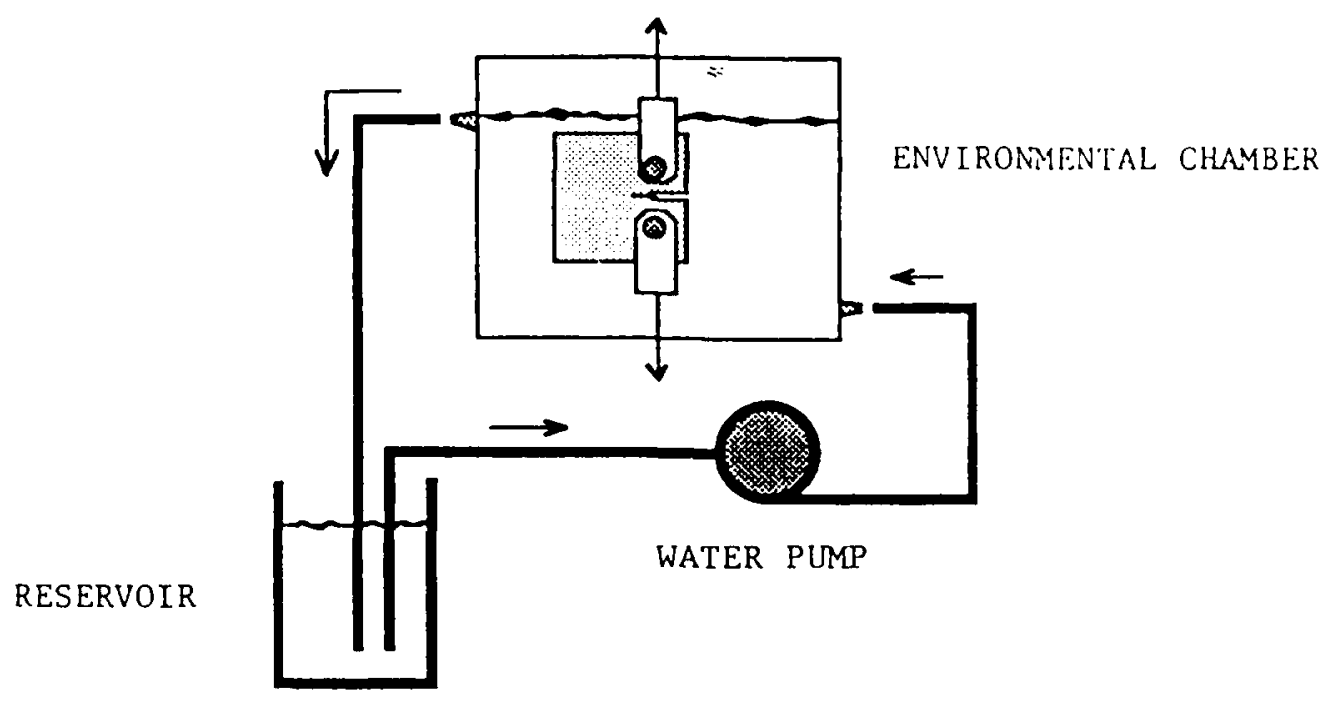

Figure 9: Experimental set-up

For dry air testing, argon was fed through a drierite bed, then passed through coppercoiled tubing immersed in methanol, chilled to $-60^{\circ} \mathrm{C}$ by dry ice additions. The dry argon was then fed into the enclosed testing chamber - afterwhich it passed through an hygrometer. The testing chamber was maintained at slight positive pressure during the test. The lowest moisture content, measured as relative humidity, was recorded to be $15 \%$.

The test solution, either distilled or salt water, was circulated through the environmental chamber via. a Delta finger pump. Distilled water $\mathrm{pH}$ at the crack tip was taken to be $3.5<32>$ The temperature of all aqueous solutions was $25^{\circ} \mathrm{C}+/-2{ }^{\circ} \mathrm{C}$. Potential of specimens immersed in a given test solution was based on a standard Calomel electrode; see Table 5 for potential readings. 
Table 5

Specimen Potential

6061

AL- $10 \mathrm{~Hz}$

$$
\text { Ave. Potential (mV) }
$$

$\mathrm{N} / \mathrm{A}$

$520 *$

WL-10

AT-10

WT-10

WT-1

ST-10

ST-1
N/A

200

450

756

750 $\underline{7090}$

AL- $10 \mathrm{~Hz}$

AT-10

WT-10

WT-1

ST-10

ST-1
Ave. Potential $(\mathrm{mV})$

N/A

N/A

384

700*

907

905

Periodically (every 10-20 mils) crack length measurements were taken. Fatigue crack growth rates were calculated using the secant method as described in ASTM-E647-81.<24> Test data for different environments and loading frequencies were fitted to polynomials of the form:

$$
\log \mathrm{da} / \mathrm{dN}=\mathrm{A}+\mathrm{m} \log (\Delta \mathrm{K})<33>
$$

where ' $\mathrm{m}$ ' and ' $\mathrm{A}$ ' are constants associated with a particular environment, orientation and frequency. The least squares method was employed to determine values for ' $m$ ', 'A' and Paris equation constants, which appear in Table 5. Fatigue crack growth rate data presented in this paper, however, is plotted on a log/inear scale, where the individual contributions of environmental and mechanical (loading frequency) effects are more readily distinguished.

* Slight $\mathrm{NaCl}$ contamination of flow path equipment may have occurred resulting in elevated potential reading for these distilled water solutions. 
Table 5

Paris Law constants for the equation: $d a / d N=A(\Delta K m)$

\begin{tabular}{|c|c|c|c|c|}
\hline Composite & environment/orientation & $\underline{m}$ & $\underline{\log A}$ & $\underline{r^{*}}$ \\
\hline \multirow[t]{7}{*}{6061} & A/L $10 \mathrm{~Hz}$ & 10.73 & -17.7 & 0.963 \\
\hline & A/T $10 \mathrm{~Hz}$ & 7.85 & -14.79 & 0.952 \\
\hline & $\mathrm{W} / \mathrm{T} 10 \mathrm{~Hz}$ & 6.45 & -13.39 & 0.994 \\
\hline & $\mathrm{S} / \mathrm{T} 10 \mathrm{~Hz}$ & 4.91 & -11.98 & 0.989 \\
\hline & $\mathrm{S} / \mathrm{T} \perp \mathrm{Hz}$ & 5.28 & -12.18 & 0.998 \\
\hline & $\mathrm{W} / \mathrm{T} 1 \mathrm{~Hz}$ & 9.83 & -16.35 & 0.970 \\
\hline & $\mathrm{W} / \mathrm{L} 10 \mathrm{~Hz}$. & 6.42 & -13.02 & 0.974 \\
\hline
\end{tabular}

7090

\begin{tabular}{llrl} 
A/L $10 \mathrm{~Hz}$. & 13.11 & -18.83 & 0.997 \\
A/T $10 \mathrm{~Hz}$. & 9.54 & -15.97 & 0.994 \\
W/T $10 \mathrm{~Hz}$. & 8.11 & -14.39 & 0.976 \\
S/T $10 \mathrm{~Hz}$. & 7.92 & -14.12 & 0.974 \\
S/T $1 \mathrm{~Hz}$. & \multicolumn{2}{c}{ insufficient data } & \\
W/T $1 \mathrm{~Hz}$. & 7.82 & -14.33 & 0.980
\end{tabular}

* ' $r$ ' is the correlation coefficient defined elsewhere. $<33>$ 


\section{COMPOSITE}

\section{AT vs. AL}

Fig. 10 compares growth rate behavior in dry argon of cracks growing longitudinally vs. transversely (to rolling direction), each subjected to a $10 \mathrm{~Hz}$ loading frequency. Growth rates are nearly identical for mid $\Delta K$ values $\left(8.3<\Delta K<11.4 \mathrm{MPa}(\mathrm{m})^{1 / 2}\right)$, reflecting the composite's relative insensitivity to orientation in this $\Delta \mathrm{K}$ range.

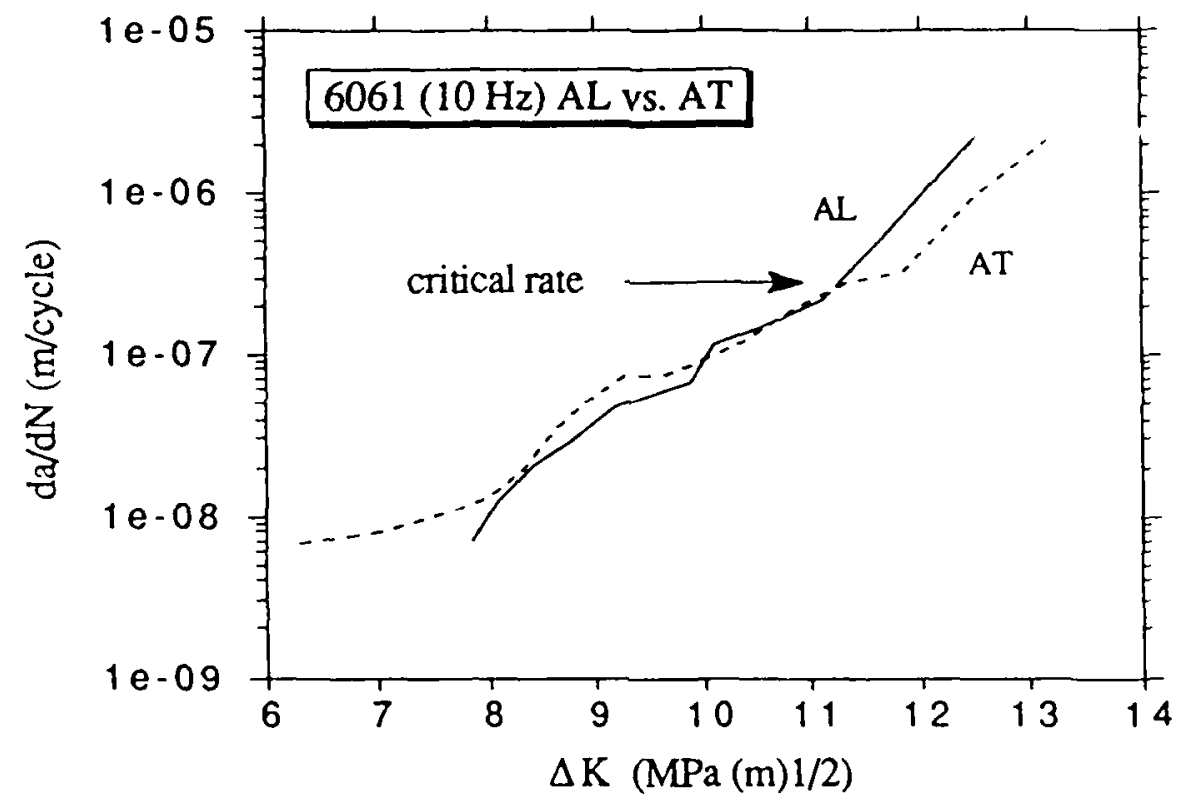

Figure 10: $6061(10 \mathrm{~Hz})$ AL vs. AT

A typical etched fracture profile for $\mathrm{AL}$ is shown in Fig. 11 for $\Delta \mathrm{K}=10 \mathrm{MPa}(\mathrm{m})^{1 / 2}$. Fracture is not dominated by inter- or transgranular processes. For $\Delta \mathrm{K}>11.4 \mathrm{MPa}(\mathrm{m})^{1 / 2}$, however, $\mathrm{AL}$ cracks grow progressively faster than AT cracks. At $\Delta \mathrm{K}=12.6 \mathrm{MPa}(\mathrm{m})^{1 / 2}$, for example. $\operatorname{rate}(A L) / \operatorname{rate}(A T)>2$. Thus there seems to be a critical rate at which the composite's macroscopic features begin to dominate the otherwise insensitive microscopic features. This phenomenon is probably due to the continuously increasing inerial energy of a growing crack which achic ves a critical value - at which point propogation behavior becomes dominated hy mechanical forces. 


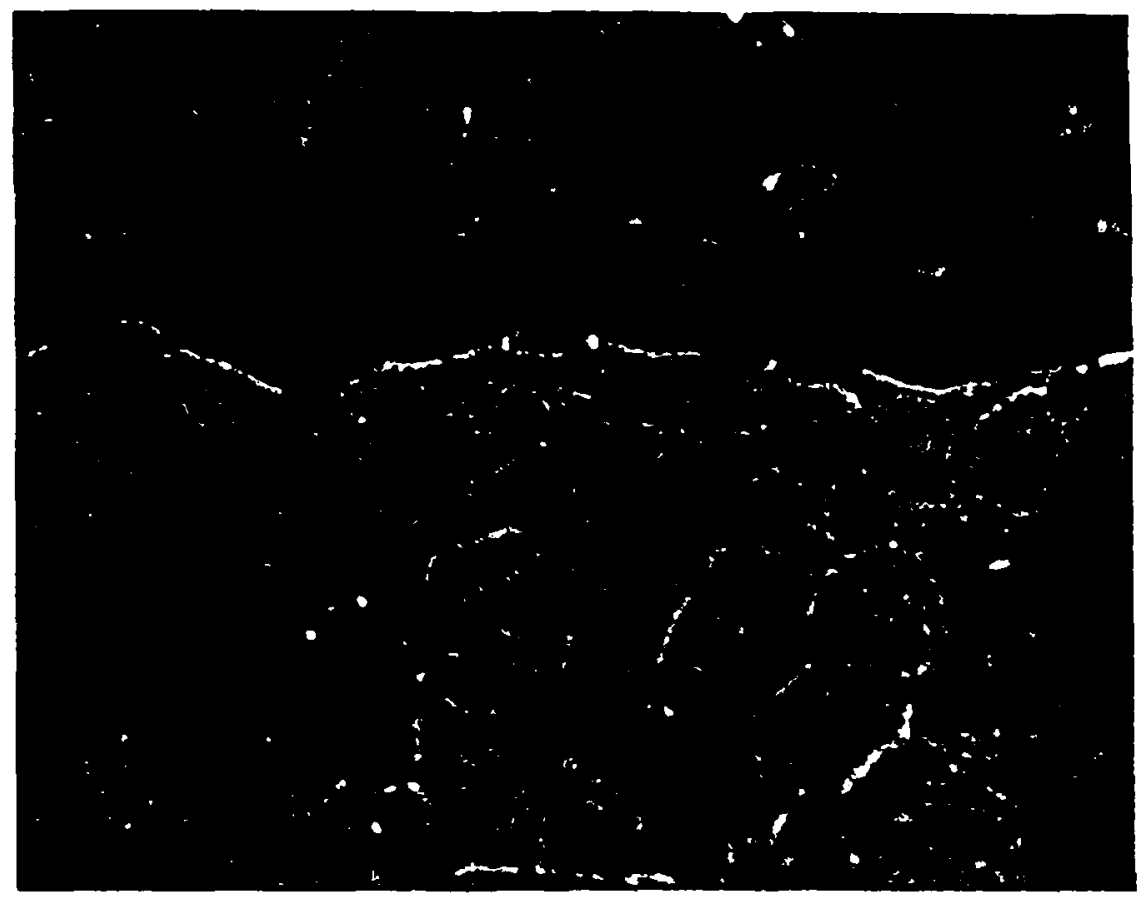

Figure 11: 6061 fracture profile. Neither inter- nor transgranular processes dominate.

At most $\triangle K$ levels for each composite SEM profile fractographs indicate that SiC particles participate in the fracture process primarily by decohering in one of two modes. Either decohesion occurs between $\mathrm{SiC}$ particles and the matrix at the interface (cleanly), or decohesion takes place not at the $\mathrm{SiC}$ - $\mathrm{Al}$ matrix interface, per se, but rather between aluminum atoms: bulk matrix $\mathrm{Al}$ atoms separate from other $\mathrm{Al}$ atoms that remain adhered to $\mathrm{SiC}$ particles. Both decohesion types can be seen in Fig. 11A. In any event $\mathrm{SiC}$ particles tend to decohere rather than crack during fatigue fracture.

An interesting feature of Fig. 10 is for $\Delta \mathrm{K}<8.3 \mathrm{MPa}(\mathrm{m})^{1 / 2}$, where FCGR for AL is lower than that of AT. This behavior can be explained by close examination and analysis of the respective fracture surfaces. 


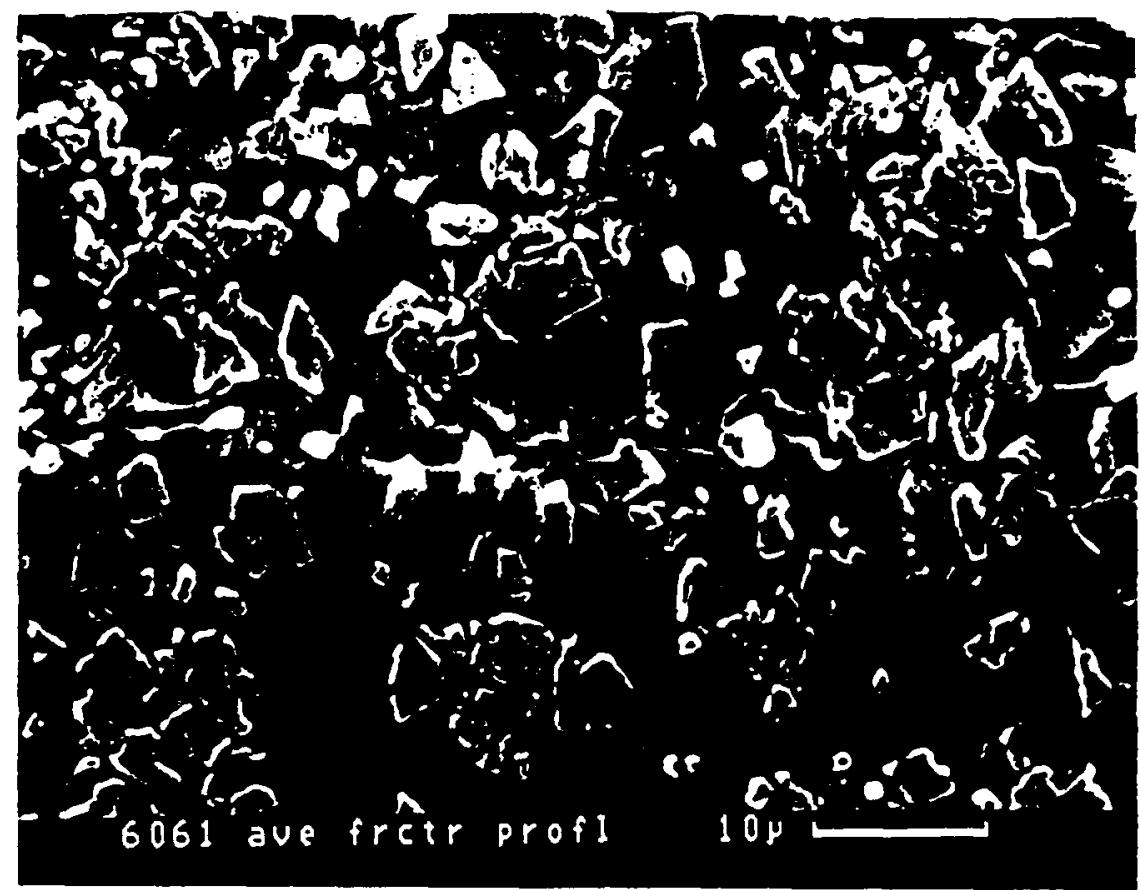

Figure 11A: 6061 fracture profile. Note the two types of decohered SiC particles.

\section{Fatigue Fracture Surface Analysis: Pinnacles. Striations and Average Valley Width}

Consider Fig. 12 (AL) for which $\Delta \mathrm{K}=7.8 \mathrm{MPa}(\mathrm{m})^{1 / 2}$. Cravk growth direction is from bottom to top of photo. Several features are important to note: 1) there is much relief, and 2) the surface is mostly comprised of tall pinnacles and deep valleys. Pinnacles typically have fatigue striations on their sides, (see Fig. 13). Valleys, forming in regions where SiC clustering has not occurred, have microvoids at their deepest points. The latter observation indicates that the fracture process begins by microvoid nucleation in regions of high stress triaxiality, followed by microvoid coalescence. The fromer suggests that fatigue fracture proceeds by creation of relatively tall pinnacles resulting from frequency loading. Considering the second process as 'ductile fatigue', pinnacles could he thought of as "macro cusps", analogous to traditional ductile failure cusps.

Further observation reveals that valleys are generally alligned parallel to the crack growth direction (presumably due to extrusion processing and subsequent SiC clustering patterns), and that their average width is $10-15 \mu$. The maximum numier of striations per pinnacle observed was 12 . Note also that individual striation width in I.ig. 12 is small. 


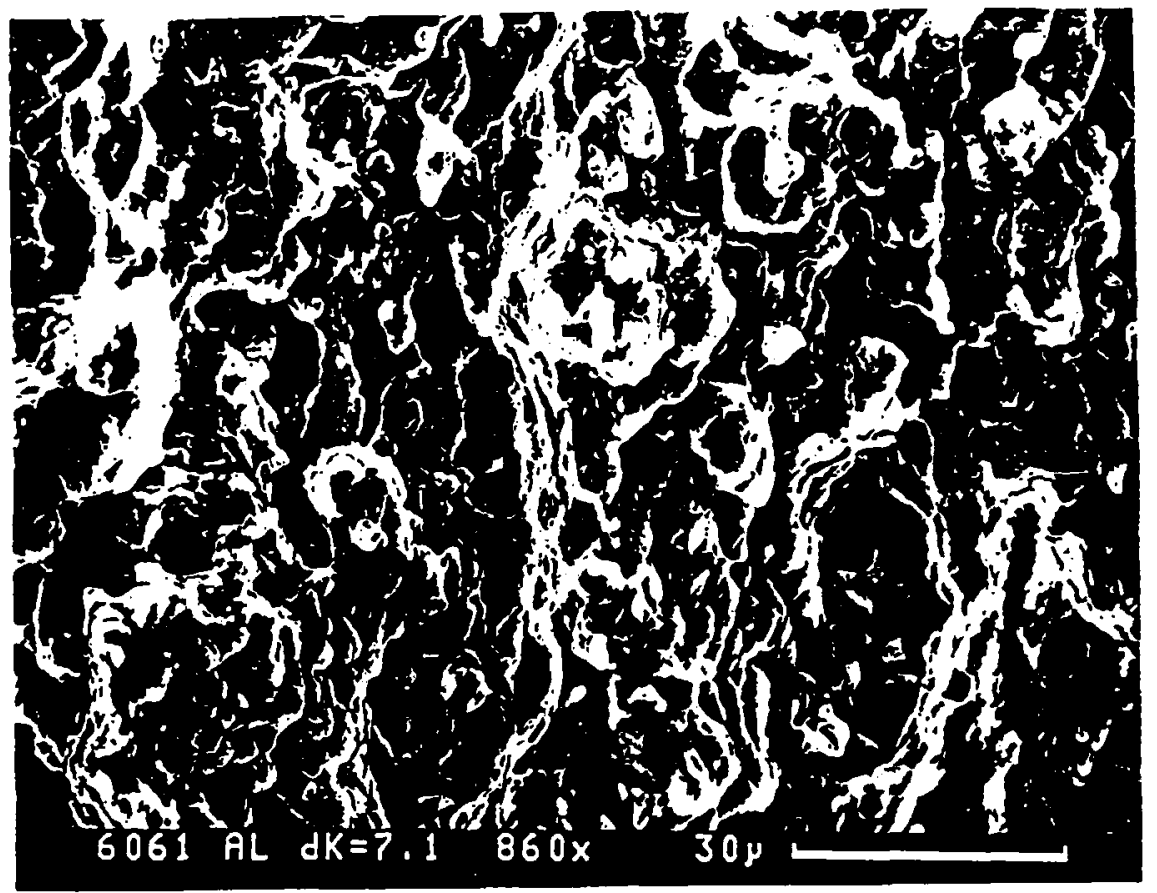

Figure 12: $6061 \mathrm{AL}$ fracture surface consisting of pinnacles and valleys. $\Delta \mathrm{K}=7.8 \mathrm{MPa}(\mathrm{m})^{1 / 2}$ $\left(7.1 \mathrm{ksi}(\mathrm{in})^{1 / 2}\right.$ )

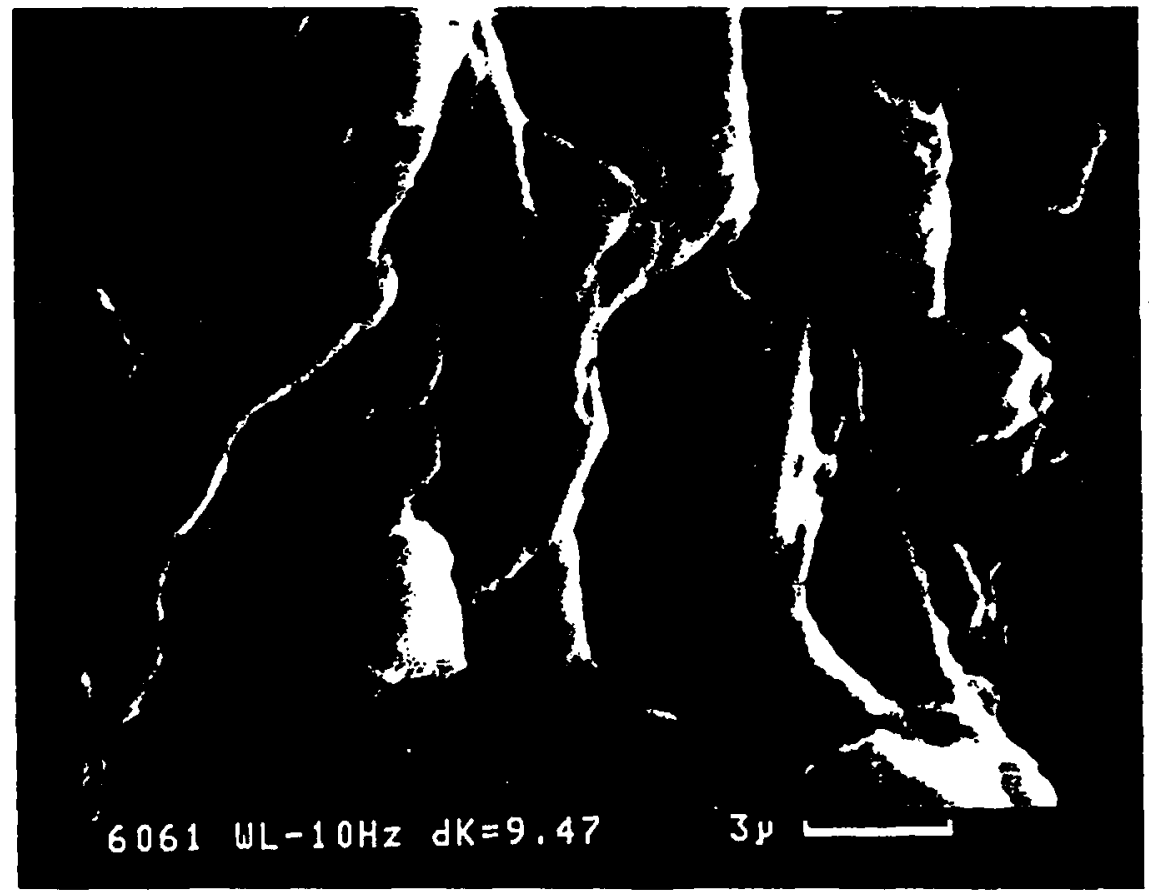

Figure 13: Fatigue striations (typical.) Note SiC pullout hole at center and SiC chip adhering to surface at lower left. 
Since crack propogation involves energy absorption by the fracturing material, and since absorbed energy scales as force (applied load) acting through a distance, it should be possible to characterize fatigue fracture behavior by a parameter having units of length. We propose that the characteristic length be defined as the total striation length, $L$, per fracture area. $L$, then, is proportional to pinnacle height, characterized by the number of striations required to form the pinnacle, and proportional to pinnacle area density (which is inversely proportional to valley width.) Moreover, the characteristic length is a function of pinnacle shape; pinnacles with eliptical cross sections have total striation lengths greater than circular cross sectioned pinnacles, given the same area. Thus because the resulting AL fatigue fracture surface contains a high number of pinnacles per fracture area (valley width $=15 \mu$ ), and a large number of striations per pinnacle (12), the characteristic length is large. As such, the composite must have absorbed a relatively large amount of energy and exhibited low $\mathrm{d} a / \mathrm{dN}$ behavior at the given $\Delta \mathrm{K}$ value.

Similar observation of the AT fracture surface at $\Delta K=7.8 \mathrm{MPa}(\mathrm{m})^{1 / 2}$ (Fig. 14) revealed a slightly different surface morphology: increased valley width $(20 \mu)$, but the same number of striations per pinnacle (12) to a first approximation. The characteristic length would be somewhat smaller, yielding a higher FCGR, per observations in Fig.10.

If average valley width influences FCGR behavior, why is it that the valley width of $A T$ is larger than that of $\mathrm{AL}$ at low $\Delta \mathrm{K}$ ? First, one must realize that valley width is just a consequence of pinnacle shape; narrow valleys tend to be associated with oblong pinnacles (aspect ratio $>2$ ), while wide valleys are related to more circular (conical) pinnacles (aspect ratio <2.) Pinnacle shape, in tum, is determined by the spatial pattern of microvoid nucleation sites, which controls tensile ductility in Al-SiC. $<26,27>$ It is these sites, which prefer regions: 1) of high stress triaxiality, 2) depleted in SiC particles, and 3) of highest stress intensity ahead of the advancing crack tip, which ultimately determine the fracture surface morphology. Preference to high stress triaxiality results in the familiar concave advancing crack. But in order for the crack to propogate, voids must nucleate and coalesce in two spatial dimensions: 1) in the direction of crack grouth. and 2) in the direction nomal to crack growth. Competition between the wo processes determunes 
void nucleation pattems, valley morphology, pinnacle size and shape, and finally, fatigue crack growth rate. In the case of $A L$, void nucleation parallel to crack growth is relatively easy, since voids nucleate in the 'soft' aluminum matrix. However nucleation and coalescence in the normal direction is more diffecult because the $\mathrm{SiC}$ particle linear density transverse to the extrusion direction is greater vs. longitudinally. Thus mictovoids nucleate, grow and coalesce with preference to the growing direction. Conversely void nucleation in AT at low $\Delta \mathrm{K}$ favors allignment normal to the growth direction. The higher proportion of microvoid sheets oriented perpendicular or at oblique angles to the growth direction in AT acts to reduce the pinnacle aspect ratio, reducing the total striation length per area. As such FCGR is greater for AT vs. AL at low $\triangle K$.

Figs.15 and 16 are fracture surfaces at mid $\Delta K\left(9.47 \mathrm{MPa}(\mathrm{m})^{1 / 2}\right)$ for AL and AT, respectively. Features are almost identical. The similar surface morphologies are expected since at this $\Delta \mathrm{K}$ value, macroscopic $\mathrm{da} / \mathrm{dN}$ behavior for each specimen is nearly coincident.

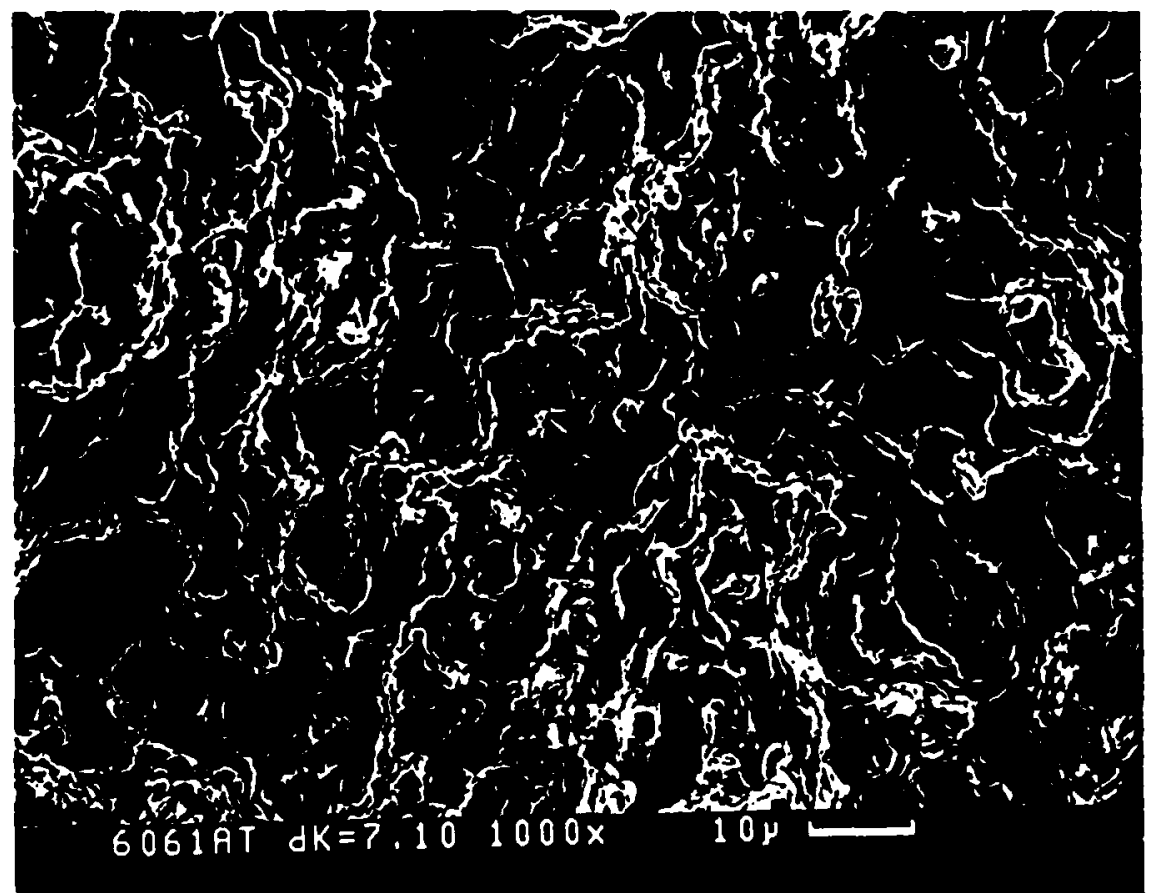

Fïgure 14: 6061 AT fracture surface. $\Delta K=7.8 \mathrm{MPa}(\mathrm{m})^{1 / 2}(7.1 \mathrm{ksi(in)})^{1 / 2}$ ) Note larger average valley width vs. AL (Fig. 12.) 


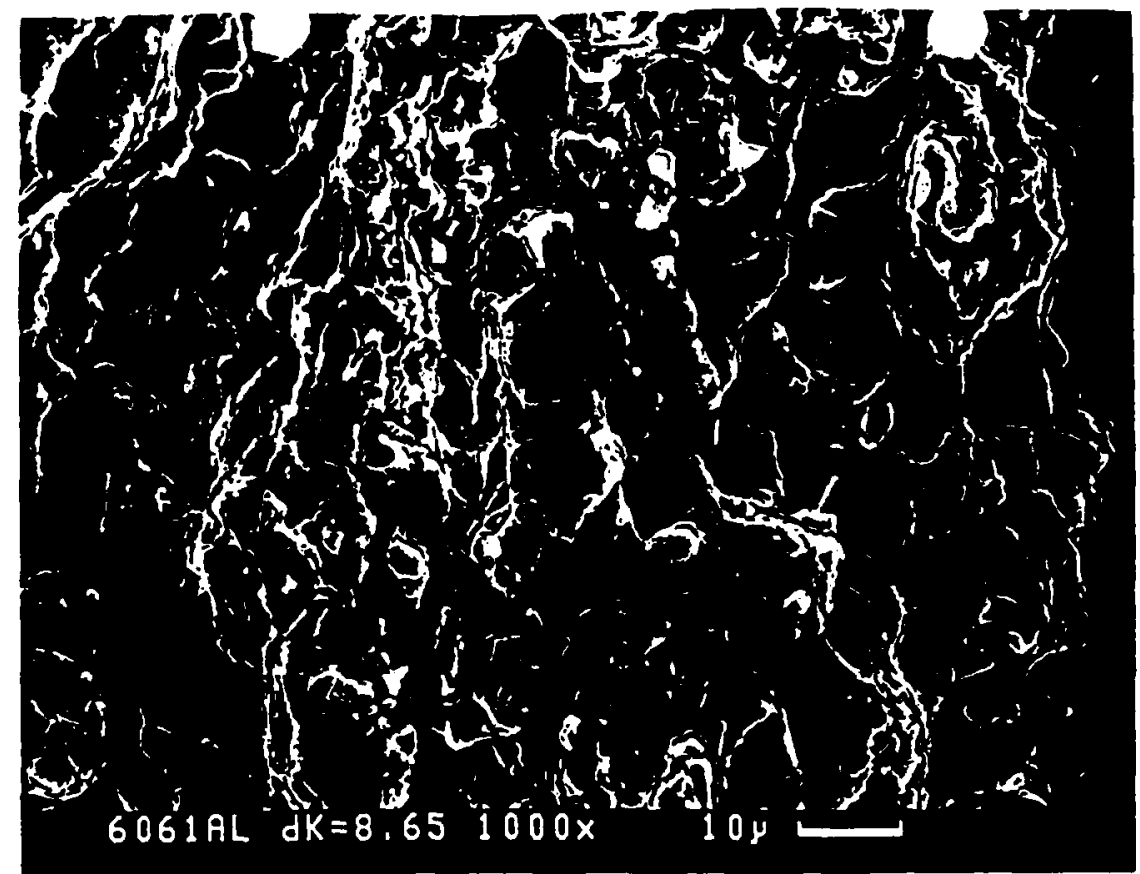

Figure 15: $6061 \mathrm{AL}$ fracture surface. $\Delta \mathrm{K}=9.47 \mathrm{MPa}(\mathrm{m})^{1 / 2}\left(8.65 \mathrm{ksi}(\mathrm{in})^{1 / 2}\right.$ ) For mid $\Delta \mathrm{K}$ fracture surface features are similar to AT. See Fig. 16.

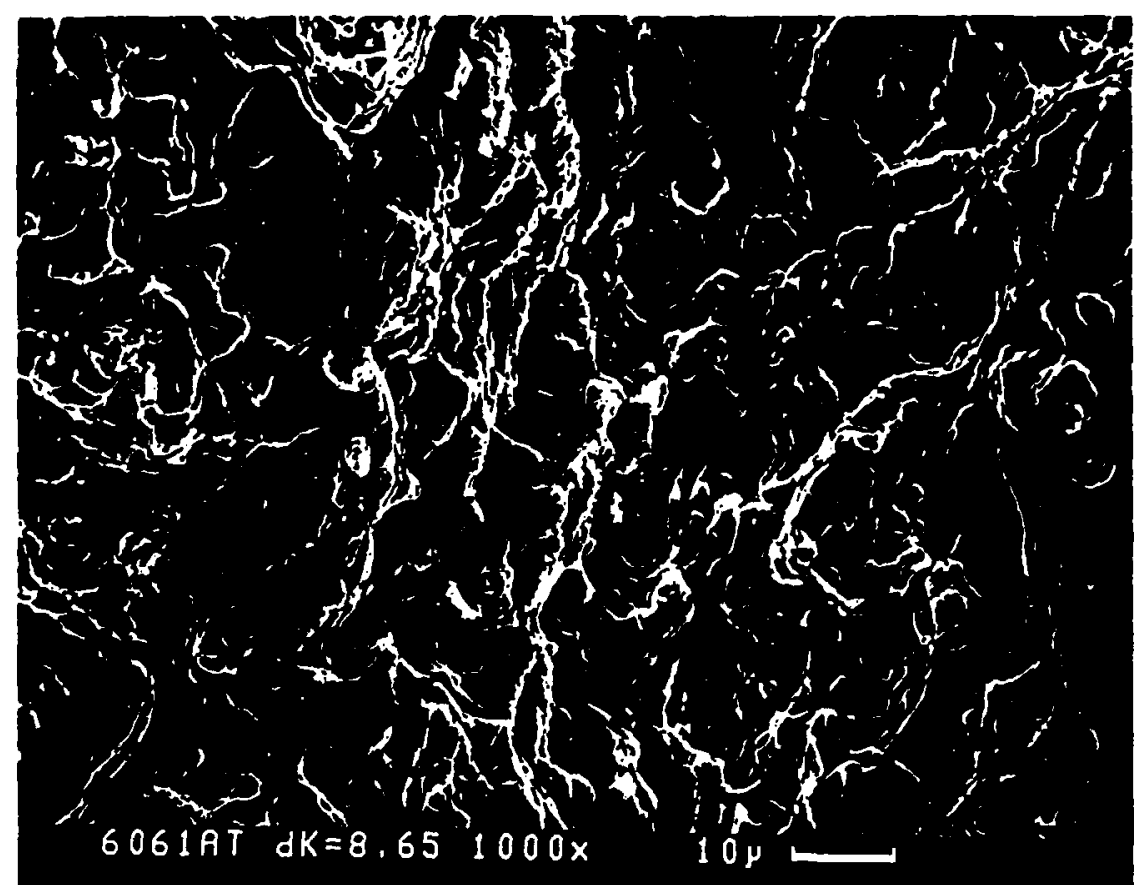

Figure 16: 6061 AT fracture surface. $\Lambda \mathrm{K}=9.47 \mathrm{MPa}(\mathrm{m})^{1 / 2}\left(8.65 \mathrm{ksi}(\mathrm{in})^{1 / 2}\right)$ Similar to Fig. 15 
At high $\Delta \mathrm{K},\left(12.5 \mathrm{MPa}(\mathrm{m})^{1 / 2}\right)$, the $\mathrm{AL}$ fracture surface is dominated by small ductile mini-cusps, elongated in the propogation direction, indicating that a prolific number of void nucleation sites developed before fracture. See Fig. 17:

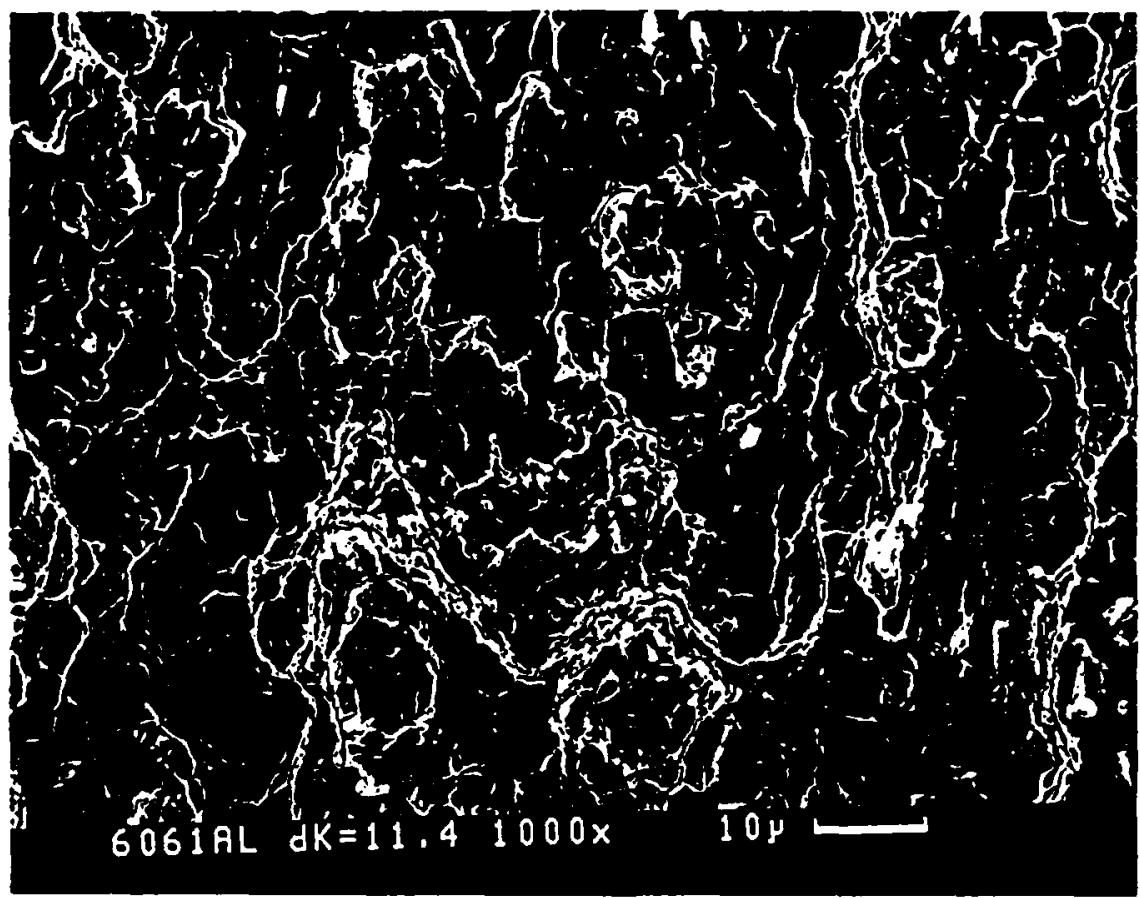

Figure 17: $6061 \mathrm{AL}$ fracture surface. $\Delta \mathrm{K}=12.5 \mathrm{MPa}(\mathrm{m})^{1 / 2}\left(11.4 \mathrm{ksi}(\mathrm{in})^{1 / 2}\right)$ Note presence of many small ductile cusps primarily elongated in the crack growth direction.

Only a small amount of energy had been absorbed by fatigue striations, resulting in a high FCGR. Conversely, the AT fracture surface is one with a very small amount of cusps - but very wide average valley width, approximately $45-50 \mu$. See Fig. 18 (also at the same $\Delta K$.) It is the ability of AT to retain a striation fracture surface morphology, albeit a very large valley width, which yields a larger characteristic length tnan $\mathrm{AL}$, and results in a lower FCGR at high $\triangle \mathrm{K}$. 


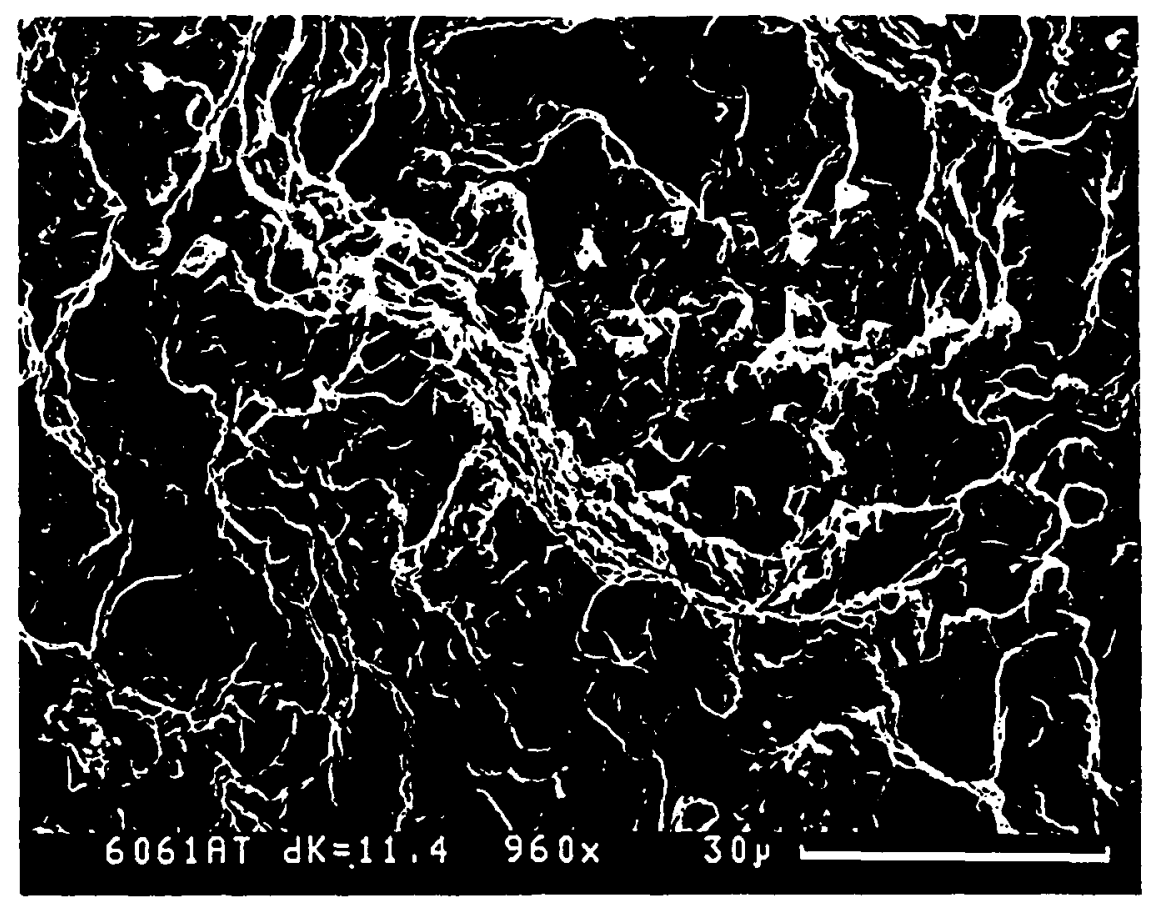

Figure 18: 6061 AT fracture surface. $\Delta K=12.5 \mathrm{MPa}(\mathrm{m})^{1 / 2}\left(11.4 \mathrm{ksi}(\mathrm{in})^{1 / 2}\right)$ Note the wide average valley width.

\section{AT vs. WT vs. ST}

Fig. 19 shows the effect of environment on the transverse FCGR. At mid-to-high $\Delta K$ values $\left(\Delta \mathrm{K}>8.6 \mathrm{MPa}(\mathrm{m})^{1 / 2}\right) \mathrm{FCGR}$ is insensitive to environment. (Though, at high $\Delta \mathrm{K}$ values, salt water may have a mitigating effect on propogation rate.) Figs. 14 and 20 show fracture surfaces at $12.7 \mathrm{MPa}(\mathrm{m})^{1 / 2}$ for AT and WT, respectively. Each exhibits nearly identical da/dN behavior since hydrogen diffusion and evolution effects are both dominated by mechanical forces at high $\Delta \mathrm{K}$ levels. Not surprisingly, many microscopic fracture features are common to both. For example, average valley widths are approximately $40-50 \mu$, and each shows a small amount of ductility. Thus Mode I transverse loading at high $\Delta \mathrm{K}$ levels seems to be associated with an increasing average valley width, or more appropriately, a decreasing pinnacle area density. The number of striations per pinnacle appears to be relatively insensitive to $\Delta \mathrm{K}$ variations. 


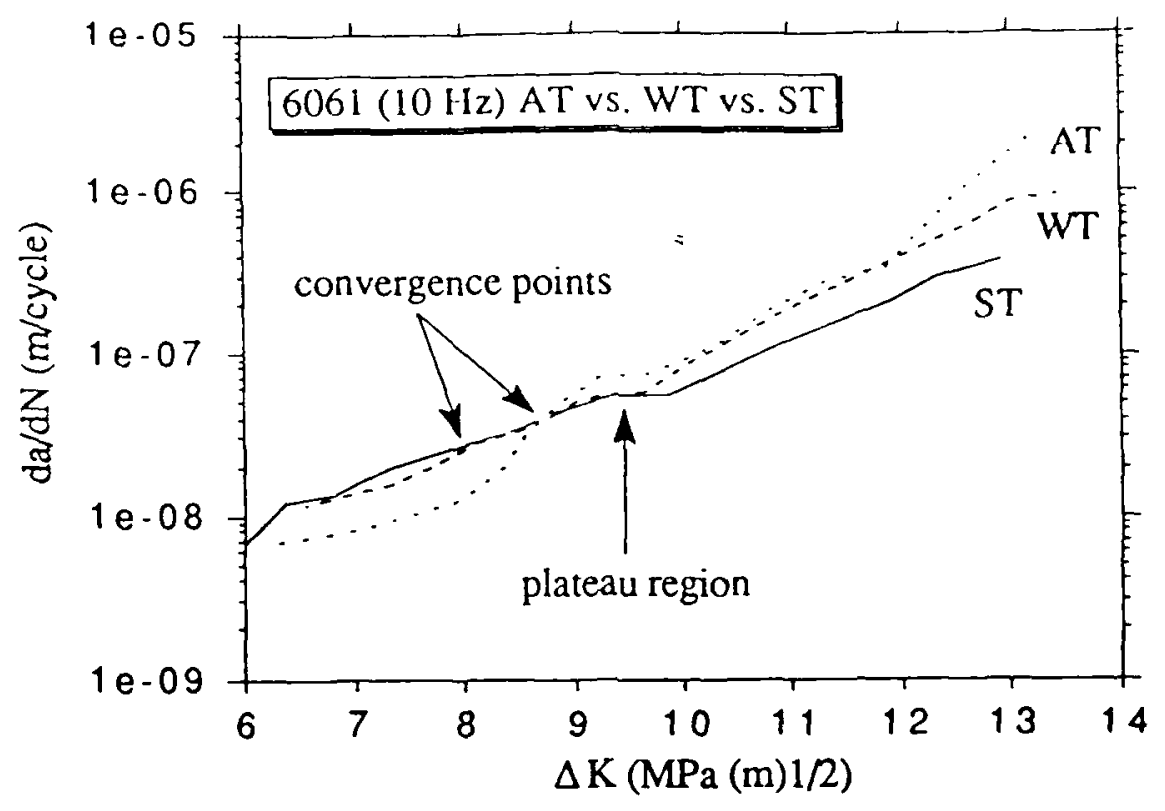

Figure 19: $6061(10 \mathrm{~Hz})$ AT vs. WT vs. ST

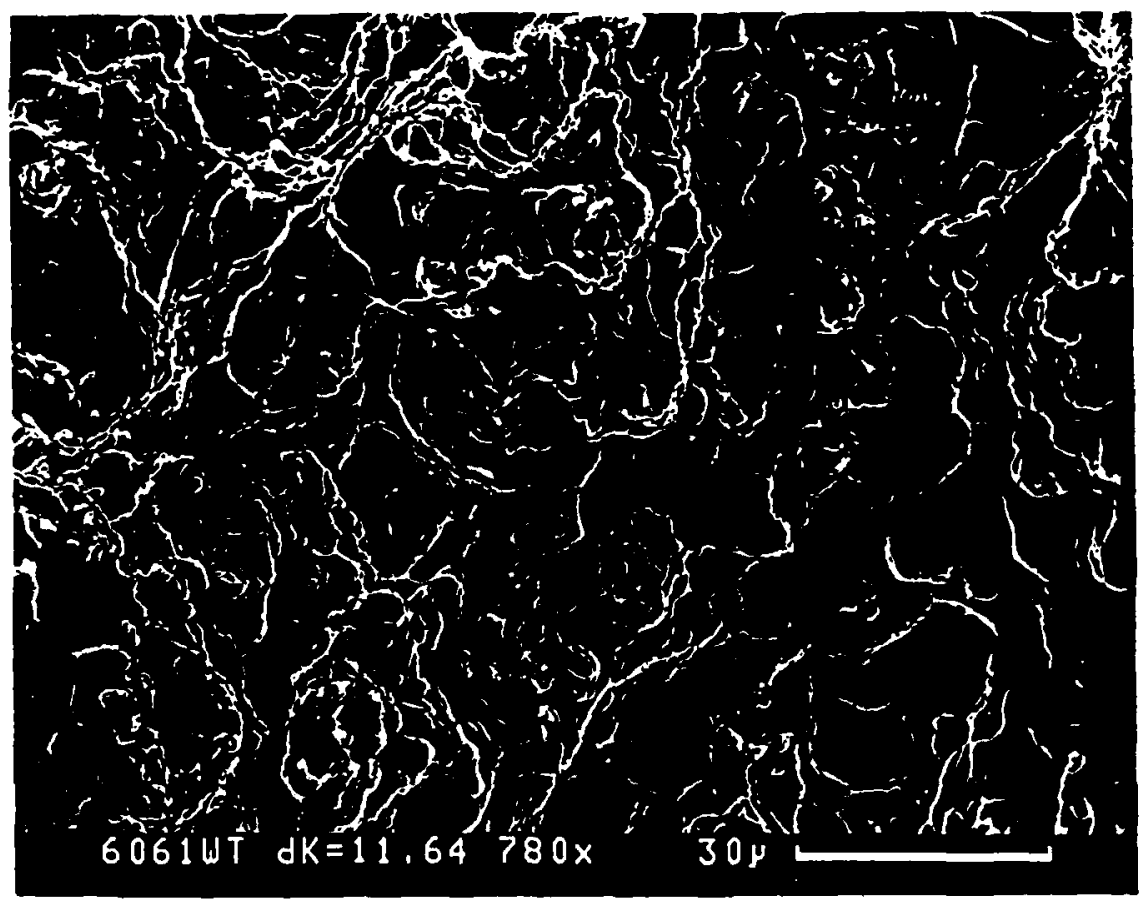

Figure 20: $6061 \mathrm{WT}$ fracture surface. $\Delta \mathrm{K}=12.7 \mathrm{MPa}(\mathrm{m})^{1 / 2}\left(11.64 \mathrm{ksi}(\mathrm{in})^{1 / 2}\right)$ Similar to Fig. 14. Both fractures at high $\Delta K$ are dominate by mechanical (inertial) forces. 
At low $\triangle \mathrm{K}\left(<8.7 \mathrm{MPa}(\mathrm{m})^{1 / 2}\right.$ and $F C G R=3.3(-8) \mathrm{m} /$ cycle $)$ the data clearly illustrates, however, that hydrogen plays a critical role in determining da/dN behavior. Crack tip hydrogen cathodic evolution effects (salt water) increase with deçreasing growth rate. Maximum sensitivity occurs at $\Delta \mathrm{K}=6.35 \mathrm{MPa}(\mathrm{m})^{1 / 2}$ where FCGR (salt water) $/$ FCGR (distilled water) $=1.8$. At a higher $\Delta \mathrm{K}\left(7.1 \mathrm{MPa}(\mathrm{m})^{1 / 2}\right)$, crack tip hydrogen diffusional effects (distilled water) causes an increase (1.9x) in FCGR relative to that of argon. See Figs. 21 and 22 for fracture surface morphologies at $\Delta \mathrm{K}=6 . \mathrm{MPa}(\mathrm{m})^{1 / 2}$ for $\mathrm{WT}$ and $\mathrm{ST}$, respectively. Clearly WT has absorbed much more fracture energy, indicated by the presence of tall pinnacles and thinly spaced striations. Average valley width is $40 \mu$. ST, though, shows no clear pinnacle formation or striation markings - only abundant corrosion products on the fracture surface. FCGR for WT and ST converge at $2.8(-8) \mathrm{m} /$ cycle, suggesting that the kinetics of cathodic hydrogen charging become dominated by hydrogen diffusion and/or transport ahead of the crack tip at this convergence rate.

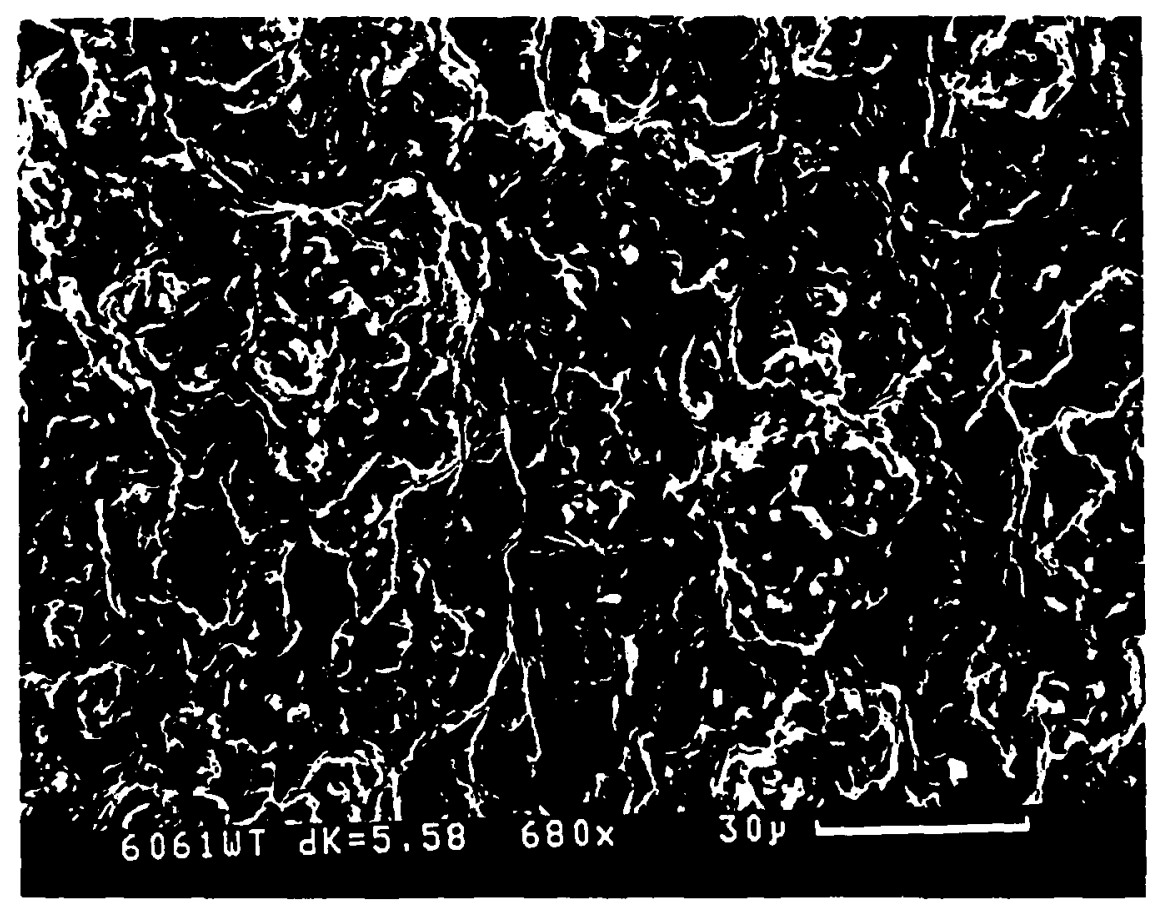

Figure 21: $6061 \mathrm{WT}$ fracture surface. $\Delta \mathrm{K}=6.11 \mathrm{MPa}(\mathrm{m})^{1 / 2}\left(5.58 \mathrm{ksi}(\mathrm{in})^{1 / 2}\right)$ More energy is absorbed than with $6061 \mathrm{ST}$ at low $\Delta K$. See Fig. 22. 


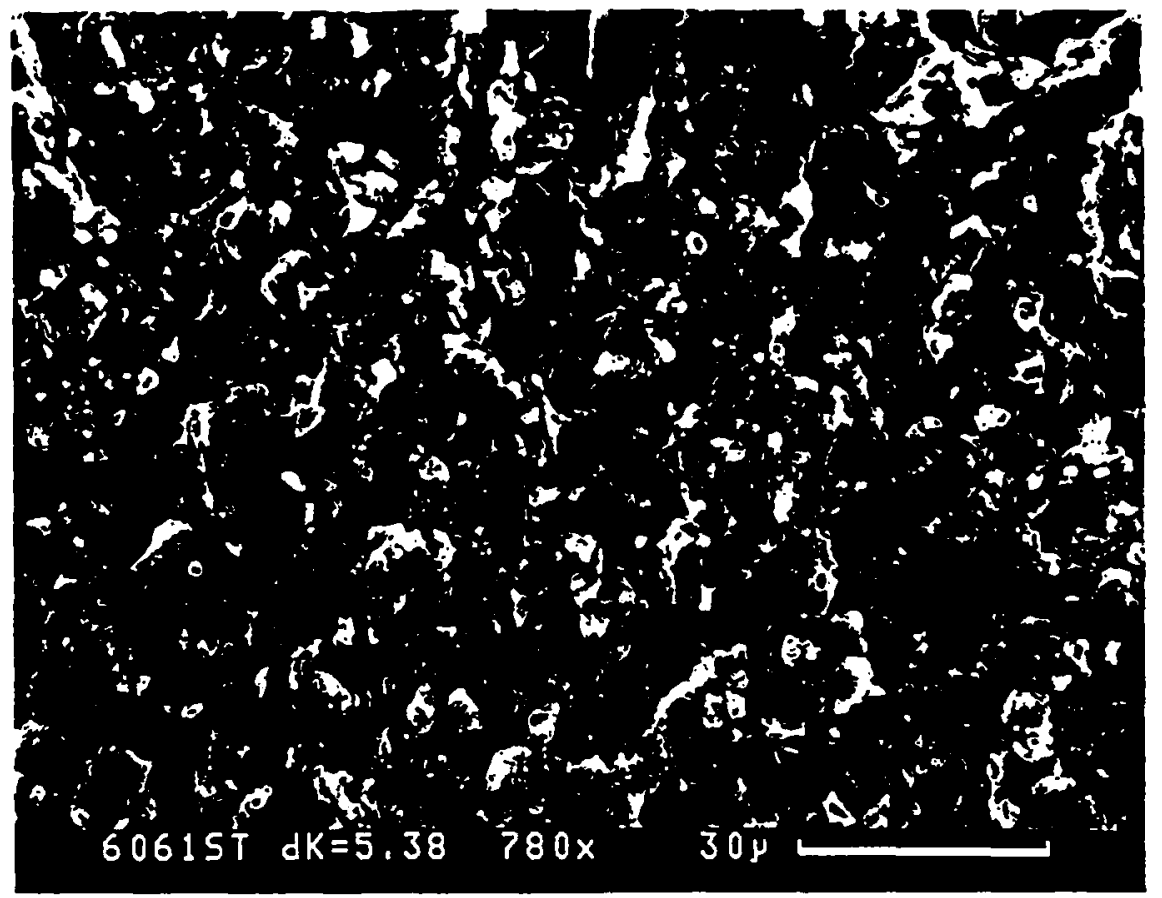

Figure 22: $6061 \mathrm{ST}$ fracture surface. $\Delta \mathrm{K}=5.89 \mathrm{MPa}(\mathrm{m})^{1 / 2}\left(5.38 \mathrm{ksi}(\mathrm{in})^{1 / 2}\right)$ Note large amount of corrosion products on surface. Less fracture energy absorbed than WT, Fig. 21.

The collapsed aqueous da/dN behavior converges with AT at $3.3(-8) \mathrm{m} / \mathrm{cycle}$, which further suggests that the previous microscopic rate-controlling mechanism (hydrogen diffusion and transport) is now dominated by macroscopic, mechanical (or inertial) effects. At still slightly higher $\Delta K$ values (after the second convergence point) for $9.2<\Delta K<9.8 \mathrm{MPa}(\mathrm{m})^{1 / 2}$, a momentary FCGR arrest for all three environments occurs, indicating possible microstructural fracture path changes. Fig. 23, an SEM photo of this region (in WT), indicates that valley width has grown to $55-60 \mu$. In the plateau region, valley width might be reaching a critical value allowing inertial forces to dominate at higher FCGR (and $\triangle \mathrm{K}$.) 


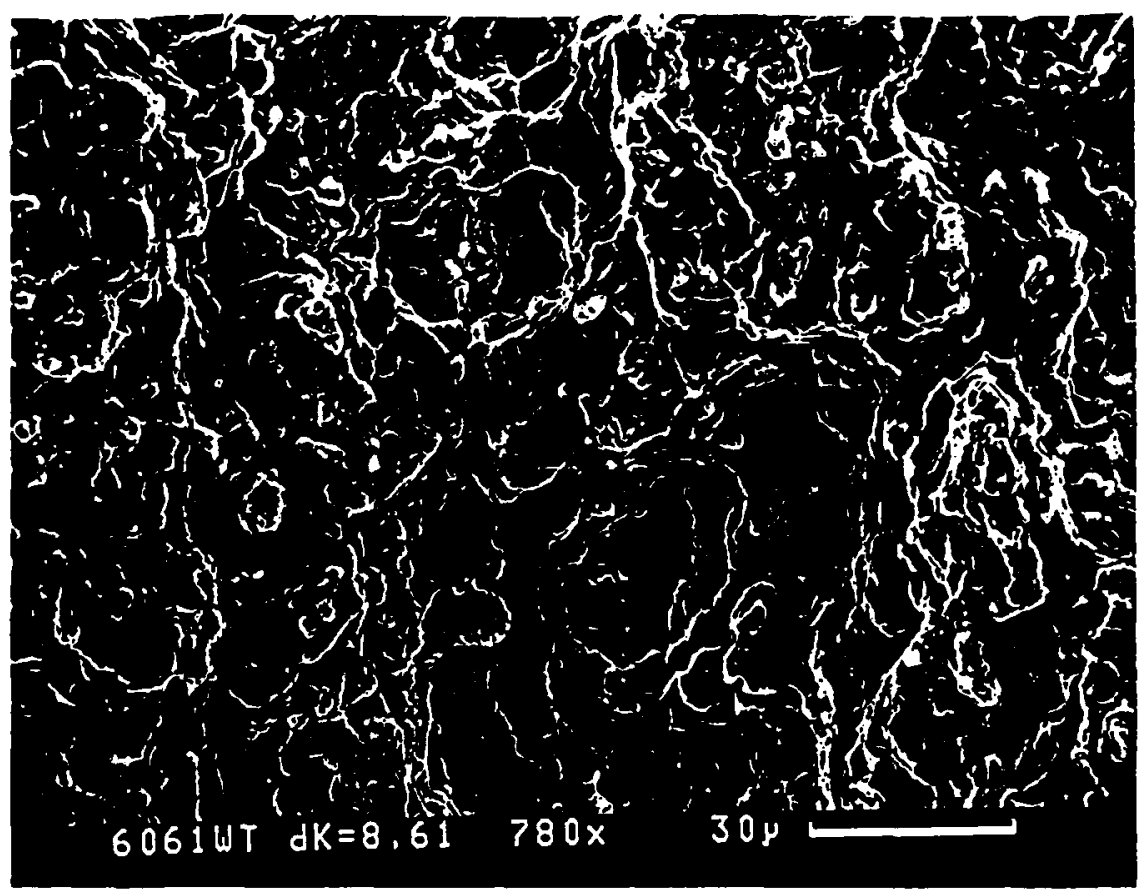

Figure 23: $6061 \mathrm{WT}$ fracture surface. $\Delta \mathrm{K}=9.43 \mathrm{MPa}(\mathrm{m})^{1 / 2}\left(8.61 \mathrm{ksi}(\mathrm{in})^{1 / 2}\right)$ Note two large coalesced voids at center right.

\section{HYDROGEN INGRESS}

Fig. 19 does not include $\mathrm{WT} d \mathrm{~d} / \mathrm{dN}$ data for $\Delta \mathrm{K}<6.25 \mathrm{MPa}(\mathrm{m})^{1 / 2}$. Instead the data is presented in Fig. 24 as a dashed line. First, however, note in Fig. 19 that both AT and ST exhibit usual crack propogation behavior at low $\triangle \mathrm{K}$ levels; then notice in Fig. 24 that WT $(10 \mathrm{~Hz})$ does not for $\Delta \mathrm{K}<6.2 \mathrm{MPa}(\mathrm{m})^{1 / 2}$. An explanation may be related to the fact that for the AT and $\mathrm{ST}$ specimens, FCGR testing commenced immediately after fatigue precracking was completed, whereas the WT specimen was stored in lab air for 7 days prior to testing. Hydrogen, a constituent of ordinary lab air may be diffusing ahead of the precrack tip and becoming entrapped in the matrix, presumably at the $\mathrm{SiC}-\mathrm{Al}$ interface. Such embrittlement behavior is not uncommon. Speidel and co-workers have shown that subcritical cracks can grow in aluminum alloys exposed to water vapor. $<19,28>$ Crack growth behavior in WT supports our theory in that FCGR at first is high for $5.9<\Delta \mathrm{K}<6.35 \mathrm{MPa}(\mathrm{m})^{1 / 2}$, but then decelerates presumably because the crack grows through regions in the matrix containing progressively less entrapped hydrogen. 
Finally, at $\Delta \mathrm{K}=6.35 \mathrm{MPa}(\mathrm{m})^{1 / 2}$ regular growth behavior resumes. The hydrogen ingress penetration depth is estimated to be 37 mils (ahead of the crack tip) after 7 days of lab air storage.

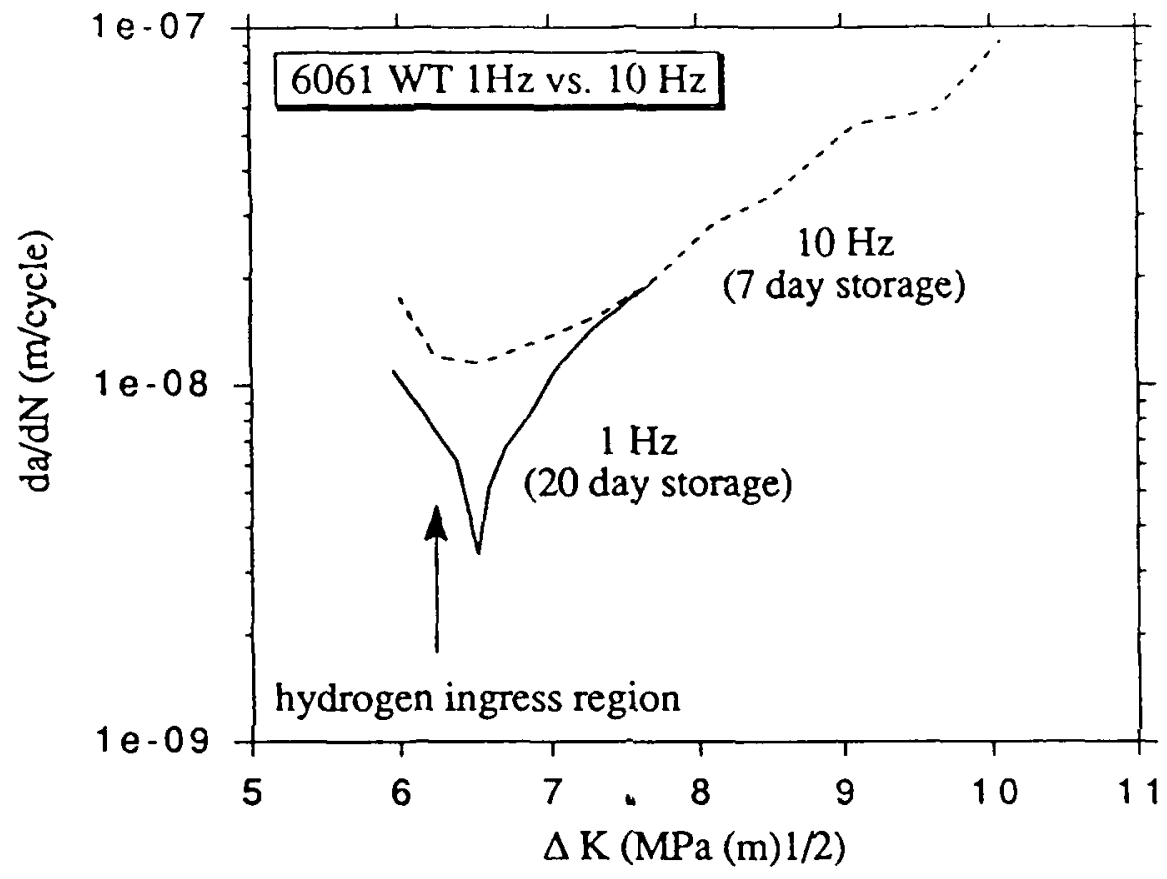

Figure 24: $6061 \mathrm{WT} 1 \mathrm{~Hz}$ vs. $10 \mathrm{~Hz}$

\section{WT-10 vs. WT-1}

The effect of cyclic loading frequency (10 hertz or 1 hertz) on $\mathrm{da} / \mathrm{dN}$ vs. $\Delta \mathrm{K}$ is also shown in Fig. 24. For $\Delta \mathrm{K}<6.5 \mathrm{MPa}(\mathrm{m})^{1 / 2}$, though, the effect of lab air storage time is superimposed over the frequency effect. Our results indicate that for FCGR $>2(-8) \mathrm{m} /$ cycle, the critical rate, cyclic frequency has no marked effect on $\mathrm{da} / \mathrm{dN}$ behavior. For $6.5<\Delta \mathrm{K}<7.3 \mathrm{MPa}(\mathrm{m})^{1 / 2}$, there appears to be no hydrogen ingress effect, since FCGR increases monotonically with $\Delta K$. In this region of slow crack advance, cyclic frequency has a dual nature. A high frequency produces large strain rates, increasing FCGR in a brittle material; but the specimen's total immersion time in a corrosive environment is minimized under high cyclic loading, which acts to lower FCGR. 
In this $\triangle \mathrm{K}$ region because FCGR for $10 \mathrm{~Hz}$. is substantially greater (up to $4 \mathrm{x}$ ) than FCGR for 1 Hz. (even though the latter's ummersion time is $10 x$ that of the former), the rate controlling mechanism is strain rate.

For the $1 \mathrm{~Hz}$. CT specimen, which was stored in lab air for 20 days prior to testing, a more pronounced hydrogen ingress behavior was seen vs. the 7 day stored sample. Since hydrogen ingress is diffusional in nature, one might expect that the effect of hydrogen ingress (elevated, but decreasing FCGR with increasing $\Delta K$ ) would increase with lab storage time. This hypothesis might be true; but since our specimens were not stored for equal time periods, we cannot corroborate such a claim at this time. Instead our data suggests that for low $\Delta \mathrm{K}$ in distilled water, a higher strain rate $(10 \mathrm{~Hz})$ outwieghs a longer lab air storage time (20 days) and results in higher FCGR. The smoother nature of the 20 day stored sample da/dN curve might be due to hydrogen entrapment being more homogeneous than after only 7 storage days.

\section{$\underline{S T-10 v s . S T-1}$}

When the 6061 composite is subjected to salt water and the frequency reduced to $1 \mathrm{~Hz}$, FCGR was found to be approximately $1.5 x$ greater than at $10 \mathrm{~Hz}$. at mid-to-high $\Delta \mathrm{K}$. See Fig. 25. Thus when crack tip hydrogen evolution occurs (as with immersion in $\mathrm{NaCl}$ solution) the rate controlling mechanism is probably electrochemical in nature. As mentioned previously, cyclic frequency dictates total time of immersion as well as strain rate. But unlike the case involving distilled water, the total immersion time in $\mathrm{NaCl}$ solution appears to dominate strain rate effects. In addition, there appears to be no convergence point at high FCGR as seen in other systems when inertial forces dominate microscopic effects. Note the hydrogen ingress behavior of ST-1 resulting from a 2 day presoak. Fig. 26 is of a fractured surface suspected of hydrogen ingress. The most dramatic feature is the unusually high number of $\mathrm{SiC}$ particles found on the fracture surface (compare to Fig. 27, of an area not suspected of hydrogen ingress.) 


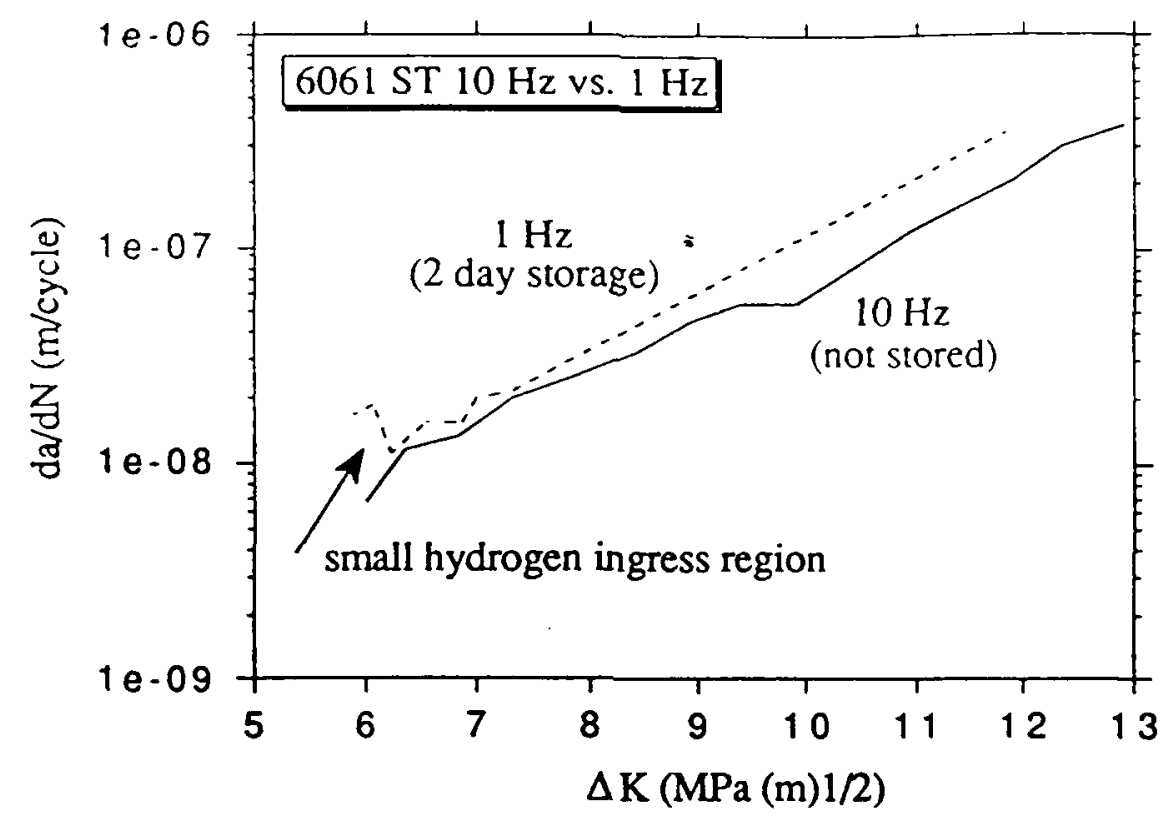

Figure 25: $6061 \mathrm{ST} 10 \mathrm{~Hz}$ vs. $1 \mathrm{~Hz}$

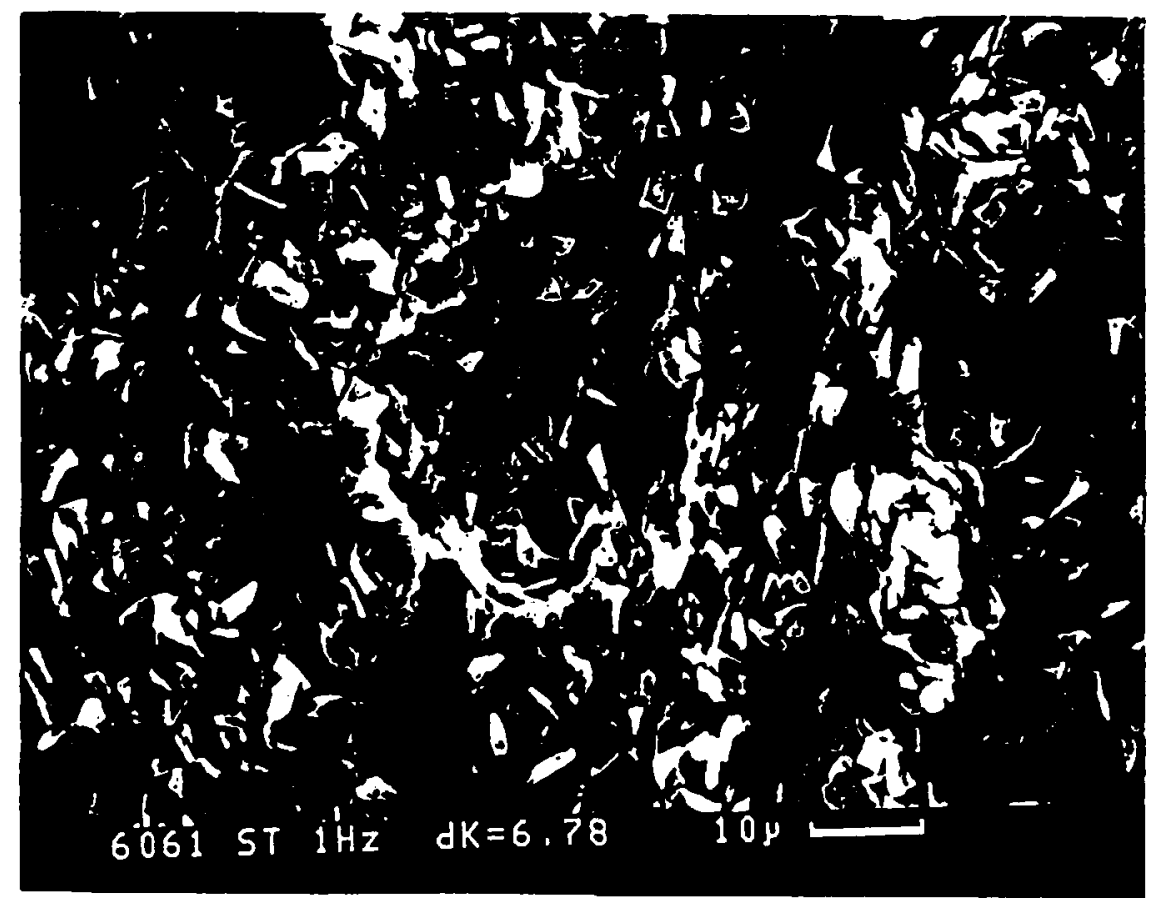

Figure 26: $6061 \mathrm{ST} 1 \mathrm{~Hz}$ fracture surface. $\Delta \mathrm{K}=6.78 \mathrm{MPa}(\mathrm{m})^{1 / 2}$ Hydrogen ingress is suspected. Note unusual number of $\mathrm{SiC}$ particles found on the fracture surface. 
If indeed, hydrogen is diffusing ahead of the crack tip during lab storage and becoming entrapped at $\mathrm{SiC}$ - Al interfaces, the net result would be slight composite embrittlement. And, the fracture surface would appear heavily decorated with $\mathrm{SiC}$ particles as in Fig. 26. This behavior may be due to the chloride ion's ability to promote hydrogen ingress near room temperature. $<31>$

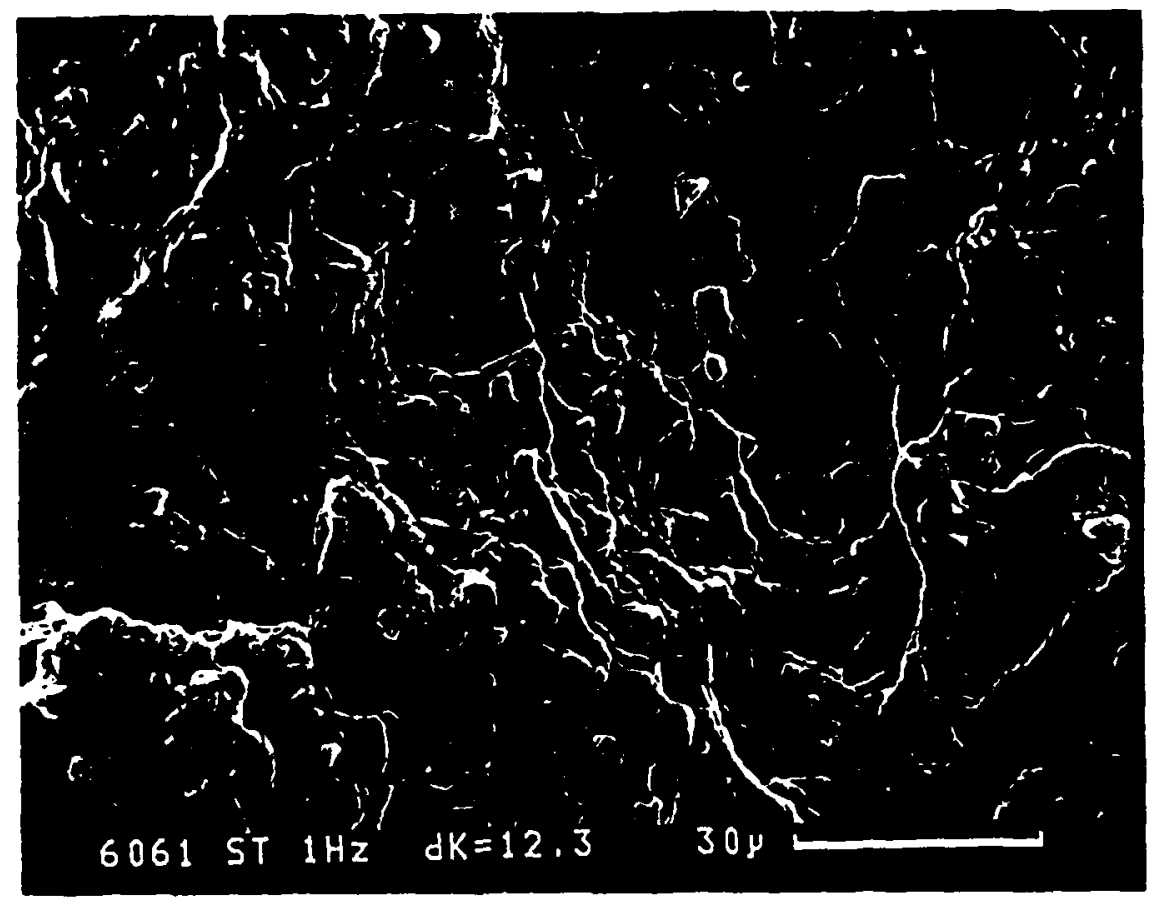

Figure 27: $6061 \mathrm{ST} 1 \mathrm{~Hz}$ fracture surface. $\Delta \mathrm{K}=6.78 \mathrm{MPa}(\mathrm{m})^{1 / 2}$ Hydrogen ingress not suspected.

\section{$\underline{\text { AL vs, WL }}$}

Distilled water had a more pronounced effect on FCGR relative to an inert environment in the TL orientation at $10 \mathrm{~Hz}$. than did LT as seen in Fig. 28 (compare with Fig. 19.) The most interesting observation is at low $\Delta \mathrm{K}$ levels where TL cracks in water grew nearly $5 \mathrm{x}$ faster than in argon. As $\Delta \mathrm{K}$ increases, $\Delta(\mathrm{FCGR})$ decreases, until at da/dN $=2(-6) \mathrm{m} /$ cycle, growth rate becomes independent of environment. This environmental convergence point occurs at a much higher FCGR than in the transverse system $(3.3(-8) \mathrm{m} / \mathrm{cycle}$.) Fig. 29 shows WL at high $\Delta \mathrm{K}$ $\left(12.9 \mathrm{MPa}(\mathrm{m})^{1 / 2}\right.$ ) where ductile cusps at the bottom of valleys are seen as in AL (Fig. 17.) 


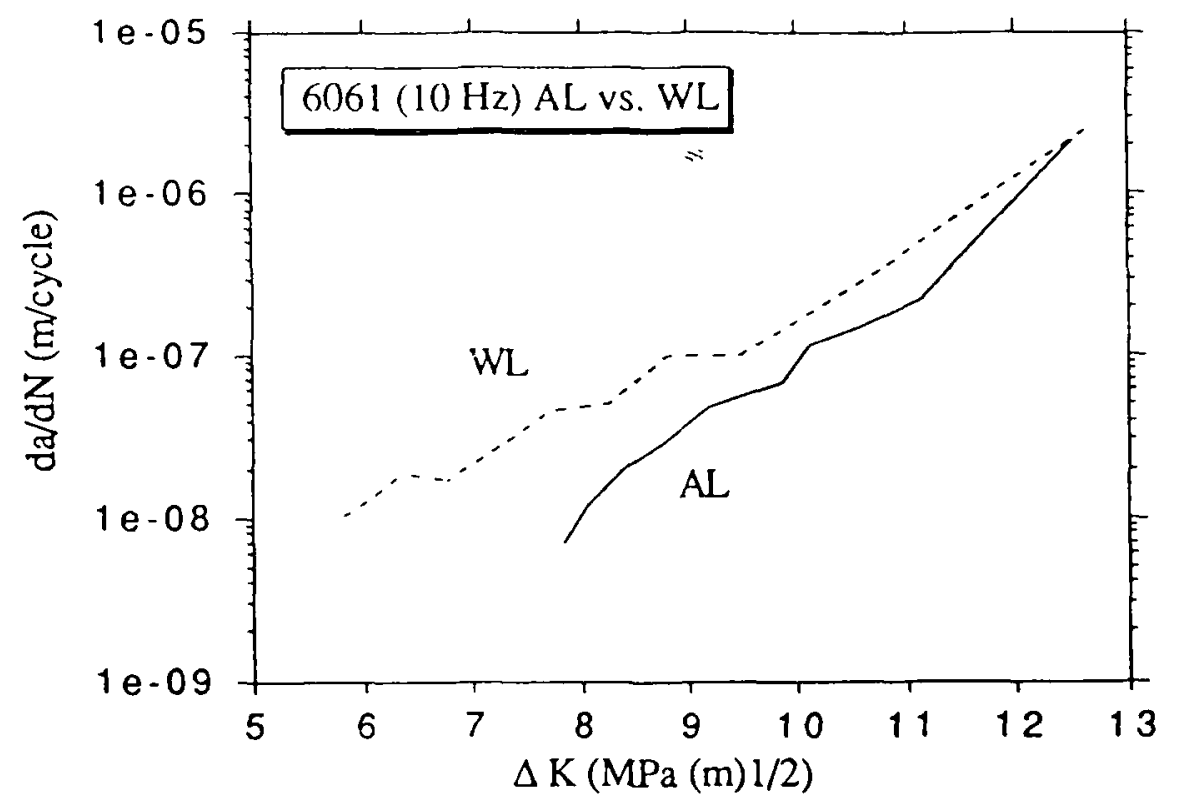

Figure 28: $6061(10 \mathrm{~Hz})$ AL vs. WL

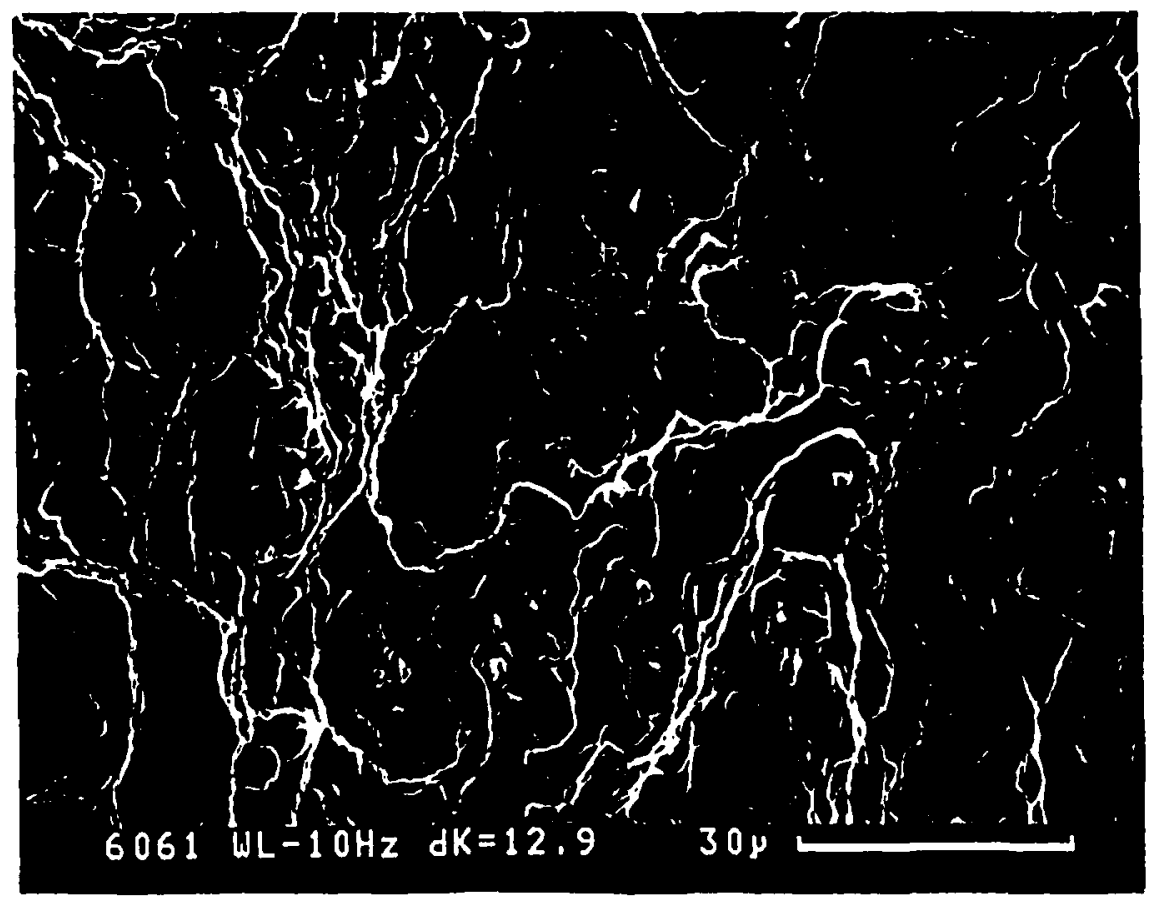

Figure 29: $6061 \mathrm{WL}$ fracture surface. $\Delta \mathrm{K}=12.9 \mathrm{MPa}(\mathrm{m})^{1 / 2}$ Note presence of ductile cusps. 


\section{AT vs. AL $(10 \mathrm{~Hz})$}

As can be seen from Fig. 30 , for $\Delta \mathrm{K}>6.8(\mathrm{da} / \mathrm{dN}>1(-8) \mathrm{m} / \mathrm{cycle})$, FCGR is sensitive to crack orientation (as in the 6061 system.) Fracture surfaces for $\Delta \mathrm{K}<6.85 \mathrm{MPa}$ (m) $)^{1 / 2}$ were similar. In Fig. $31\left(\mathrm{AL}, \Delta \mathrm{K}=6.55 \mathrm{MPa}(\mathrm{m})^{1 / 2}\right.$, typical) note two important differences from 6061 (ie. Fig. 12): 1) $\mathrm{SiC}$ pullout is much more common, indicating weaker interfacial bonding or poor wetability, and 2) there is a lower number of striations per pinnacle, indicating a more brittle material. At higher $\mathrm{da} / \mathrm{dN}$ values, mechanical inertial forces dominate short range microstructural features. Void nucleation is extensive; see Fig. 32 (note scale.) Figs. $33\left(\mathrm{AL}, 10.1 \mathrm{MPa}(\mathrm{m})^{1 / 2}\right.$ ) and $34\left(\mathrm{AT}, 9.8 \mathrm{MPa}(\mathrm{m})^{1 / 2}\right.$ ) clearly show that the average valley width for AL is greater than $100 \mu$, while only $50 \mu$ for AT. Thus the characteristic length for AT is larger than $A L$, resulting in a lower FCGR. In fact, $\operatorname{rate}(A L) / \operatorname{rate}(A T)>4$ at this high $\Delta K$.

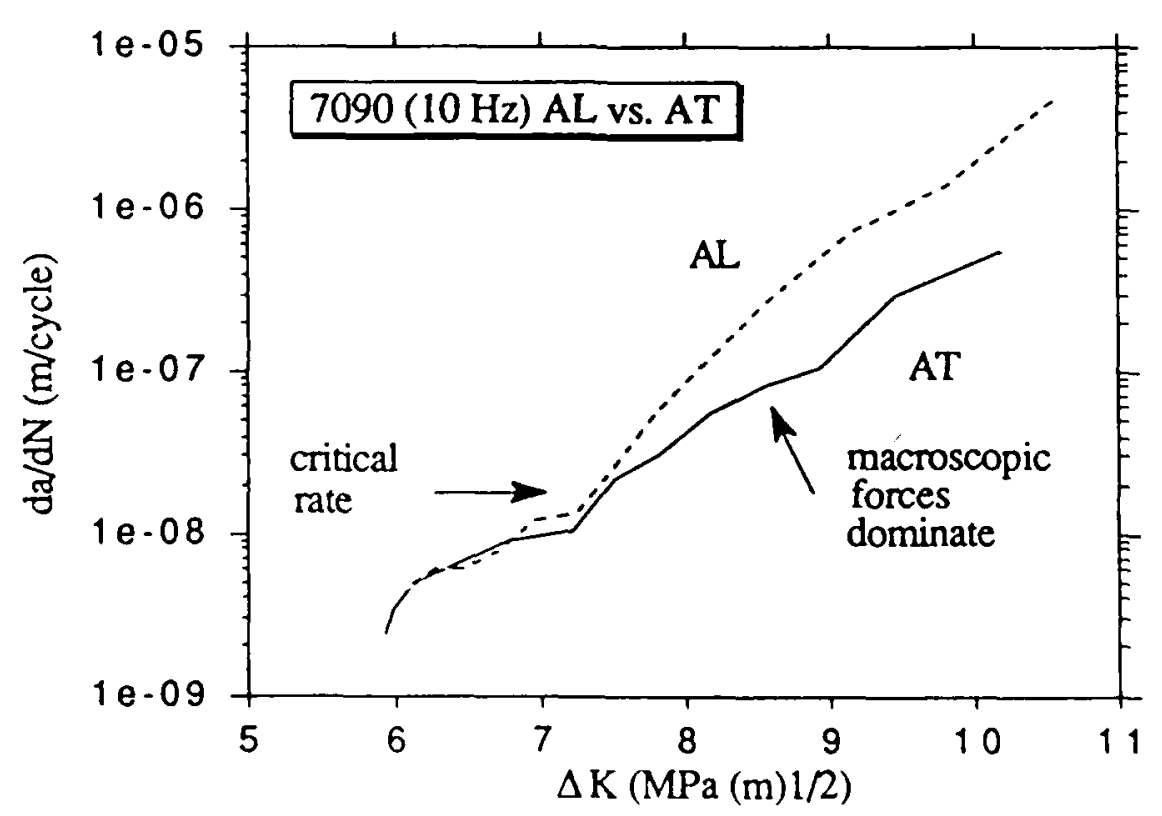

Figure 30: $7090(10 \mathrm{~Hz})$ AL vs. AT 


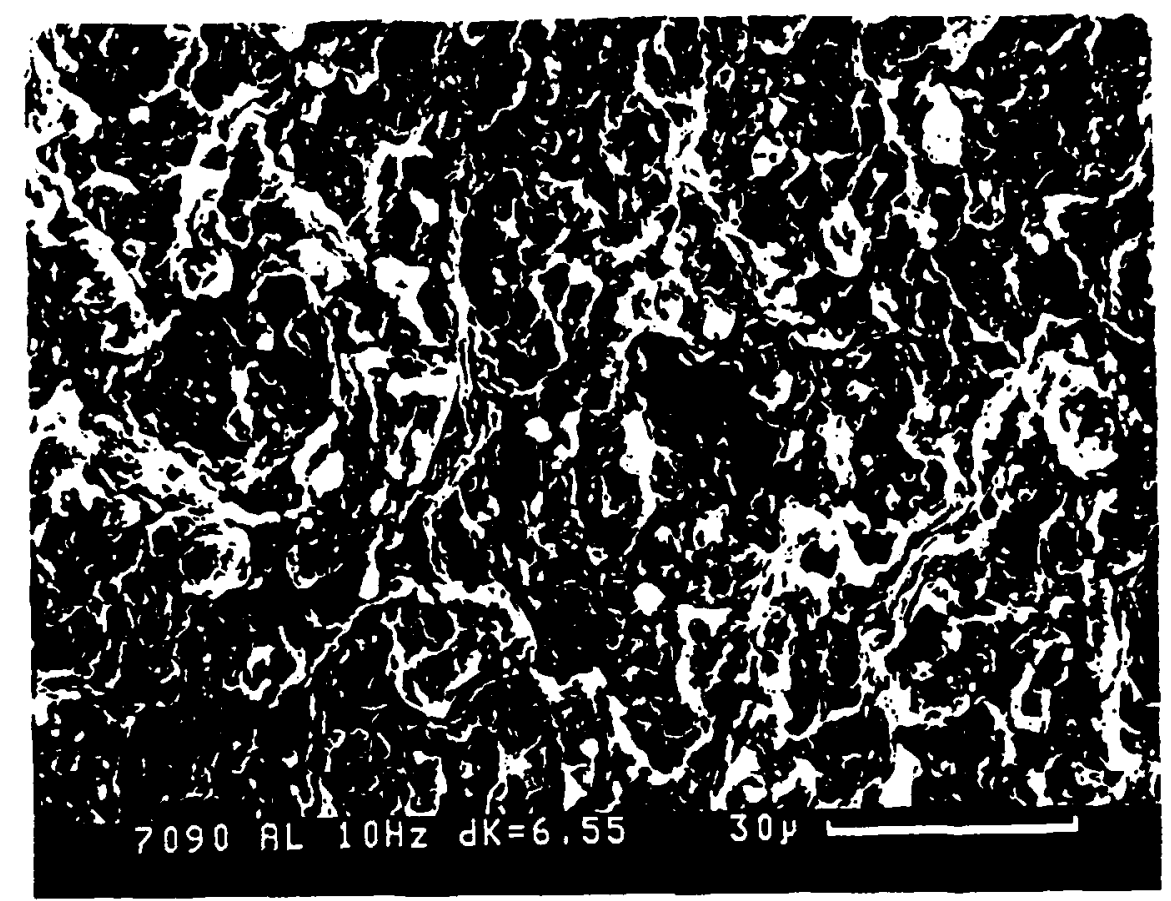

Figure 31: $7090 \mathrm{AL}$ fracture surface. $\Delta \mathrm{K}=6.55 \mathrm{MPa}(\mathrm{m})^{1 / 2}$ Note higher amount of $\mathrm{SiC}$ pullout, and smaller average pinnacle height vs. the 6061 composite.

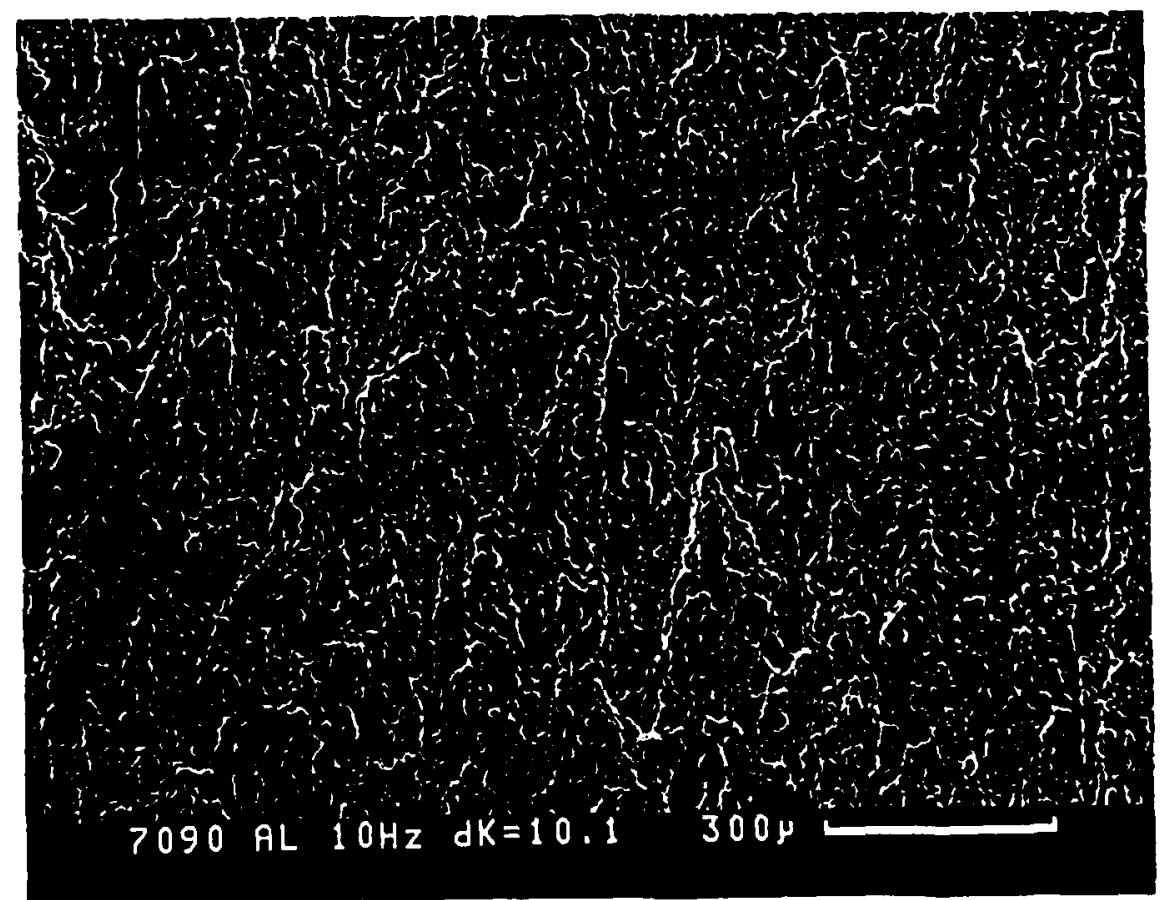

Figure 32: $1090 \mathrm{AL}$ fracture surface. $\Delta \mathrm{K}=10.1 \mathrm{MPa}(\mathrm{m})^{1 / 2}$ (low mag.) Prolific void nucleation. 


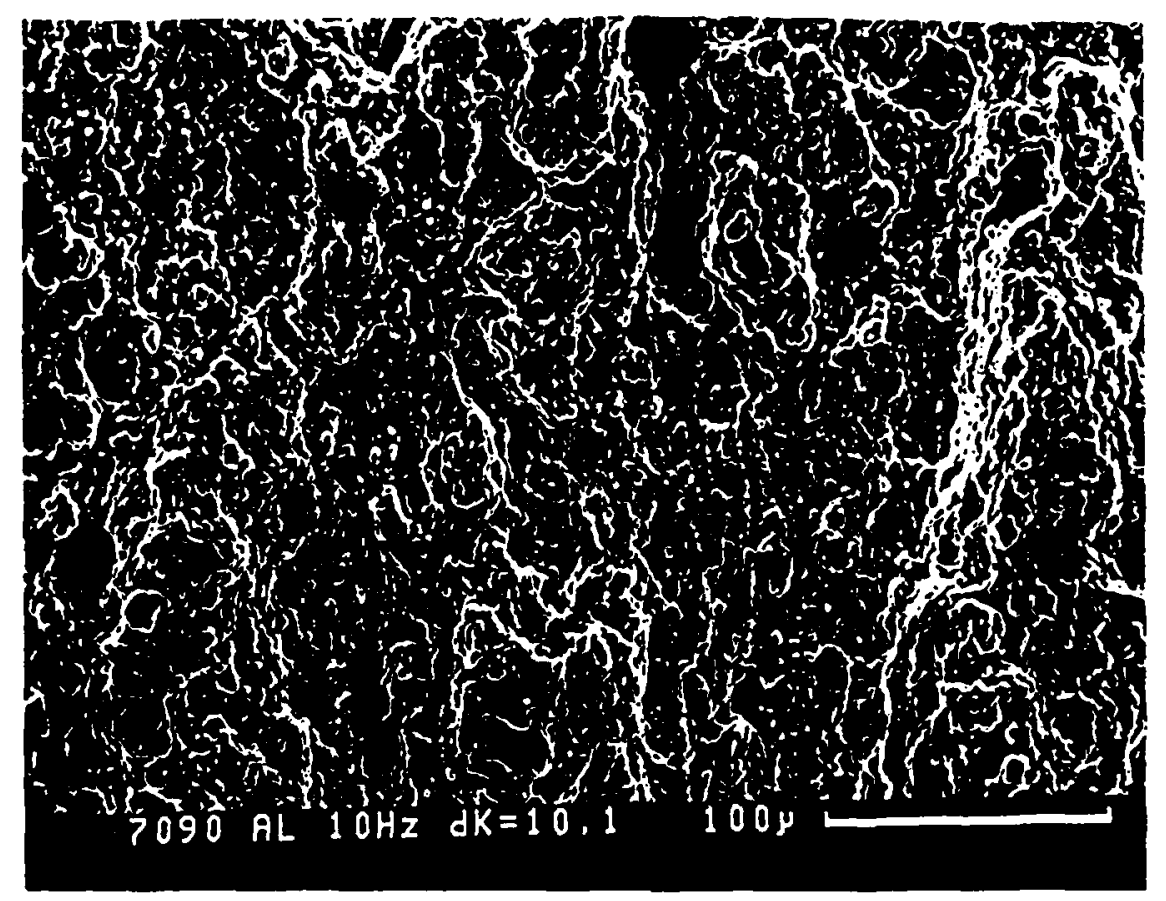

Figure 33: $7090 \mathrm{AL}$ fracture surface. $\Delta \mathrm{K}=10.1 \mathrm{MPa}(\mathrm{m})^{1 / 2}$ (high magnification) Average valley width $>100 \mu$.

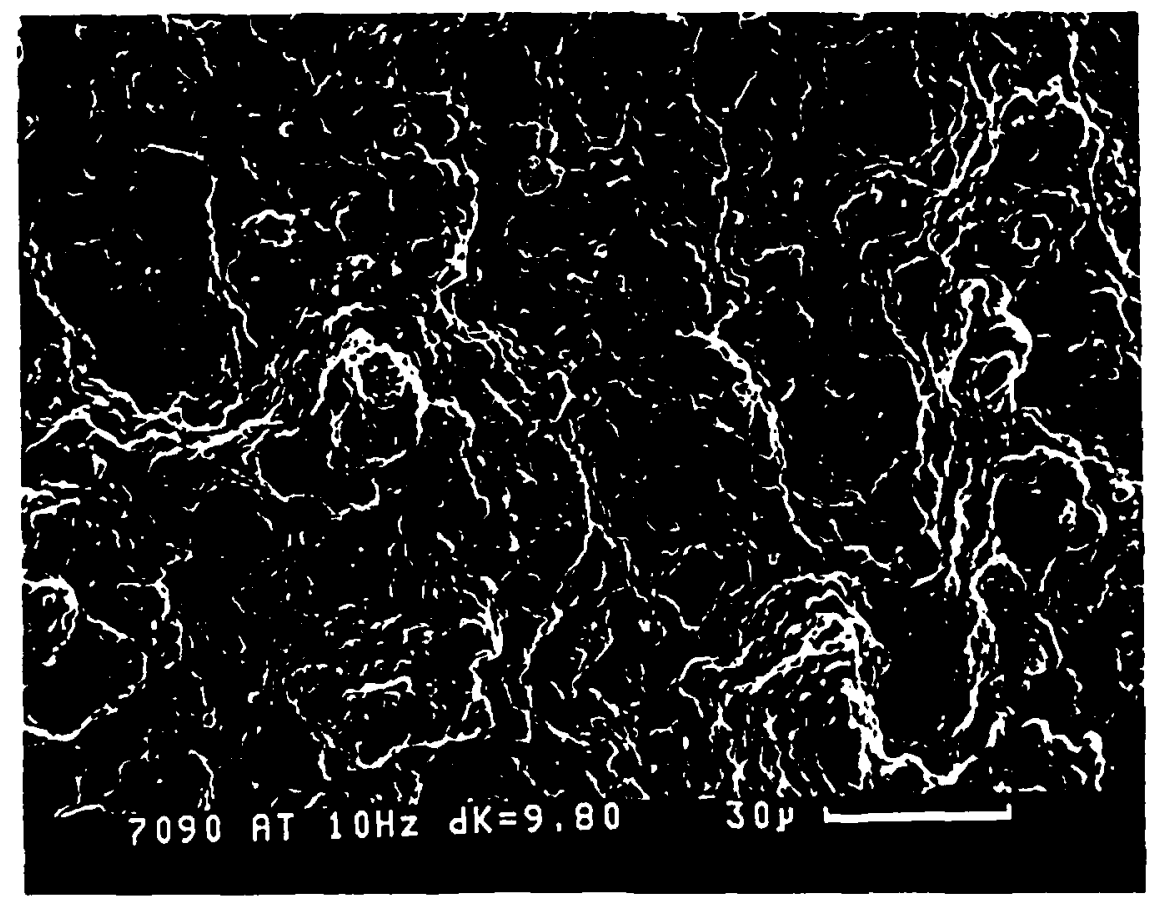

Figure 34: 7090 AT fracture surface. $\Delta K=9.8 \mathrm{MPa}(\mathrm{m})^{1 / 2}$ Average valley width $=50 \mu$ 


\section{AT vs. WT vs. ST $(10 \mathrm{~Hz})$}

As Fig. 35 illustrates, FCGR behavior is independent of environment at high $\triangle \mathrm{K} ; \mathrm{SiC}$ particles do not influence the fatigue fracture behavior significantly in this $\Delta \mathrm{K}$ region, as also reported elsewhere. $<29>$ At low $\Delta K$ levels, though, FCGR behavior is very environmentsensitive with rate (water) $/$ rate $($ argon $)>2$, and rate $($ salt $) /$ rate $($ argon $)>4$. Like the 6061 composite, $\mathrm{da} / \mathrm{dN}$ vs $\Delta \mathrm{K}$ for all three environments eventually converge, although water/argon curves coni $\because:$ se at a lower FCGR and $\Delta \mathrm{K}\left(1.4(-8) \mathrm{m} /\right.$ cycle, $8.0 \mathrm{MPa}(\mathrm{m})^{1 / 2}$.) Such behavior indicates that hydrogen effects at the crack tip are potential dependent. Salt water/argon convergence occurs at $1.2(-7) \mathrm{m} /$ cycle $\left(\Delta \mathrm{K}=8.6 \mathrm{MPa}(\mathrm{m})^{1 / 2}\right)$. Since more hydrogen is present at the crack tip (greater electrochemical potential), transportation of more hydrogen into the plastic zone via. mobile dislocations perhaps is occurring, as found in other aluminum composites. $<30,31>$ This hypothesis would account for the direct proportionality between FCGR and potential.

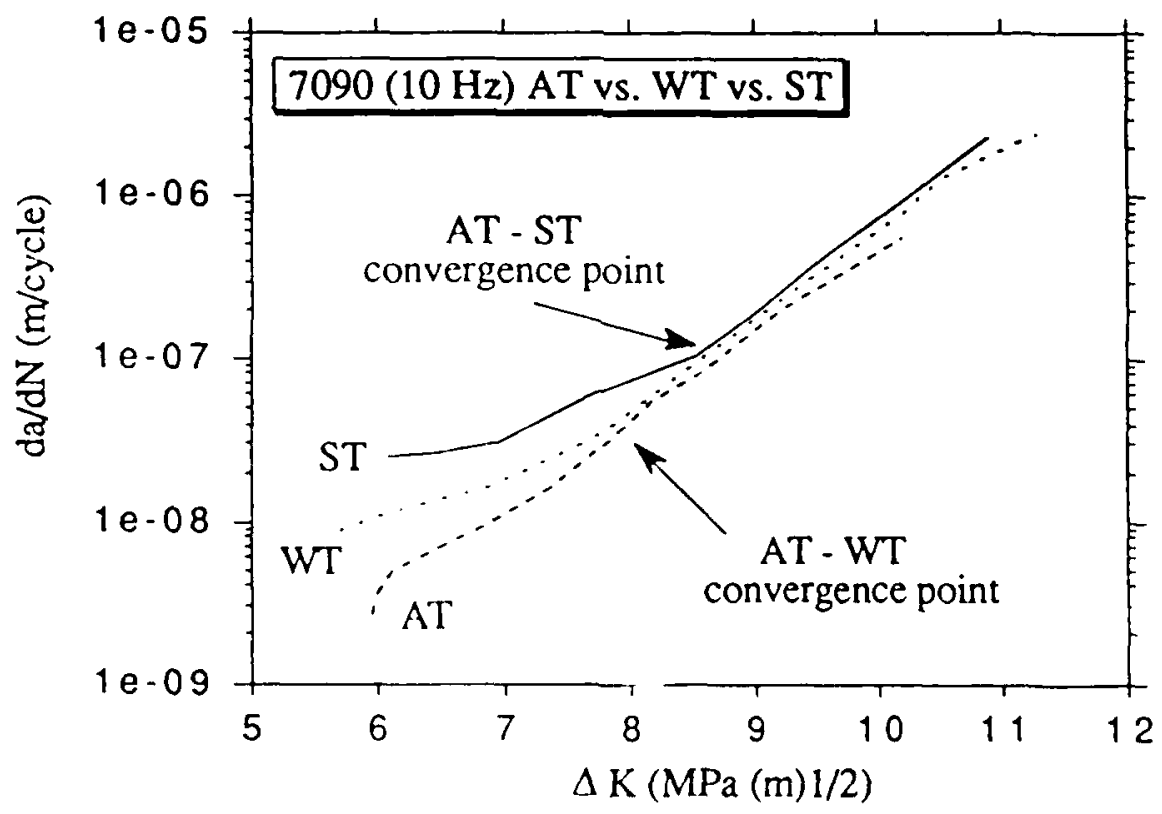

Figure 35: $7090(10 \mathrm{~Hz})$ AT vs. WT vs. ST 


\section{$\underline{\text { Pinnacle Plateaus }}$}

A typical feature found on 7090 composite fatigue fracture surfaces subjected to all three environments for mid-to-high $\Delta \mathrm{K}$ is shown in Fig. 36: the 'pinnacle plateau'. Here pinnacles seem to have been suddenly truncated in the fracture process.

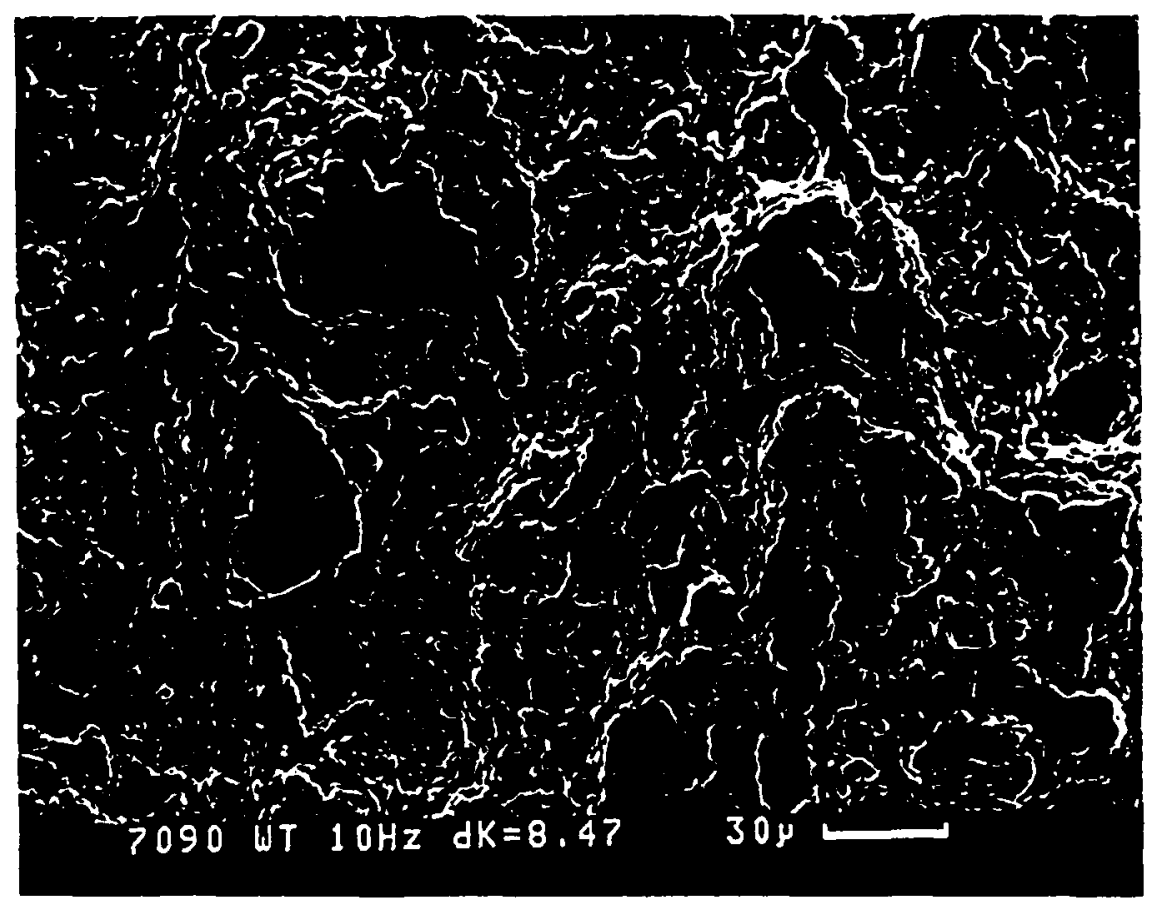

Figure 36: $7090 \mathrm{WT}$ fracture surface. $\Delta \mathrm{K}=8.47 \mathrm{MPa}(\mathrm{m})^{1 / 2}$ (low magnification) Note truncated pinnacles. This phenomenon may be due to the composite's low strain hardening capability.

These plateaus are only found at FCGR $>8(-8) \mathrm{m} /$ cycle $\left(\Delta \mathrm{K}>8.5 \mathrm{MPa}(\mathrm{m})^{1 / 2}\right)$, possibly indicating that a critical strain rate is needed to produce pinnacle truncation. It is suspected that since the 7090 co. : posite exhibits very little ductility and strain hardening, these plateau tops are brittle fracture surfaces. See Fig. 37. 


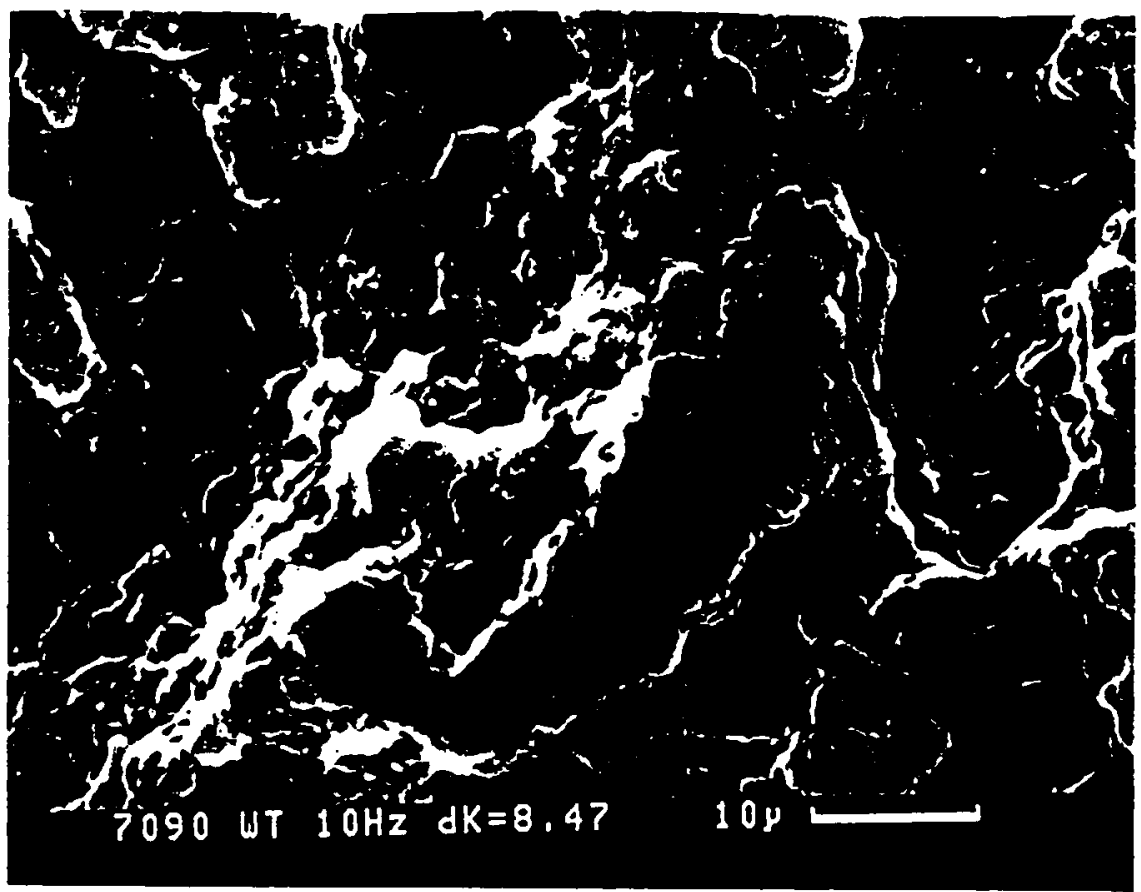

Figure 37: $7090 \mathrm{WT}$ fracture surface. $\Delta \mathrm{K}=8.47 \mathrm{MPa}(\mathrm{m})^{1 / 2}$ (high mag.) Pinnacle tops are brittle.

\section{WT-10 vs. WT -1}

It appears that lowering the load frequency reduces FCGR in 7090. This behavior is shown in Fig. 38. Higher frequency loading produces larger strain rates, which raises FCGR in a brittle composite. At low $\Delta \mathrm{K}$, rate $(\mathrm{WT}-10) /$ rate $(\mathrm{WT}-1)>1.5$, but steadily decreases (as $\Delta \mathrm{K}$

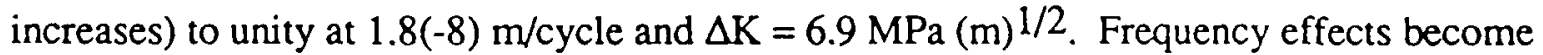
unimportant at high FCGR because strain rate, or impulse levels are relatively unaffected by frequency variations. However, momentum, the first derivative of kinetic energy with respect to velocity, is directly proportional to $\mathrm{da} / \mathrm{dN}$, and continues to rise. It is at $\mathrm{da} / \mathrm{dN}=1.8(-8) \mathrm{m} /$ cycle that momentum begins to dominate impulse effects, and the curves converge.

ST-10 vs. ST-1

FCGR behavior in salt water for these two frequencies was similar, as with WT-10 vs. WT-1, except slightly more dramatic: $\operatorname{rate}(\mathrm{ST}-10) / \mathrm{rate}(\mathrm{ST}-1)=1.7$ at low $\Delta \mathrm{K}$ values. See Fig. 39. This data indicates that even when the 7090 composite is subjected to an aggressive environment for prolonged times (ie. $1 \mathrm{~Hz}$ specimen.), impulse or strain rate effects dominate the 
relatively short order microstructural effects of hydrogen evolution (cathodic), and hydrogen diffusion/dislocation transport. FCGR at $10 \mathrm{~Hz}$ is therefore greater than FCGR at $1 \mathrm{~Hz}$.

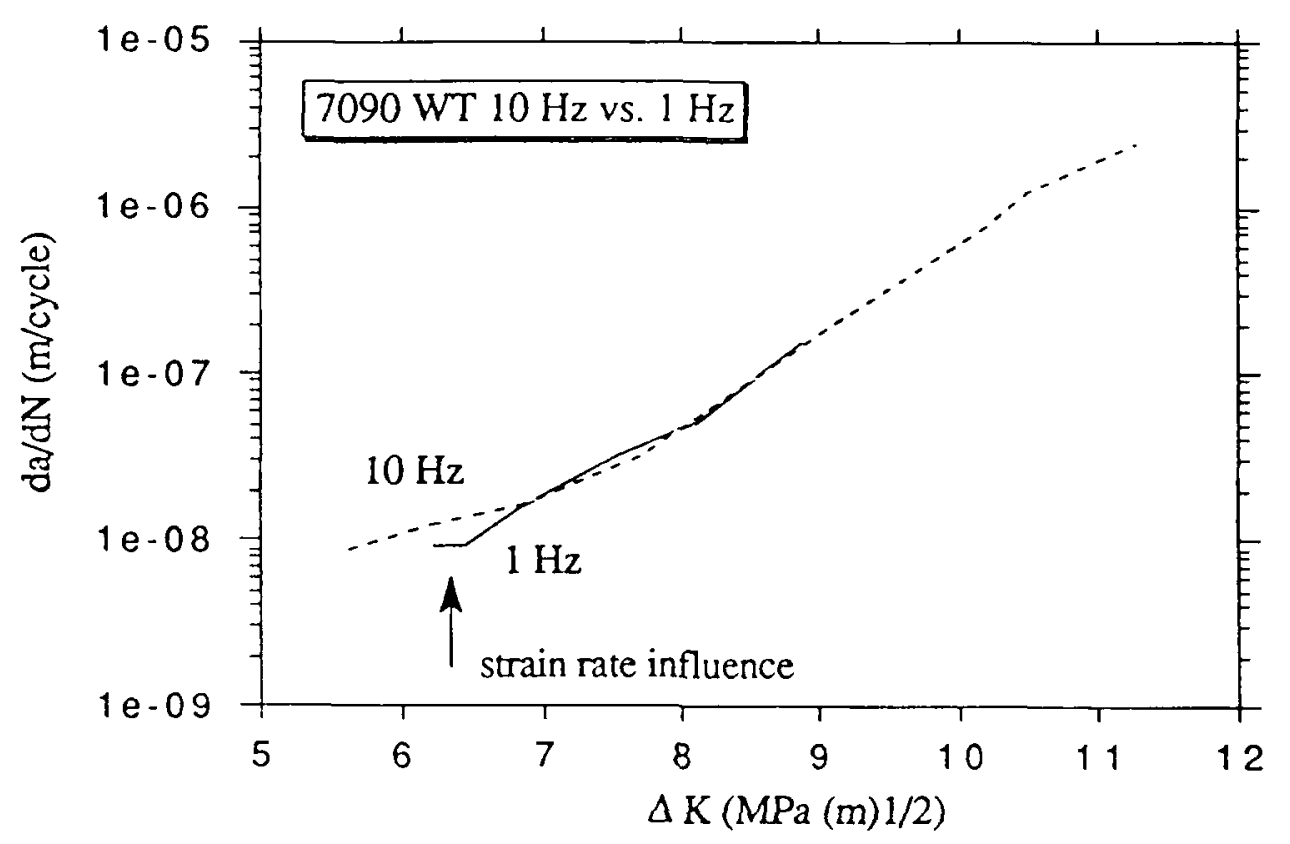

Figure 38: $7090 \mathrm{WT} 10 \mathrm{~Hz}$ vs. $1 \mathrm{~Hz}$

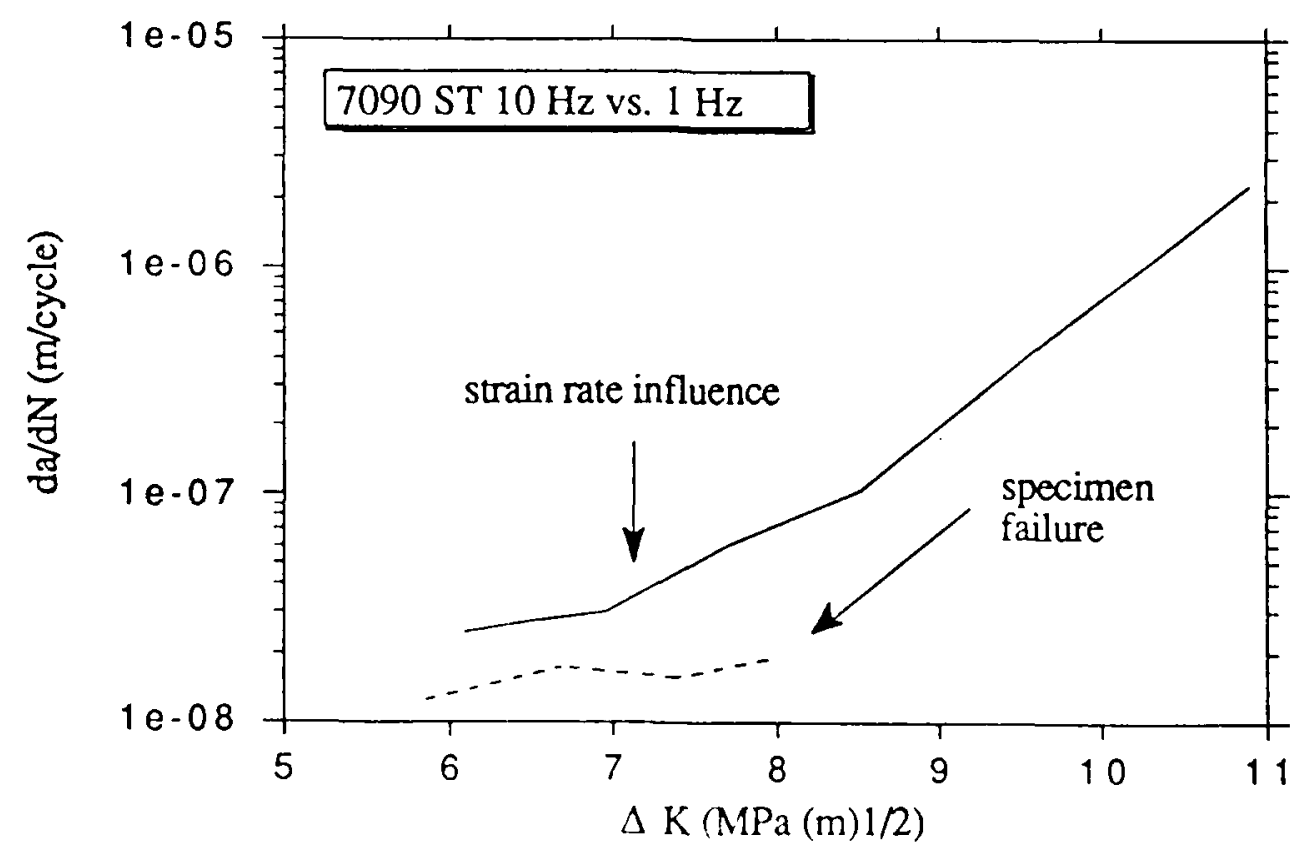

Figure 39: $7090 \mathrm{ST} 10 \mathrm{~Hz}$ vs. $1 \mathrm{~Hz}$ 


\section{SUMMARY \& CONCLUSIONS}

\section{Composite}

AL vs. AT (orientation influence)

Low $\triangle K$ : $\operatorname{FCGR}_{(A T)}>F_{C G R}(A L)$. This behavior is a direct result of the heterogeneous void nucleation pattern of AL which favors allignment with crack growth direction. This nucleation preference creates oblong pinnacles (aspect ratio $>2$ ) and a longer total striation length than AT. Since void nucleation patterns are ultimately rate controlling, and patterns in AT are relatively homogeneous, producing circular (conical) pinnacles, total striation length is shorter in AT than in AL. Thus more energy is absorbed in the AL fatigue fracture process than with AT.

Mid $\triangle K$ : FCGR is insensitive to orientation; fracture is not dominated by inter- or transgranular failure.

High $\triangle \mathrm{K}: \mathrm{FCGR}_{(\mathrm{AL})}>\mathrm{FCGR}_{(\mathrm{AT})}$. AL fracture surface contains many ductile minicusps and few striations (short total striation length). AT surface has small amount of ductile cusps and a large amount of striations. Since AT has a longer total striation length, which is rate controlling, AT absorbs more energy during fracture, and hence has a lower FCGR than AL.

AT vs. WT. vs. ST (environmental influence)

Low $\Delta \mathrm{K}$ : Crack tip hydrogen cathodic effects (from salt water) is rate controlling, but this effect decreases as FCGR (and $\Delta \mathrm{K}$ ) increases.

Mid $\Delta K$ : Hydrogen crack tip concentation (and diffusion and/or transport ahead of the crack tip) is rate controlling, but this effect also decreases as FCGR (and $\Delta K$ ) increases.

High $\triangle \mathrm{K}:$ FCGR is insensitive to environment above a critical rate. Mechanical, inertial macroscopic effects, such as the number of barriers ( $\mathrm{SiC}$ particles) encountered per crack length, per fatigue cycle, is rate controlling. 
WT $10 \mathrm{~Hz}$ vs. $1 \mathrm{~Hz}$ (frequency influence)

Low and mid $\triangle \mathrm{K}$ : Competing effects - immersion time vs strain rate. At a high frequency $(10 \mathrm{~Hz})$ immersion time is short, but strain rate is high. At a low frequency $(1 \mathrm{~Hz})$ immersion tine is long, but strain rate is low. It was found that strain rate is rate controlling, but as FCGR increases, the strain rate effect decreases.

High $\Delta \mathrm{K}$ : insensitive to frequency.

ST 10 vs. $1 \mathrm{~Hz}$ (frequency influence)

Low, mid and high $\Delta \mathrm{K}$ : Competing effects - immersion time vs. strain rate. Immersion time is rate controlling (opposite to WT 10 vs. $1 \mathrm{~Hz}$, above.)

AL vs. WL (environmental influence)

Low and mid $\Delta \mathrm{K}: \mathrm{pH}$ or hydrogen concentration (diffusion and/or transport ahead of the crack tip) is rate controlling. This observation implies that $D_{H}$ (extrusion direction) $>D_{H}$ (normal to extrusion direction), and is attributed to $\mathrm{SiC}$ clustering, or the ability of $\mathrm{SiC}$ to trap hydrogen.

High $\Delta \mathrm{K}:$ Inertial forces dominate.

Hydrogen ingress (environmental effect)

The 6061 composite is susceptable to hydrogen ingress when stored in an atmosphere containing water vapor. It is suspected that $\mathrm{SiC}$ particles are acting as hydrogen trap sites. Homogenization of hydrogen concentration profile in the composite depends on storage period.

A schematic representation of the forces which influence FCGR behavior in the 6061 composite system is shown in Fig. 40. 


\section{$6061+20 \% \mathrm{SiC}$}

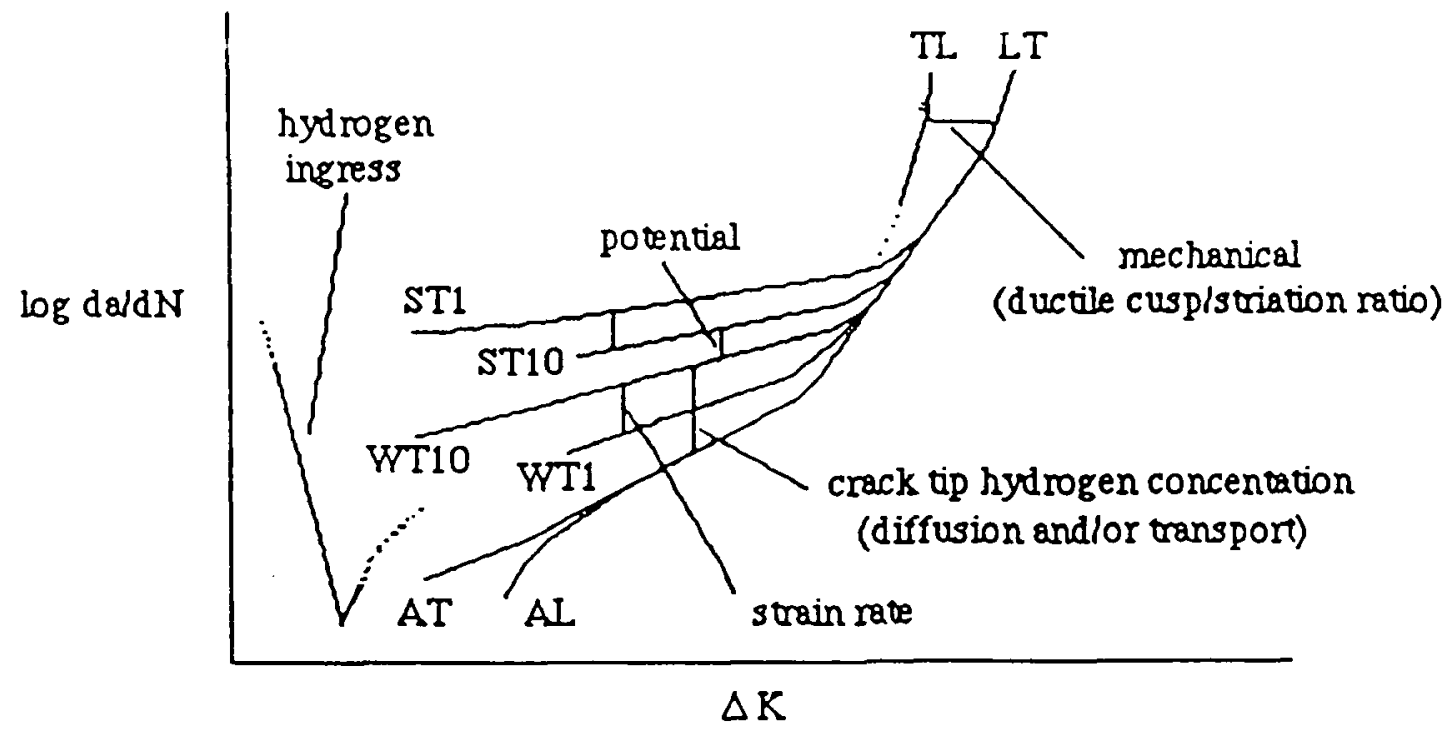

Figure 40: Schematic representation of fatigue crack growth rate influences in 6061 composite.

\section{Composite}

General comments: SiC pullout during fatigue fracture is more common than in the 6061 composite, and the average pinnacle height is shorter than with the 6061 system.

AL vs. AT (orientatin influence)

Low $\Delta \mathrm{K}$ : insensitive to orientation.

Mid and high $\triangle \mathrm{K}: \mathrm{FCGR}_{(\mathrm{AL})}>\mathrm{FCGR}(\mathrm{AT})$. Fracture dominated by inertial effects.

AT v.s. WT vs. ST (environmental influence)

Low $\Delta \mathrm{K}$ : Very environment (hydrogen) dependent. In salt solution, cathodic reaction is rate limiting; in distilled water. hydrogen concentration (diffusion and/or transport) controls fatigue crack growth rate.

Mid to high $\triangle K$ : Inertial forces dominate. Pinnacles suffer abrupt truncation, probably due to the composite's low strain hardening capability. 
WT 1 vs. $10 \mathrm{~Hz} \&$ ST 1 vs. ST $10 \mathrm{~Hz}$ (frequency influence)

Low and mid $\Delta \mathrm{K}$ : Immersion time vs. strain rate (discussed above.) Strain rate dominates.

High $\Delta \mathrm{K}$ : Inertial forces dominate. Inertial effects are proportional to crack velocity which continuously increases with crack length. Strain rate, however, is relatively insensitive to growth rate. Thus at high $\triangle \mathrm{K}$ inertial forces control FCGR.

A schematic representation of influential forces in the 7090 system appears in Fig. 41.

\section{$7090+20 \% \mathrm{SiC}$}

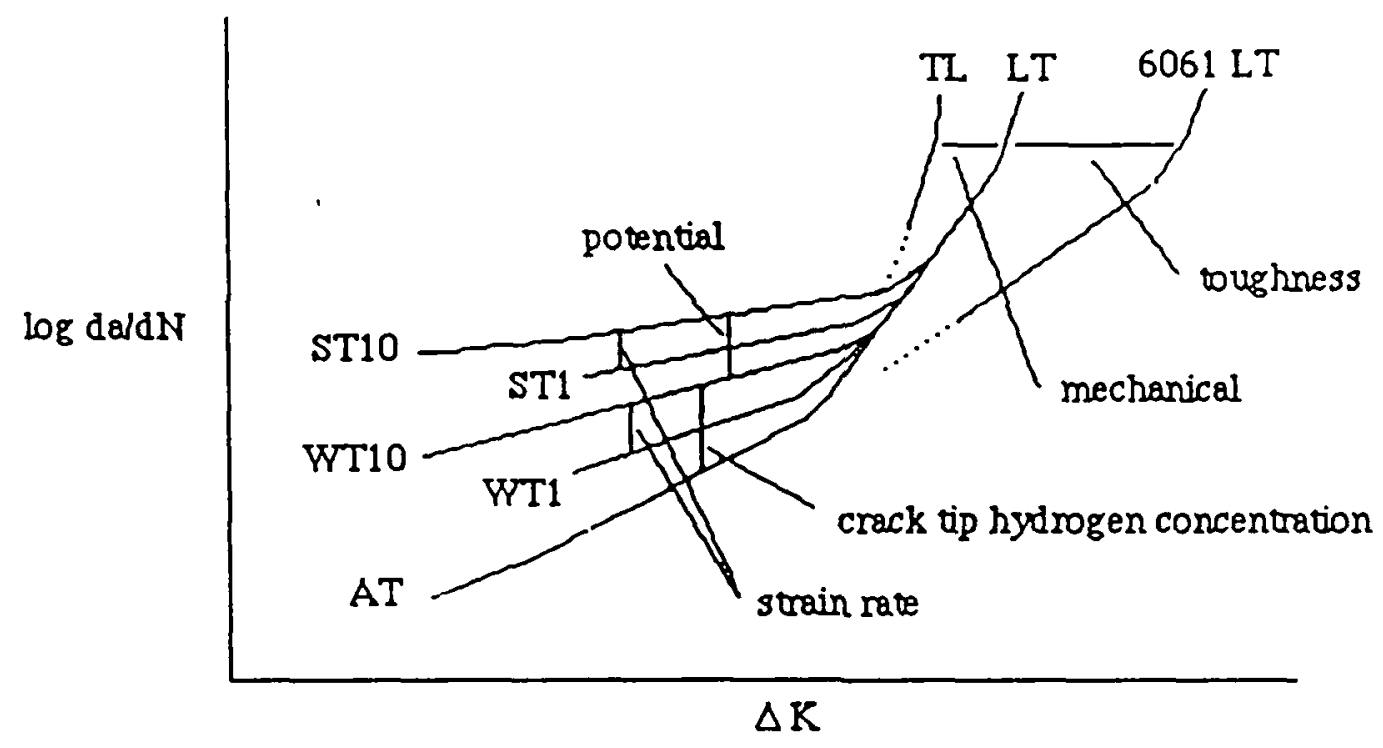

Figure 41: Schematic representation of fatigue crack growth rate influences in 7090 composite.

\section{ACKNOWLEDGEMENTS}

Special thanks go to Mrs. Kezhong Li, Ms. Amy Perry and Mr. \& Mrs. R.F. Buck, Sr. for their support and help in completing the research. This work supported by AFOSR to whom we are thankful under contract \# 86-0238. 


\section{REFERENCES}

1 W.C. Harrigan, Jr., G. Goebler, E. Davis, E. Levin, 'Mechanical Behavior of Metal Matrix Composites', Proceedings of the 111 th AIME Annual Meeting, Dallas, Texas, February 16, 1982.

2 D.L. McDaniels, 'Analysis of Stress-Strain, Fracture, and Ductility Behavior of Aluminum-Matrix Composites Containing Discontinuous Silicon Carbide Particulate Reinforcements', Metallurgical Transactions-A, 16A, June '85, p. 1105.

3 W.A. Logsdon, P.K. Liaw, Tensile, Fracture Toughness \& Fatigue Crack Growth Rate Properties of Silicon-Carbide Whiskers \& Particulate Reinforced Aluminum Metal Matrix Composites', Engineering Fracture Mechanics, 24, 1986, p. 737.

4 R.J. Arsenault, R.M. Fisher, 'Microstructure of Fiber \& Particulate SiC in 6061 Aluminum Composite', Scripta Metallurgica, 17, 1983, p. 67.

5 D.F. Hasson, C.R. Crowe, Proc. 5th Int'l. Conf, on Composite Materials, W. Harrigan, J. Strife, A.Dhingra (eds.), The Metallurgical Society of AIME, Warrendale, PA, 1985, p. 147.

6 S.S. Yau, G. Mayer, Material Science Engineering, 82, 1986, p.45.

7 T.E. Steelman, A.D. Bakalyar, L. Konopka, 'Aluminum Matrix Composite Structural Design Development', Technical Report AFWAL-TR-86, Rockwell International Corp., Canoga Park, CA, 1986.

8 D.R. Williams, M.E. Fine, Proc. 5 th Int'l. Conf, on Composite Materials, p. 639.

9 C.R. Crowe, D.F. Hasson in Strength of Metals and Alloys - V, R.C. Grifkins (ed.), Pergamon Press, Oxford, 2, 1982, p. 859.

10 R.J. Jacko, D.J. Duquette, Metallurgical Transactions-A, 8A, 1977, p.1821.

11 R.M. Pelloux, Proc. 2nd Int'l Conf, of Fracture, Brighton, U.K., 1969, p. 731.

12 R.J. Selines, R.M. Pelloux, Metallurgical Transactions-A, 3A, 1972, p. 2525.

13 T. Broom, A. Nicholson, J. Inst. Metals, 89, 1960, p.183.

14 R.F. Wei, Int'l J. Fracture Mech, 5, 1969, p.71.

15 R.E. Stoltz, R.M. Pelloux, Corrosion. NACE, 29, No. 1, 1973, p.13.

16 M.O. Speidel, NATO Advanced Study Institure of SCC, 1975, Copenhagen, Denmark.

17 F.P. Ford, Corrosion, NACE, 35, No. 7, 1979, p.281.

18 T. Pyle, V. Rollins, D. Howard, Proc. Int'l Conf. on Corrosion Fatigue, Storrs, CT, 1971, p. 312. 
M.O. Speidel, Hydrogen in Metals, Proc. Int'l. Conf. on the Effects of Hydrogen in Metals, Champion, PA, 1973, p. 249.

A.W. Thompson, I.M. Bernstein, 'Fundamentals of Interfacial Strength in Composite Materials', AFSOR Annual Report \# 86-0238.

R.J. Jacko, D.J. Duquette, "The Role of Hydrogen on Environmental Fatigue of High Strength Aluminum Alloys', Hydrogen in Metals, A.W. Thompson, I.M. Bernstein (eds.), 1980, ASM, p. 477.

F.S. Lin, E.A. Starke, 'Mechanisms of Corrosion Fatigue Crack Propogation of $7 x x x$ Aluminum Alloys in Aqueous Environments', Hydrogen in Metals, 1980, p. 485.

C.P. You, A.W. Thompson, I.M. Bernstein, 'Proposed Failure Mechanism in a Discontinuously Reinforced Aluminum Alloy', AFOSR Technical report.

Standard Test Method for Constant-Load-Amplitude Fatigue Crack Growth Rates Above 10(-8) $\mathrm{m} /$ Cycle, ASTM E647-81, ASTM Standards.

S.V. Nair, J.K. Tien, R.C. Bates, 'SiC-Reinforced Aluminum Metal Matrix Composites', Int'l Metals Review, 30, 1985, No. 6, p. 275.

26 J.J. Lewandowski, C. Liu, W.H. Hunt, Jr., 'Microstructural Effects on the Fracture Micromechanisms in 7xxx Al P/M - SiC Particulate Metal-Matrix Composites', Powder Metallurgy Composites, M. Kumer, K. Vedula, A.M. Ritter (eds.), The Metallurgical Society, 1987.

27 C.R. Crowe, R.A. Gray, D.F. Hasson, 'Microstructure Controlled Fracture Toughness of SiC/Al Metal Matrix Composites', Office of Naval Research, Technical report.

28 M.O. Speidel, 'The Theory of Stress Corrosion Cracking in Alloys', NATO Scientific Affairs Division, Brussels, 1971, p.289.

29 J. Shang, R.O. Ritchie, 'Role of Silicon Carbide Particles in Fatigue Crack Growth in SiC Particulate-Reinforced Aluminum Alloy Composites', Materials Science \& Eng., Oct. '87.

30 J.M. Papazian, P.N. Adler, 'Micro-mechanisms of Deformation in SiC/Al Composites', Grumman Corp. Research Center Report RE-724, Second Annual Technical Report.

31 J. Albrecht, I.M. Bernstein, A.W. Thompson, 'Evidence for Dislocation Transport of Hydrogen in Aluminum', Metallurgical Transactions-A, 13A, 1982, p. 811.

32 W.Y. Chu, Y.B. Wang, C.M. Hsiao, 'Researgh of Hydrogen Induced Cracking \& Stress Corrosion Cracking in an Aluminum Alloy', Corrosion. NACE, 38, 1982, p.561.

33 S.J. Hudak, Jr., A. Saxena, R.J. Bucci, R.C. Malcolm, 'Development of Standard Methods of Testing and Analyzing Fatigue Crack Growth Rate Data', Technical Report AFML-TR-78-40, May, 1978.

34 V.C. Nardone and K.M. Prewo, 'On the Strength of Discontinuous Silicon Carbide Reinforced Aluminum Composites', Scripta Metallurgica, 20, 1986, p. 43.

35 A.D. Divecha, S.G. Fishman, 'Proc. 3rd Int'1. Conf, on Mechanical Behavior of Materials', K.J. Miller, R.F. Smith (eds.), Pergamon Press, 1980, p. 351. 


\section{PART 2}

\section{LOW-TOUGHNESS FRACTURE IN AI 7191-SiC METAL MATRIX COMPOSITES}

H. Yousef, S. Mostovoy, M. Dollar and I.M. Bernstein

Illinois Institute of Technology 


\title{
LOW-TOUGHNESS FRACTURE IN AI 7191-SiC METAL MATRIX COMPOSITES
}

\author{
H. Yousef, S. Mostovoy, M. Dollar and I.M. Bernstein \\ Dept. of Metallurgical and Materials Engineering \\ Illinois Institute of Technology \\ Chicago, Illinois 60616
}

This section summarizes the work conducted under subcontract at Illinois Institute of Technology to investigate the mechanical behavior and low-toughness fracture of $\mathrm{Al}$-SiC metal matrix composites. The experimental and numerical results are described, concentrating on work completed since the prior annual report.

\section{Mechanical Properties of Al 7191-SiC Composites}

Addition of $20 \% \mathrm{SiC}_{\mathrm{p}}$ to the $\mathrm{Al}$ alloy matrix resulted in a $50 \%$ increase in the elastic modulus, an increasc about the same as for other $\mathrm{Al}$-base composites using $\mathrm{SiC}$ with different alloy matrices, as reported in the literature. However, the increase in the yield and ultimate strengths was much less than the increase in the modulus. For the peak-aged material, for example, the increase was only about $10 \%$. This is consistent with the trend followed by other composites with different alloy matrices, where the relative improvement in the strength decreases as the absolute strength of the matrix increases.

Increasing the volume fraction of $\mathrm{SiC}_{\mathrm{p}}$ from $20 \%$ to $30 \%$ did not significantly increase the strength of the material. Only a 2 to $3 \%$ increase was obtained, indicating that strengthening in these composites does not follow a linear relationship between the volume fraction reinforcement and the composite strength (the same is true for other metal matrix composites). The results obtained from tensile testing are consistent with those from hardness testing, which gave almost the same increase in material hardness due to incorporation of $\mathrm{SiC}$ particles in the $\mathrm{Al}$ alloy matrix.

The tensile ductility values were low, even compared to other composite materials. Values of the strain to failure were decreased from about $12 \%$ to about $2 \%$ for the peak-aged temper. This decrease is consistent with the decrease in fracture tough;ness values; the plane strain fracture toughness, $K_{I c}$, decreased from 42 to $15 \mathrm{ksi}$-in. ${ }^{1 / 2}$. The degradations in tensile ductility and toughness are equivalent if compared on the basis of the strain energy release rate, $\mathrm{G}_{\mathrm{Ic}}$. Moreover, fracture of these composites was found to follow the stress-modified critical strain criterion, developed for fracture by microvoid coalescence in classical ductile fracture. This fracture was in fact observed in studies of the fracture surface (see following section) and was the dominant mechanism of failure in these materials.

\section{Scanning Electron Microscopy Studies}

Fractographic examination of fracture surfaces was conducted in detail, and results of that examination were included in the previous annual report. A summary of those results is presented here. Numerous microcracks were observed in the stress field of a sharp crack. All these microcracks were associated with $\mathrm{SiC}$ particles, and a majority lay along interfaces between the $\mathrm{SiC}$ particles and the matrix. Others were associated with cracking of $\mathrm{SiC}$ particles. 
Microcracking ahead of the crack tip extended to a distance of about $250 \mu \mathrm{m}$ on both sides of the crack flank. The fracture surfaces of the crack arrest epecimens showed a higher intensity of microcracks at the crack initiation and arrest areas. Moreover, cracking normal to the crack plane was observed, mainly by intergranular failure.

Compared to the sharp-crack specimens just discussed, different fracture modes were observed on the fracture surfaces of the tensile bars. While $\mathrm{SiC}$ particles continued to fracture by apparent cleavage, the matrix material failed in a ductile manner by void initiation, growth, and coalescence. An intergranular fracture mode was also observed and may be attributed to the presence of $\mathrm{MgO}$ on the grain boundaries. This compound $(\mathrm{MgO})$ was associated with the formation of cracks on the fracture surfaces by delamination.

The energy dispersive X-ray (EDX) method was utilized to study the surface chemistry of the failure initiation sites on the fracture surfaces of tensile bars. A statistical study was conducted using 25 specimens in different tempers. It was found that $\mathrm{MgO}$ is the dominant failure initiation site in these composites (more than $30 \%$ of the failed specimens). This type of intermetallic is believed to form in large amounts due to the processing technique utilized by the manufacturer. Consolidation at a supersolidus temperature results in reaction between $\mathrm{Mg}$ (present in the base alloy) and oxygen (present in oxides on the powder surfaces). Some of these $\mathrm{MgO}$ intermetallics were found to be quite large (more than $80 \mu \mathrm{m}$ diameter).

A second important fracture initiation site was located at agglomerates of $\mathrm{SiC}$ particles. Other fracture initiation sites occasionally identified included large $\mathrm{SiC}$ particles, Fe-rich inclusions, $(\mathrm{P}, \mathrm{S})$-rich inclusions, and $(\mathrm{Zn}, \mathrm{Cu})$-rich inclusions. In all cases, these sites gave rise to predominantly microvoid coalescence fractures. Thus it would be expected that areas rich in such particles would be preferentially involved in ductile fracture.

As an example, the average area fraction of $\mathrm{SiC}$ particles on the fracture surfaces was examined for different tempers and different state of stresses, e.g. comparing fractures at the center and near the side surfaces of the crack arrest specimens. This examination showed an averaged SiC area which was more than $30 \%$ higher than the expected average on a polished surface, $20 \%$. Altering the matrix temper did not significantly alter the average area of $\mathrm{SiC}$ particles on the fracture surfaces. However, using $\mathrm{X}$-rays is not the most suitable measurement technique for this average area in case of failure in areas very close to the interface. This is attributed to the penetration depth of X-rays. A more suitable method in this case might be Auger spectroscopy which has a limited penetration depth of a few atomic layers, though it in turn may be affected by surface films.

\section{Finite Element Studies}

Finite element (FE) studies were conducted to study the main reasons leading to the lowtoughness fracture of these metal matrix composites. The stress and strain fields resulting from the differential thermal expansion between the $\mathrm{Al}$ matrix and $\mathrm{SiC}$ particles during processing were calculated. This approach utilized the aluminum alloy 7075 as the matrix alloy due to a lack of data for Al 7191, requiring an estimate for the coefficient of thermal expansion and flow stress as altered by the working temperature. A second model was used to study the deformation and stress fields evolved during composite loading with and without the presence of a sharp crack.

\section{A. Thermal Stress and Strain Fields due to Processing}

Finite element calculations showed that a temperature change during processing results in generation of tessellated thermal stresses which can exceed the matrix yield strength. Consequently, the matrix will plastically flow and strain harden. Values of the equivalent plastic 
strain were found to be a function of particle size, aspect ratio, interparticle spacing, and the quench temperature. For example, for an aspect ratio of 4 , the plastic strain could be as much as $4 \%$ at the interface.

Due to quenching, a hydrostatic compression field is developed in the $\mathrm{SiC}$ particles while the stresses in the matrix are mainly tensile (two components are tensile while the third one is compressive). The hydrostatic tension in the matrix will likely degrade the material toughness by promoting void initiation and crack propagation, particularly as the value of the effective stress (in the matrix) at the interface exceeds the matrix yield strength. This value decreased as the distance from the interface increased, consistent with that reported in the literature. The stress field was obtained for temperature changes of 500,450 , and $400^{\circ} \mathrm{C}$; as expected, the stress field was lower when the temperature change was less.

From the above calculations, the following conclusions can be drawn. The low-toughness fracture of these composites is enhanced by the tensile stress field developed in the matrix alloy at the interface area. Void nucleation and growth will be promoted by such a stress field (hydrostatic tension). Moreover, a part of the strain hardening capacity of the matrix alloy at the interface (more than $4 \%$ ) is consumed, leading to lower values of strain-to-fracture. This implies that the matrix adjacent to the interface was degraded after processing and a premature failure in these zones can be expected due to: (i) the low toughness of these zones due to the consumed part of the material strain hardening capacity, (ii) stress concentration due to the presence of stiff particles having sharp corners, and (iii) the hydrostatic tensile field evolved which promotes void nucleation and growth.

An attempted confirming qualitative study of the thermal stresses generated due to processing was conducted using X-ray diffraction. The line positions for Al planes (111), (200), and (220) were measured for the monolithic alloy, and for the composite material having the same heat treatment process. Due to the difficulty in getting a smooth polished surface for the composite material from electropolishing, the study results permitted only a qualitative comparison. This difficulty came from the difference in reaction rates between perchloric solution and the two constituents of the composite material, $\mathrm{Al}$ and $\mathrm{SiC}$.

Shifts in the line, ;ition for the different diffracting planes were indeed observed. Moreover, peak broadening $\mathrm{a}$. . arly observed for the composite material, which indicates that the matrix alloy had deformed plastically during the quenching step. This is consistent with the numerical results obtained from FE calculations. Moreover, the peak intensity of the (111) plane fo. the composite material appeared to be three times higher than that for the monolithic alloy, an unlikely result from random variation, considering that the diffracting planes for the composite material arise from about $80 \%$ as much material as that for the base alloy. Studying the texture of both materials revealed that the base alloy ilas a stronger (111) texture. These planes were strongly oriented 30 degree to the plane of the sheet and, consequently, did not participate in the ensuing high intensity during the $2 \theta$ scan.

\section{B. Stress Fields due to External Loading}

A double edge notch specimen was modelled and the stress field evolved upon loading was studied. However, the specimen was too long to simulate a tensile bar at the upper portion far from the crack tip. The effect of matrix strain hardening after processing was included in this problem where three different solutions were obtained. The first solution was for the unreinforced monolithic Al 7191 (yield strength - $78 \mathrm{ksi}$ ). In the second case, the solution was for a composite material saving $15 \% \mathrm{SiC}$ and a matrix similar to the first case (not hardened). In the third, the matrix was considered to be strain hardened after processing due to the differential thermal expansion between $\mathrm{Al}$ and $\mathrm{SiC}$. The three problems were solved for both plane stress and plane strain conditions. 
The stress field evolved in the matrix due to tensile loading (upper portion of the modelled specimen) showed the following results:

(i) As the remote stress reaches $57 \mathrm{ksi}$, the effective stress at the interface reaches the matrix yield strength $(78 \mathrm{ksi})$. This means that local yielding will occur at these regions.

As the remote stress reaches $72 \mathrm{ksi}$, the effective stress in the matrix at the interface exceeds the fracture stress value. At the same, time, the maximum normal stress in an average $\mathrm{SiC}$ particle is still much below the ultimate tensile strength of $\mathrm{SiC}$ (it is recognized that $\mathrm{SiC}$ particles containing large flaws may fracture even at $72 \mathrm{ksi}$ ). Consequently, fracture should primarily occur at the interface in the matrix alloy. An excellent correlation between the finite element calculations and experimental observations was obtained. Isostress contours were calculated for the composite material ahead of the crack tip. It was found that the contour representing an effective stress of $72 \mathrm{ksi}$ was equivalent to that enveloping the microcracks developed ahead of the crack tip. Both the finite element caluculations and experimental observations were for plane stress conditions (side surfaces of the crack arrest specimen).

(iii) The effective stress distribution in the matrix alloy was extremely non-homogeneous. While the value at the interface exceeded the matrix ultimate tensile strength (remote stress $=72 \mathrm{ksi}$ ), the effective stress was less than one half of the matrix fracture stress at areas between $\mathrm{SiC}$ particles. This is likely to lead to equilibrium between the external forces and the internal ones. The non-homogeneous stress distribution will cause local plastic flow in the matrix alloy and premature fracture at the interface zones.

(iv) Matrix hardening due to processing does not have a significant effect on the stress distribution in the matrix. However, the dominant effect of matrix hardening is the limitation to the amount of plastic dissipation work, which will be reflected as lower toughness values of the composite material. For the same strain energy supplied to the specimen, the plastic dissipation work for the material having a non-hardened matrix was almost twice that for the composite having a hardened matrix.

(v) The composite material showed a high degree of triaxiality at the interface. The severity of the triaxial state of stresses was measured in terms of the mean and effective stresses though the factor $\sigma_{\mathrm{m}} / \sigma_{\mathrm{c} f r}$. This value equals zero for pure shear, 0.33 for simple tension, and is infinite for pure hydrostatic tension or compression. At remote stresses of $57 \mathrm{ksi}$ and $72 \mathrm{ksi}$, this value was 0.45 and 0.62 , respectively, at the interface. This is equivalent to a more than $30 \%$ and $90 \%$ increase in the degree of triaxiality, compared to simple tension for the monolithic alloy.

As mentioned previnusly, the matrix hardening due to processing does not significantly affect the stress fields developed during loading. The dominant factors which affect these fields are the elastic properties (elastic modulus and Poisson's ratio) of the two constituents, the Al matrix and reinforcements. When the modulus of the reinforcement was decreased from the actual value (70 million psi) to a hypothetical value of 40 million psi, the nonhomogeneity of the stress field was greatly reduced. A similar effect was obtained when Poisson's ratio was increased from the actual value $(0.24)$ to a hypothetical one of 0.33 (which is equal to the ratio for the matrix alloy). Of course the detrimental effects of the high $\mathrm{SiC}$ modulus on stress field homogeneity is to some extent counteracted by its benefits in raising the overall modulus of the composite.

The stress field ahead of the crack tip was also affected in a similar manner by the presence of stiff $\mathrm{SiC}$ particles. When a SiC particle was very close to the crack tip, stresses at the interface was 
considerably magnified, indicating a tendency towards cracking at these areas. As mentioned before, the plastic dissipation work is greatly reduced due to the addition of $\mathrm{SiC}$ to the base alloy. This means a smaller plastic zone and lower values of fracture toughness.

\section{Conclusions}

The previous results strongly indicates that the matrix material adjacent to the interface is the fracture process zone. This zone is degraded during processing by the factors mentioned before. Moreover, a high triaxial state of stresses will evolve due to external loading. This triaxiality is due to the constrained plastic flow of the matrix which is bonded to stiff particles having a modulus seven times that for the base alloy. Stress concentrations due to the particle geometry will increase the degree of nonhomogeneity of the stress field in the matrix. Consequently, local plastic flow and possible premature fracture will take place. All these factors will lead to the observed lowtoughness fracture in these metal matrix composites.

What are the possibilities of improving the toughness of these composites in the future? From the current study it seems that the mechanical behavior of these composites is strongly dependent on the differential properties of the two constituents, $\mathrm{Al}$ and $\mathrm{SiC}$. These properties include the coefficient of thermal expansion, elastic modulus, and Poisson's ratio. While the differential thermal expansion consumes more than $4 \%$ of the matrix tensile dunctility, the differential elastic properties results in a very non-homogeneous stress field in the matrix upon loading. Consequently, it can be said that the low-toughness fracture of these composites is an inherent property of these materials. For example, if the processing techniques were able to get rid of all the dominant fracture initiation sites, the values of strain-to-fracture might not be significantly increased. It would appear that the fracture behavior can only be changed by major alterations in matrix microstructure, particle shape, or processing, and that a creative and innovative approach will be needed to improve composite toughness. 